\title{
Evapotranspiration Studies for Protective Barriers: FY 1990 Status Report
}

S. O. Link J. L. Downs M. E. Thiede

D. J. Lettau

T. R. Twaddell

R. A. Black ${ }^{(a)}$

May 1992

Prepared for the U.S. Department of Energy under Contract DE-AC06-76RLO 1830

Pacific Northwest Laboratory

Richland, Washington 99352

(a) Washington State University Pullman, Washington 


\section{SUMMABY}

Evapotranspiration, the combined loss of water from plants and soil surfaces to the atmosphere, is a process that must be predictable to adequately model soil water dynamics. In support of the U.S. Department of Energy's Protective Barrier Development Program, Pacitic Northwest Laboratory (PNL) is conducting research at the Hanford Site to allow the prediction of evapotranspiration. This document describes the results of technological developments and experiments during FY 1990. Research was conducted at the Small Tube Lysimeter Facility (STLF), Lower Snively Field, Snively Canyon, and the Field Lysimeter Test Facility (FLTF).

Pacific Northwest Laboratory built additional air conditioning units for the gas exchange system that PNL is using to study evapotranspiration. The system will control internal temperature and relative humidity for a total of four chambers. The integration of the replicate gas exchange chambers into the data acquisition and control system awaits additional funding. With the gas exchange system configured as in FY 1989, we were able to measure evaporation, evapotranspiration, and carbon dioxide exchange rates from the STLF lysimeters on the soil surface with and without cheatgrass, Bromus tectorum. Evapotranspiration was higher on the lysimeters with B. tectorum than on the lysimeters with bare soil. Leaf area of B. tectorum was positively correlated with evapotranspiration rates.

Growth dynarnics of $\mathrm{B}$. tectorum as a function of water and nitrogen treatments were documented at Lower Snively Field from October 1989 through May 1990. Green-leaf-area index and green-shoot biomass were measured monthly over the period. Very little change in shoot growth was observed until April, when temperatures warmed. The additional water and nitrogen increased growth when added singly, and when added together, they increased growth much more. The size of the plant is one factor that influences the rate at which water is transpired back to the atmosphere. Thus, we have initiated studies to develop simple models of growth that will support efforts to predict soil water dynamics for the protective barrier.

The whole-plant gas exchange system was used to develop simple models of transpiration and carbon gain for $\mathrm{B}$ tectorum growing at Snively Canyon. The relationships between stomatal conductance and net photosynthesis and the driving 
variables of light, vapor pressure gradient, temperature, and xylem pressure potential were parameterized. These equations were used to predict transpiration and net photosynthesis for 2 days in June. The models were able to successfully predict these processes.

Lastly, PNL began measuring transpiration of Artemisia tridentata growing on the FLTF precision weighing lysimeters. A new technique that measures stem flow in woody plants by using heat flux was able to measure transpiration rates in $A$. tridentata. The technique will make it possible to observe transpiration rates of $A$ tridentata continuously without disturbing the environment of either the shoot or the roots.

Future research will entail the parameterization for model development of relationships between evapotranspiration, transpiration, soil evaporation, carbon dioxide exchange, growth, and the abiotic and biotic factors that drive these processes. 


\section{ACKNOWLEDGEMENTS}

Discussions with Glendon Gee of Pacific Northwest Laboratory are gratefully acknowledged. The technical assistance of M.J. Harris, J.M. Dumm, M.C. Anderson, E. Torres, and R.C. Dick is greatly appreciated. 


\section{CONTENTS}

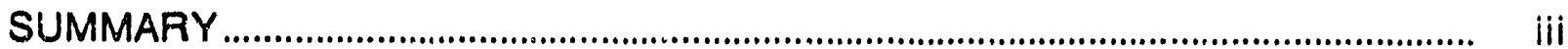

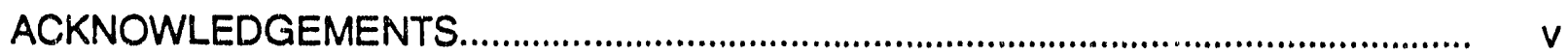

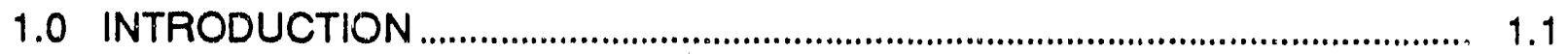

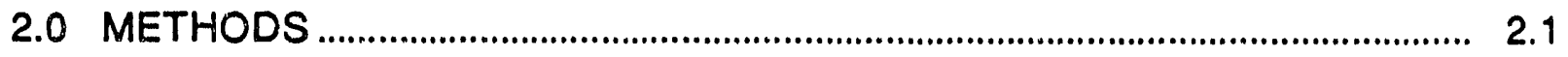

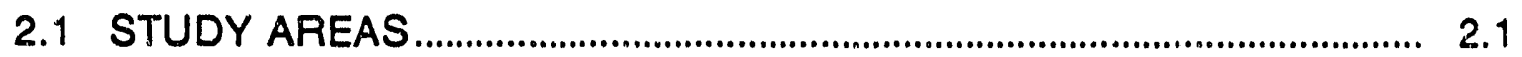

2.2 EXPERIMENTAL DESIGNS AND SAMPLING................................... 2.1

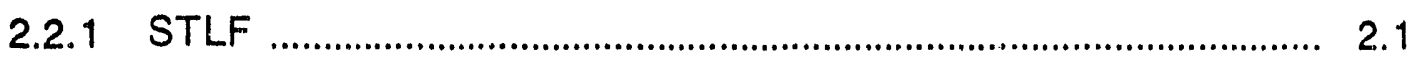

2.2.2 Lower Snively Field ......................................................................... 2.1

2.2.3 Snively Canyon .......................................................................... 2.2

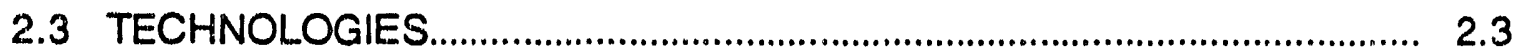

2.3.1 Whole-Plant Gas Exchange System............................................. 2.3

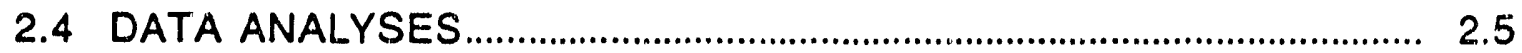

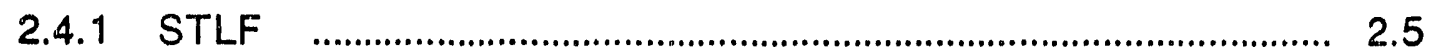

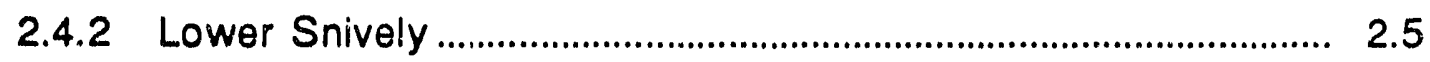

2.4.3 Snively Canyon ....................................................................... 2.5

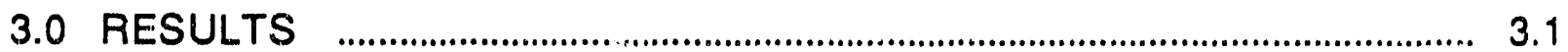

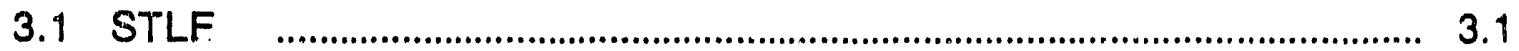

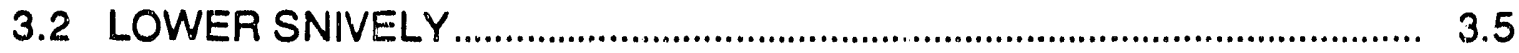

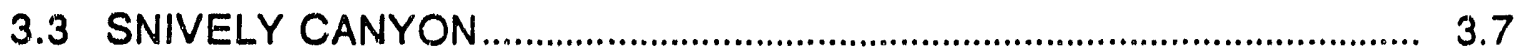

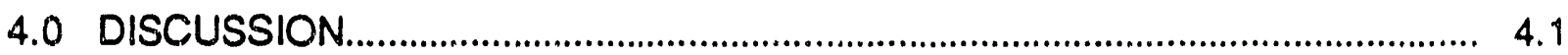

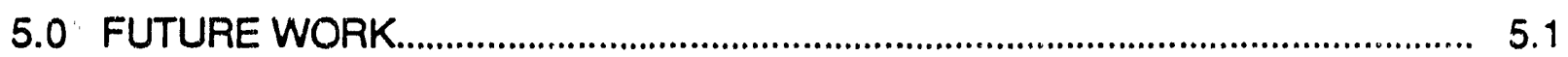

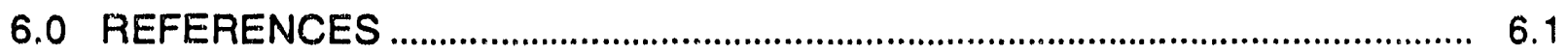

APPENDIX A - MEASUREMENT OF SHRUB TRANSPIRATION USING THE STEM HEAT FIUX TECHNIQUE 


\section{EIGURES}

3.1 Evapotranspiration from Bare-Soil and Bromus tectorum Lysimeters in April 1990.

3.2 Carbon Dioxide Flux from Bare-Soil and Bromus tectorum Lysimeters in April 1990.

3.3 The Relationship Between Leaf Area and Evapotranspiration for the Bromus tectorum Lysimeters in April 1990

3.4 The Effect of Water and Nitrogen Treatments on Bromus tectorum Green-Leaf-Area Index

3.5 The Effect of Water and Nitrogen Treatments on Bromus tectorum Green-Shoot Biomass Development.

3.6 The Relationship Between Stomatal Conductance and Photosynthetically Active Radiation

3.7 The Relationship Between Stomatal Conductance and Vapor Pressure Gradient.

3.8 The Relationship Between Stomatal Conductance and Leaf Temperature

3.9 The Relationship Between Stomatal Conductance and Xylem Pressure Potential.

3.10 The Relationship Between Carboxylation and Photosynthetically Active Radiation

3.19 The Relationship Between Net Photosynthesis and Photosynthetically Active Radiation

3.12 The Relationship Between Dark Respiration and Leaf Temperature

3.13 The Relationship Between Carboxylation and Leaf Temperature

3.14 Photosynthetically Active Radiation at Snively Canyon on June 8, 1990....

3.15 Chamber-Air, Leaf, and Outside-Air Temperatures at Snively Canyon on June 8, 1990

3.16 Dewpoint Temperature of Chamber Air and Outside Air at Snively Canyon on June 8, 1990 
3.17 Vapor Pressure Gradient Inside the Chamber at Snively Canyon on June 8, 1990

3.18 Xylem Pressure Potential of Bromus tectorum at Snively Canyon on June 8, 1990

3.19 Predicted and Observed Stomatal Conductance of Bromus tecterum at Snively Canyon on June 8, 1990

3.20 Predicted and Observed Transpiration of Bromus tectorum at Snively Canyon on June 8, 1990

3.21 Predicted and Observed Net Photosynthesis of Bromus tectorum at Snively Canyon on June 8, 1990

3.22. Internal $\mathrm{CO}_{2}$ Concentration of Bromus tectorum at Snively Canyon on June 8,1990

3.23 Water-Use Efficiency of Bromus tectorum at Snively Canyon on June 8, 1990

3.24 Predicted and Observed Stomatal Conductance of Bromus lecterum at Snively Canyon on June 8, 1990, Using Scaling Parameters Estimated with Data Collected on June 16, 1990

3.25 Predicted and Observed Transpiration of Bromus Lecterum at Snively Canyon on June 8, 1990, Using Scaling Parameters Estimated with Data Collected on June 16, 1990.

3.26 Predicted and Observed Net Photosynthesis of Bromus tec'orum at Snively Canyon on June 8, 1990, Using Scaling Parameters Estimated with Data Collected on June 16, 1990.

3.27 Photosynthetically Active Radiation at Snively Canyon on June 16, 1990.3 .35

3.28 Chamber-Air, Leaf, and Outside-Air Temperatures at Snively Canyon on June 16, 1990.

3.29 Dewpoint Temperature of Chamber Air and Outside Air at Snively Canyon on June 16, 1990.

3.30 Vapor Pressure Gradient Inside the Chamber at Snively Canyon on June 16, 1990.

3.31 Xylem Pressure Potential of Bromus tectorum at Snively Canyon on June 16, 1990. 
3.32 Predicted and Observed Stomatal Conductance of Bromus tectorum at Snively Canyon on June 16, 1990.

3.33 Predicted and Obsenved Transpiration of Bromus tectorum at Snively Canyon on June $16,1990$.

3.34 Predicted and Observed Net Photosynthesis of Bromus tectorum at Snively Canyon on June 16, 1990.

3.35 Internal $\mathrm{CO}_{2}$ Concentration of Bromus tecterum at Snively Canyon on June 16,1990

3.36 Water-Use Efficiency of Bromus tectorum at Snively Canyon on June 16, 1990

3.37 Predicted and Observed Stomatal Conductance of Bromus tectorum at Snively Canyon on June 16,1990, Using Scaling Parameters Estimated with Data Collected on June 8, 1990.

3.38 Predicted and Observed Transpiration of Bromus tectorum at Snively Canyon on June 16,1990, Using Scaling Parameters Estimated with Data Collected on June 8, 1990 .....

3.39 Predicted and Observed Net Photosynthesis of Bromus tectorum at Snively Canyon on June 16, 1990, Using Scaling Parameters Estimated with Data Collected on June 8, 1990. 


\section{IABLES}

3.1 Statistical Characteristics of the Regressions for Equations (2.1) through (2.10), Parameter Estimates, and Associated Asymptotic Standard Errors.

3.2 Statistical Characteristics for Scalar Parameterization of Stomatal Conductance Given in Equation (2.6)...

3.3 Statistical Characteristics for Scalar Parameterization of Net Photosynthesis Given in Equation (2.11) 


\subsection{INTBODUCTION}

Pacific Northwest Laboratory (PNL)(a) and Westinghouse Hanford Company (Westinghouse Hanford) are working together to develop for the U.S. Department of Energy (DOE) protective barriers for the near-surface disposal of hazardous waste at the Hanford Site. The proposed barrier design consists of a layer of fine-textured soil overlying a series of layers grading from sand to basalt riprap (USDOE 1987). A multiyear research program is being conducted to assess the long-term performance of barrier configurations in restricting plants, animals, and water from contacting buried wastes (Adams and Wing 1986).

The purpose of this report is to review work done up to July 31 in FY 1990 on the evapotranspiration subtask of the water infiltration task.

As stated in the test plan (Link and Waugh 1989), specific objectives of PNL's evapotranspiration work were to

1) Develop and test an environmentally controlled whole-plant gas exchange system.

2) Collect evapotranspiration data at the whole-plant level on the small-tube lysimeters.

3) Collect transpirtion data on shrubs at McGee Ranch.

4) Collect data necessary to parameterize the plant component of the UNSAT-H code.

This report describes the results for objectives 1, 2, 3, and 4 accomplished in FY 199n. Results for objective 3 were presented in Link et al. (1989) and were extended in FY 1990 with the use of stem flow devices to measure transpiration on Artemisia tridentata shrubs growing on the Field Lysimeter Test Facility (FLTF) precision

(a) Operated for the U.S. Department of Energy by Battelle Memorial Institute. 
weighing lysimeters. Gas exchange data were collected at the Small Tube Lysimeter Facility (STLF) to compare rates from lysimeters with and without plants for objective 2 . Growth data for Bromus tectorum (cheatgrass), meteorological data, and soil water data were collected at Lower Snively Field to support objective 4. In addition, data were collected at Snively Canyon to develop gas exchange models for B. tectorum to support objective 4 .

The report 1) describes the study areas, the experimental designs and sampling methods used, and the whole-plant gas exchange system; 2) gives the equations used to analyze the data; 3 ) presents and discusses the results for the three sites; and 4) identifies future work that will be conducted. 


\subsection{METHODS}

\subsection{STUDY AREAS}

Work on the transpiration task was conducted at three study sites during FY 1990. The STLF is located adjacent to the FLTF. The STLF study area is described in Relyea et al. (1990) and in Waugh and Link (1989). Lower Snively field is located on the Arid Lands Ecology Reserve (119 $\left.49^{\circ}, 46^{\circ} 28^{\prime}\right)$ at an elevation of $320 \mathrm{~m}$. The site had been used to grow dryland wheat until 1943, after which it was abandoned. It continues to be dominated by B. tectorum (Rickard 1985). Snively Canyon is located on the Arid Lands Ecology Reserve approximately $3 \mathrm{~km}$ southwest of Lower Snively Field. The study area is in a protected portion of the canyon where $B_{\text {. tecterum }}$ remains active late into the growing season.

\subsection{EXPERIMENTAL DESIGNS AND SAMPLING}

\subsubsection{STLF}

A complete description of the experimental design for the STLF is given in Waugh and Link (1989). The gas exchange experiments were carried out on a subset of the treatments described in Waugh and Link (1989). Observations were taken in those lysimeter treatments experiencing normal precipitation with and without B. tectorum growing in them. Four replicate lysimeters were observed in each treatment. Observations were taken in April when the plants were active and again in July after the piants had senesced.

Four replicate lysimeters were measured between 09:00 and 15:00 hours, depending on the conditions of any given day. Chamber conditions were as follows: air temperature of $25.0 \pm 0.5^{\circ} \mathrm{C}$, dewpoint temperature of $8.5 \pm 1^{\circ} \mathrm{C}$, full light, chamber $\mathrm{CO}_{2}$ concentration of $345 \pm 5 \mathrm{pprn}$, and an overpressure of $2.5 \pm 2.0 \mathrm{~cm} \mathrm{H}_{2} \mathrm{O}$.

\subsubsection{Lower Snively Field}

Twenty randomly located plots, each $25 \mathrm{~m}^{2}$, were established at the site. The four treatments consisted of untreated controls, additional nitrogen, additionai water, 
and additional nitrogen and water. The nitrogen treatment was created by the addition of $714 \mathrm{~g} \mathrm{NH}_{4} \mathrm{NO}_{3}$ dissolved in $10 \mathrm{~L}$ of water yielding $10 \mathrm{~g} / \mathrm{m}^{2}$ of $\mathrm{N}$ in January 1990 . The water treatment was created by adding enough water to equal the 30-year maximum value from October 1 until the time of irrigation, which was in February. Water was obtained from nearby springs and applied by drip irrigation. The nitrogenand-water treatment was created by adding nitrogen and water together as in the nitrogen and water treatmonts. Each trealment consisted of five replicate plots.

Growth and phenology were monitored on the replicated plots for all four treatments. Meassurements of shoot height, leat area index, and green biomass were made monthly from October 1989 until May 1990. Leaf areas were measured using a digital image analysis system (DIAS) (Decagon Devices, Pullman, Washington). Biomass was determined as oven-dried weight of green vegetative material ovendried at $55^{\circ} \mathrm{C}$ for $48 \mathrm{~h}$.

Observations of maximum rooting depth were made by trenching outside the treatment plots. To determine treatment effects on root density, in March and May of 1990 soil and root cores to depths of $60 \mathrm{~cm}$ were taken within the treatment plots using a small 1 -in.-diameter coring tool.

\subsubsection{Snively Canvon}

The experimental design for model development work was simple. No hypotheses were tested. Data were collected to parameterize the driving relationships for transpiration and net photosynthesis. The driving variables are vapor pressure gradient, light, temperature, and xylem pressure potential. Data were collected concurrently to parameterize the relationships between transpiration and net photosynthesis and these driving variables. In addition, two diurnal curves were generated for model testing.

The response curve for vapor pressure gradient was generated at midday by varying the chamber dewpoint temperature. Operating conditions were photosynthetically active radiation (PAR) of $1650 \mu \mathrm{mol}$ fhotons $\mathrm{m}^{-2} \mathrm{~s}^{-1}$ and leaf temperature of $23^{\circ} \mathrm{C}$. The light response curve was generated at midday by using 
cheesecloth to reduce the light level by intervals from 2000 to $0 \mu \mathrm{mol}$ photons $\mathrm{m}^{-2} \mathrm{~s}^{-1}$. A black cloth was draped over the chamber to obtain a light level of $0 \mu \mathrm{mol}$ photons $\mathrm{m}^{-2} \mathrm{~s}^{-1}$. Operating conditions were a vapor pressure gradient (VPG) of $1.9 \mathrm{kPa}$ and a leaf temperature of $23^{\circ} \mathrm{C}$.

The temperature response curve in the light was generated at midday by varying the chamber air temperature from 14 to $37^{\circ} \mathrm{C}$, which yielded leaf temperatures ranging from 12 to $37^{\circ} \mathrm{C}$. The PAR remained at a level of approximately $1300 \mathrm{kmol}$ photons $\mathrm{m} \cdot 2 \mathrm{~s}-1$. The VPG could not be held constant, and varied from $0.9 \mathrm{kPa}$ at 12 to $4.2 \mathrm{kPa}$ at $37^{\circ} \mathrm{C}$. The temperature response curve in the dark was generated at midday by varying the temperature from 12 to $38^{\circ} \mathrm{C}$, which yielded leaf temperatures ranging from 9 to $38^{\circ} \mathrm{C}$. Darkness was achieved by enveloping the chamber in a black cloth. The VPG ranged from 0.6 to $5.2 \mathrm{kPa}$. The curve for xylem pressure potential was generated by allowing the plant material to change from nighest values of xylem pressure potential $(P=-2.8 \mathrm{MPa})$ at pre dawn to minimal values $(P=-4.0$ $\mathrm{MPa}$ ) in the late afternoon. Operating conditions were as follows: PAR of $1800 \mu \mathrm{mol}$ photons $\mathrm{m}^{-2} \mathrm{~s}^{-1}, V P G$ of $2.3 \mathrm{kPa}$, and leaf temperature of $26^{\circ} \mathrm{C}$. Xylem pressure potential was measured on shoot material taken from the chamber every $2 \mathrm{~h}$ using a pressure chamber system (Soil Moisture Equipment, Santa Barbara, California). A humid atmosphere was maintained in the chamber with a damp towel. Measurements were taken immediately after cutting the leaf material, and the chamber was pressurized slowly and consistently for all observations.

\subsection{IECHNOLOGIES}

The gas exchange technology used in this work has been described before (Waugh and Link 1988; Link et al. 1989). We describe in more detail here the configuration of the whole-plant gas exchange system as used at the STLF and at Snively Canyon.

\subsubsection{Whole-Plant Gas Exchange System}

The whole-plant gas exchange system is portable, so that measurements can be made away from electrical and water supplies. Instrumentation is housed in a motor 
home that is climate-controlled. An 87-A diesel generator is used to supply power for the instruments. The power is filtered using a line conditioner. A water pump is used to circulate cooling water through the air compressor system in a closed loop.

The whole-plant gas exchange system was patterned after that described in Caldwell et al. (1983), and is an open system. Carbon dioxide concentrations were measured with an ADC 225 MKIII infrared gas analyzer (IRGA) (Analytical Development Co. Ltd., Hoddesdon, England). An accompanying gas-routing device (WA-357, Analytical Development Co. Ltd., Hoddesdon, England) allowed for computer-controlled calibration and measurement in absolute and differential modes. The IRGA was calibrated either before each lysinieter was obsoned or every $2 \mathrm{~h}$. Water vapor concentrations entering and leaving the gas exchange chamber and in the ambient air were measured with thee DEW-10 dewpoint hygrometers (General Eastern Instruments, Inc., Watertown, Massachusetts). Dewpoint temperature was measured with RTD platinum resistance sensors. Fine-wire copper-constantin thermocouples were used to measure all other temperatures, including leaf tempeiature, chamber air temperature, heat-exchanger fin iemperature, and air temperature in air lines just ahead of the dewpoint hygromeiers. Photosynthetically active radiation was measured with a LI-COR 190SB Quantum sensor (Li-Cor Inc., Lincoln, Nebraska). Supplemental lighting was provided by a $300-W$ quartz-filament slide projector bulb suspended over the gas exchange chamber when skies were overcast.

The gas exchange chamber used for these experiments was consiructed of clear acrylic plastic. The $46-\mathrm{L}$ chamber was cylindrical $(65 \mathrm{~cm}$ tall and $30 \mathrm{~cm}$ in diameter) with a flat plastic top. The chamber is lined with clear Teflon tape to minimize gas absorption by the plastic (Bloom et al. 1980). The seal between the chamber and the lysimeter was made with an aluminum ring lined with closed-cell foam constructed to conform to the aluminium lifting tabs of the lysimeter and having grooves lined with closed-cell foam on the other side for sealing to the chamber. A 5-cm-dia inlet for recirculating air was located $22 \mathrm{~cm}$ below a similar outlet port. An air-tight air conditioning unit fabricated of stainless steel was attached to the ports for temperature control. Temperature control was accomplished with Peltier chips, heat-exchanger fins, and a circulating fan. The heatexchanger fins were made of nickel-plated copper. The air conditioning housing was insulated with $0.64-\mathrm{cm}$-thick closed-cell foam covered with aluminum foil to reflect solar 
radiation and was always placed on the north side of the lysimeter to avoid shading the plants. The heat exchanger and fan motor (located outside the air conditioning unit) were water-cooled by circulating water through the heat exchanger and a radiator with a 1.5-hp water pump.

Process air was taken from a height of $1.5 \mathrm{~m}$ by an oilless air compressor, passed through a chilled water jacket to remove water from the air, and maintained at a pressure of 40 psi ahead of two air filters and a Tylan (FC-262) mass flow controller. The mass flow controller was used to control the flow of air for maintenance of a constant chamber dewpoint temperature. All air liries were of Bev-e-lin tubing. Sample lines were diverted to measure the dewpoint temperature and $\mathrm{CO}_{2}$ concentration (in absolute and differential mode) of the air going into the chamber. Sample air was pumped out of the chamber through Bev-e-lin tubing to measure dewpoint temperature and $\mathrm{CO}_{2}$ concentration of the air leaving the chamber.

Data were acquired and instruments controlled with a WB-820 board system (Omega Engineering, Inc.) in association with an IBM-AT microcomputer.

\subsection{DATA ANALYSES}

\subsubsection{STLE}

Data are presented as means with one standard-error bar. Treatment comparisons are made with Duncan's Multiple-Range Test at the $95 \%$ confidence level.

\subsubsection{Lewer Snively}

Data are presented as means with one standard-error bar.

\subsubsection{Snively Canyon}

Model development entailed estimating parameters for the response curves and subsequently estimating empirical scaling parameters for the diurnal data sets. 
The relationships between stomatal conductance and the driving variables were determined by controlled experimentation as described above. Transpiration is then computed by multiplying the stomatal conductance by the vapor pressure gradient.

The relationship between stomatal conductance and vapor pressure gradient is as follows:

$$
f(V P G)=9 v p g \min +9 v p g \max /\left(1+(V P G / B)^{n}\right)
$$

where $f(V P G)=$ stomatal conductance

gvpgmin $=$ minimal stomatal conductance

gvpgmax $=$ maximal stomatal conductance

$B=$ a parameter describing the sensitivity of stomates to VPG

$\mathrm{n}=$ an empirical curvature parameter.

The relationship between stomatal conductance and PAR is as follows:

$$
g(P A R)=g \text { parmin }+ \text { gparmax }\left(1-\theta^{(-c P A R / g} \text { parmax }\right)
$$

where $g(P A R)=$ stomatal conductance

Iparmin = minimal stomatal conductance

gparmax $=$ maximal stomatal conductance

$\mathrm{c}=$ an empirical curvaturis parameter.

The relationship between stomatal conductance and leaf temperature $\left(T_{1},{ }^{\circ} \mathrm{K}\right)$ is as follows:

$$
h\left(T_{1}\right)=b_{0}+b_{1} T_{1}
$$

where $h\left(T_{1}\right)$ is stornatal conductance and $b_{0}$ and $b_{1}$ are linear-regression parameters. Because VPG could not be held constant for the temperature relationship, the 
parameters in Equation (2.3) were estimated in the context of changing VPG by multiplying Equation (2.1) by Equation (2.3) as follows:

$$
h\left(T_{1}\right)=f(V P G) *\left(b_{0}+b_{1} T_{1}\right)
$$

where the parameters for $f(V P G)$ are known, as described in Equation (2.1).

The relationship between stomatal conductance and xylem pressure potential $(P)$ is as follows:

$$
i(P)=g p \max +b_{1} P
$$

where $i(P)$ is stomatal conductance, gpmax is maximal stomatal conductance when $P=0$, and $D_{1}$ is a parameter describing the sensitivity of stomates to xylem pressure potential.

To estimate scaling parameters, the response Equations (2.1) through (2.4) were combined as follows:

$$
g h=a^{*} f+b^{*} g+c^{*} h+d^{*} i+\theta^{*} f^{*} g^{*} h^{*} i
$$

where $\mathrm{gh}$ is stomatal conductance and $\mathrm{a}, \mathrm{b}, \mathrm{c}, \mathrm{d}$. and $\mathrm{e}$ are empirical scaling parameters and $f, g, h$, and $i$ are as defined in Equations (2.1) through (2.4).

Net photosynthesis $(\mathrm{Pn})$ was modeled as the resultant of carboxylation $(\mathrm{Pc})$ and dark respiration (Rd) as follows:

$$
P n=P c-R d
$$

Carboxylation was estimated as the resultant of net photosynthesis and dark respiration in the context of controlled experimentation. Carboxylation was found to be a function of PAR and $T_{1}$, and dark respiration was found to be a function of $T_{1}$. No relationship was found for $P n$ and VPG or xylem pressure potential. 
The relationship between carboxylation and PAR/1000 is described using the Smith Equation (Smith 1937) as follows:

$$
j(P A R)=P n+R d=P c_{e f f} P A R /\left(1+c P^{2} R^{2}\right) 0.5
$$

where $j(P A R)=$ carboxylation

$R d=$ dark respiration at a $T /$ of $23^{\circ} \mathrm{C}$

$P c_{\text {eff }}=$ the initial light-use efficiency

$c=$ an empirical curvature parameter.

The Arrhenius relationship between $R d$ and $T_{k}$ is as follows:

$$
k(T k)=R d=r_{\theta}(E / R T k)
$$

where $r$ is an empirical scaling parameter, $E$ is an activation energy, $R$ is the universal gas constant (8.31), and TK is leaf́ temperature in ${ }^{\circ} \mathrm{K}$.

The relationship between carboxylation and leat temperature $\left(T,{ }^{\circ} \mathrm{K}\right)$ is as follows:

$$
I\left(T_{1}\right)=P n+R d=b_{0}+b_{1} T_{1}+b_{2} T_{1}^{2}+b_{3} T_{1}^{3}
$$

where $l\left(T_{1}\right)$ is carboxylation and $b_{0}, b_{1}, b_{2}$, and $b_{3}$ are linear-regression parameters.

The response Equations (2.8) through (2.10) were combined to estimate scaling parameters as follows:

$$
P n=P c-R d=a^{*} j+b^{*} I+c^{*} j^{*} \mid-d^{*} k
$$

where $a, b, c$, and $d$ are empirical scaling parameters and $j, k$, and $l$ are as defined in Equations (8) through (10).

Scaling parameters were estimated for both diurnal data sets. 
To predict rates on June 8 , the models were verified using the parameters estimated with the diurnal data set collected on June 16. To predict rates on June 16, the models were verified again using the parameters estimated with the diurnal data set collected on June 8 .

All computer work was done with the Statistical Analysis System (SAS) software. Nonlinear regression was used for parameter estimation. 


\subsection{BESULTS}

\subsection{STLF}

Evapotranspiration rates in April were apparently higher for the $\mathrm{B}$ tectorum lysimeters than for the bare-soil lysimeters (Figure 3.1) although the rates were not different statistically. The variation about the mean for the B. tecterum lysimeters was 10 times as great as that for the bare-soil lysimeters. Net carbon flux on the B. tectorum lysimeters was significantly different from the flux on the bare-soil lysimeters (Figure 3.2) even though variation was greater about the mean for the $\mathbf{B}$. tectorum lysimeters than for the bare-soil lysimeters. The $\mathrm{B}$ tectorum lysimeters showed a net carbon gain through photosynthesis while the bare-soil lysimeters showed a net carbon loss through soil respiration. The data presented in Figures 3.1 and 3.2 are relative to the surface area of the lysimeter. The reason for greater variation in the data for the $\mathrm{B}$. tectorum lysimeters can be seen in Figure 3.3, which shows the strong positive correlation $\left(R^{2}=0.89\right)$ between evapotranspiration rates and leaf area. This significant source of variation (plant leaf area) was not taken into account for the data presented in Figures 3.1 and 3.2. Data collected in July await processing.

\subsection{LOWER SNIVELY}

During the spring growing season, the treatment applications of nitrogen and water at the Lower Snively site significantly affected both leaf area index (LAI) and mean biomass of $B$ lectorum (Figures 3.4 and 3.5). During the fall and winter, no discernable differences between treatments were noted. The mean biomass and LAI for the treatments receiving nitrogen began to increase in February. The biomass and leaf area of the treatment receiving only additional water were not significantly greater until April. In May, both the LAl and mean biomass began to decline for all treatments, as plants began to senesce.

No results are available yet concerning the possible effects of added nitrogen and/or water on root density with depth. Root/soil samples are being processed and roots washed from the soils. 


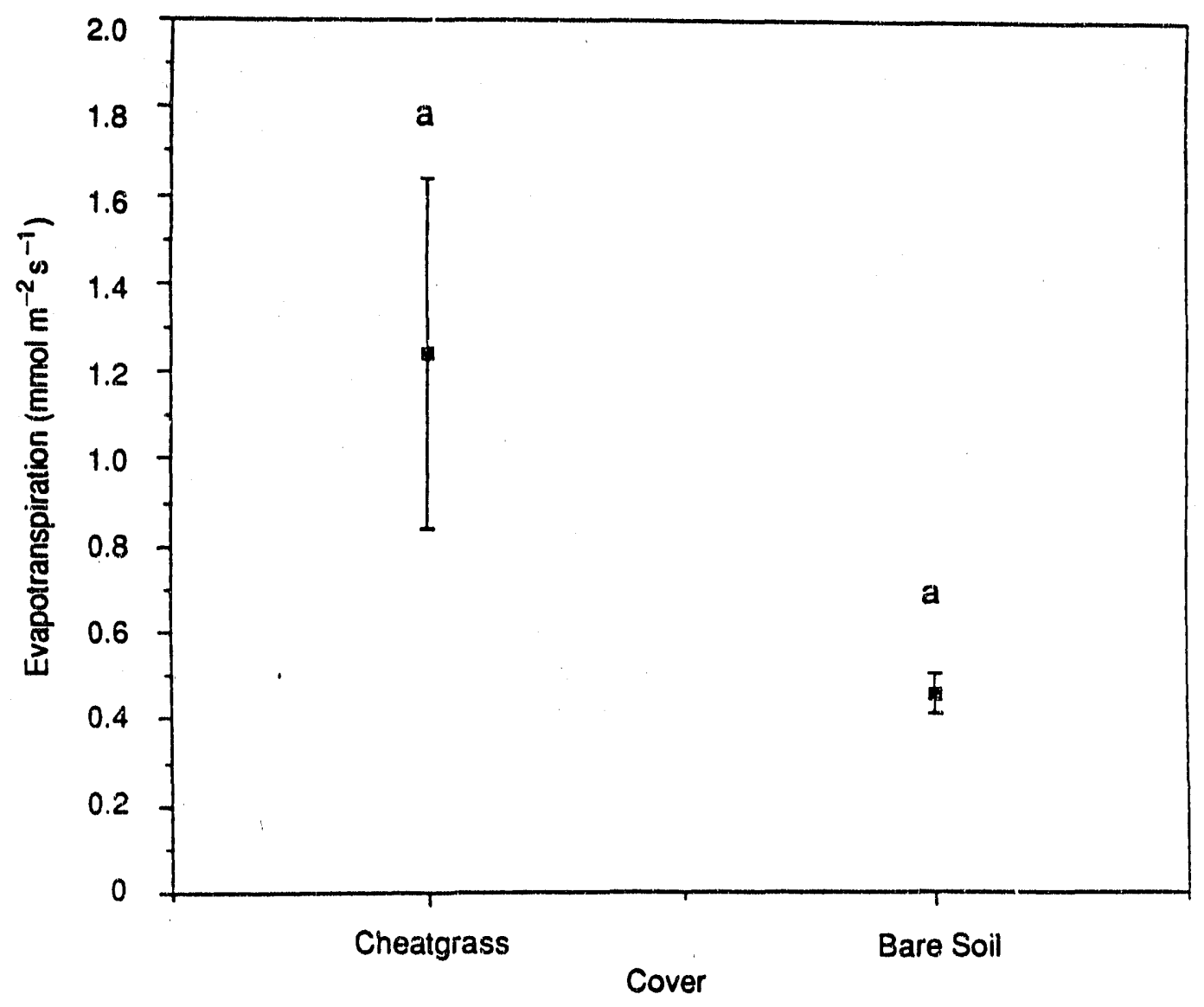

FIGURE 3.1. Evapotranspiration from Bare-Soil and Bromus tectorum Lysimeters in April 1990 


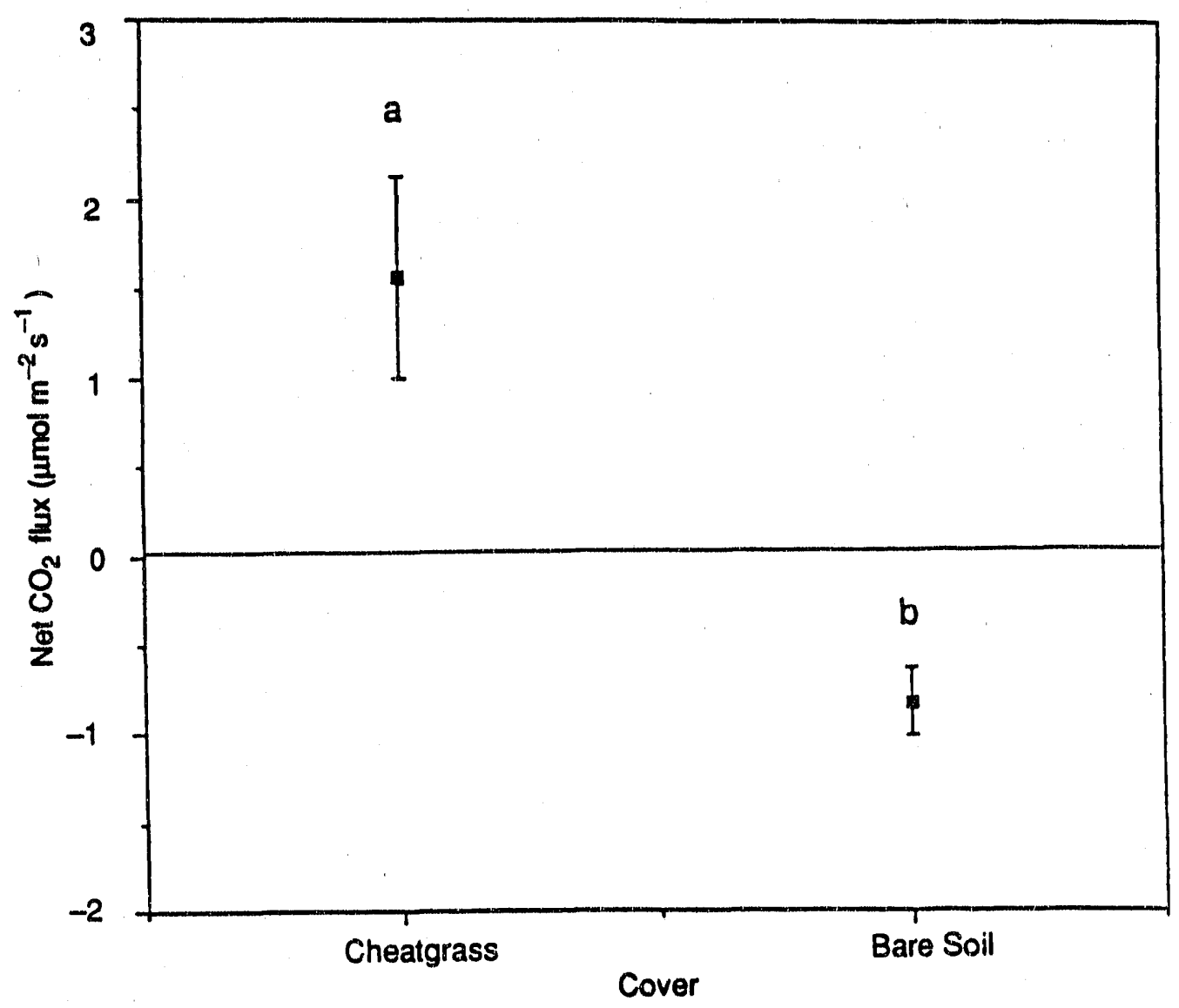

FIGURE 3.2. Carbon Dioxide Flux from Bare-Soil and Bromus tectorum Lysimeters in April 1990 


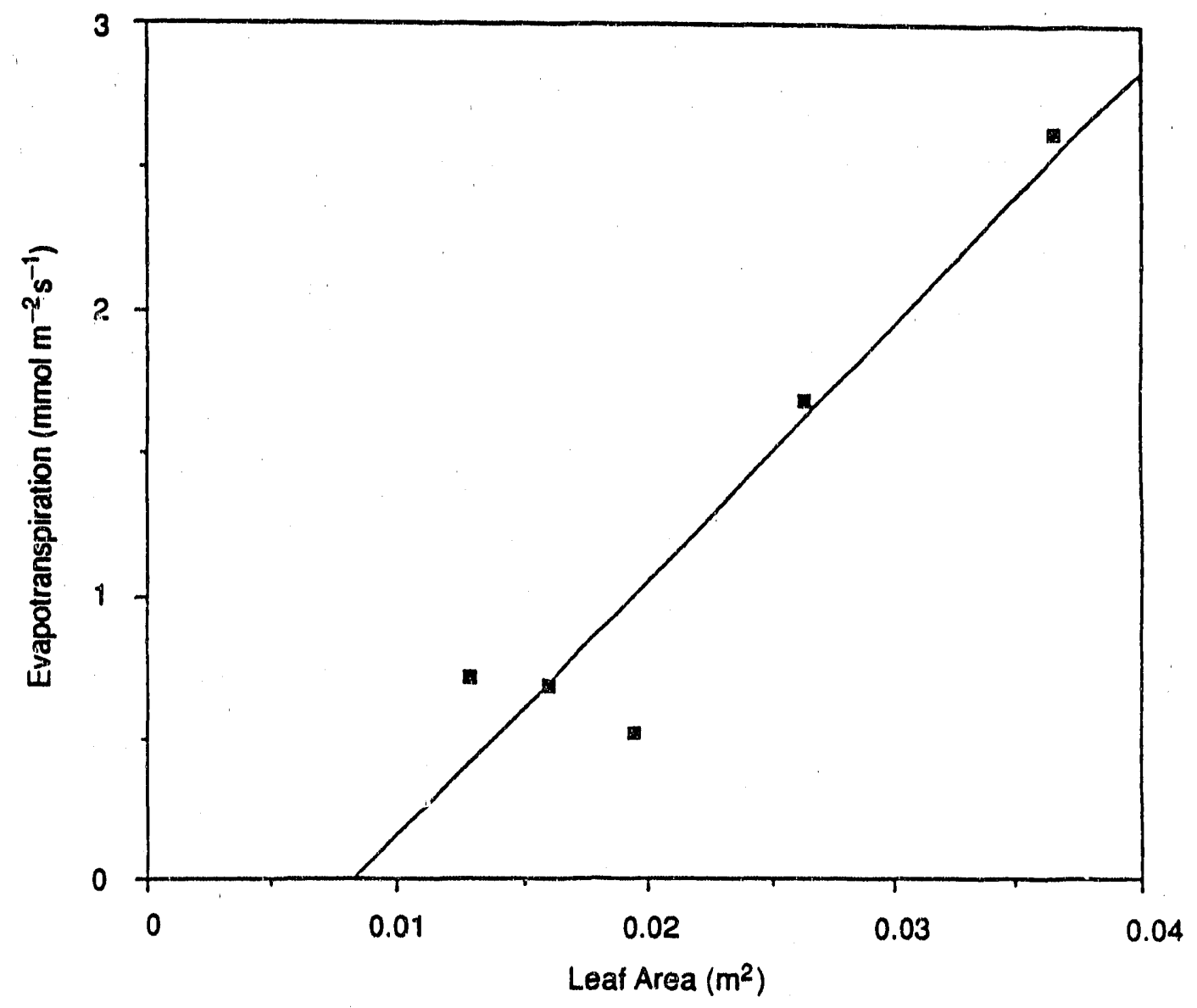

FIGURE 3.3. The Relationship Between Leaf Area and Evapotranspiration for the Bromus tectorum Lysimeters in April 1990 


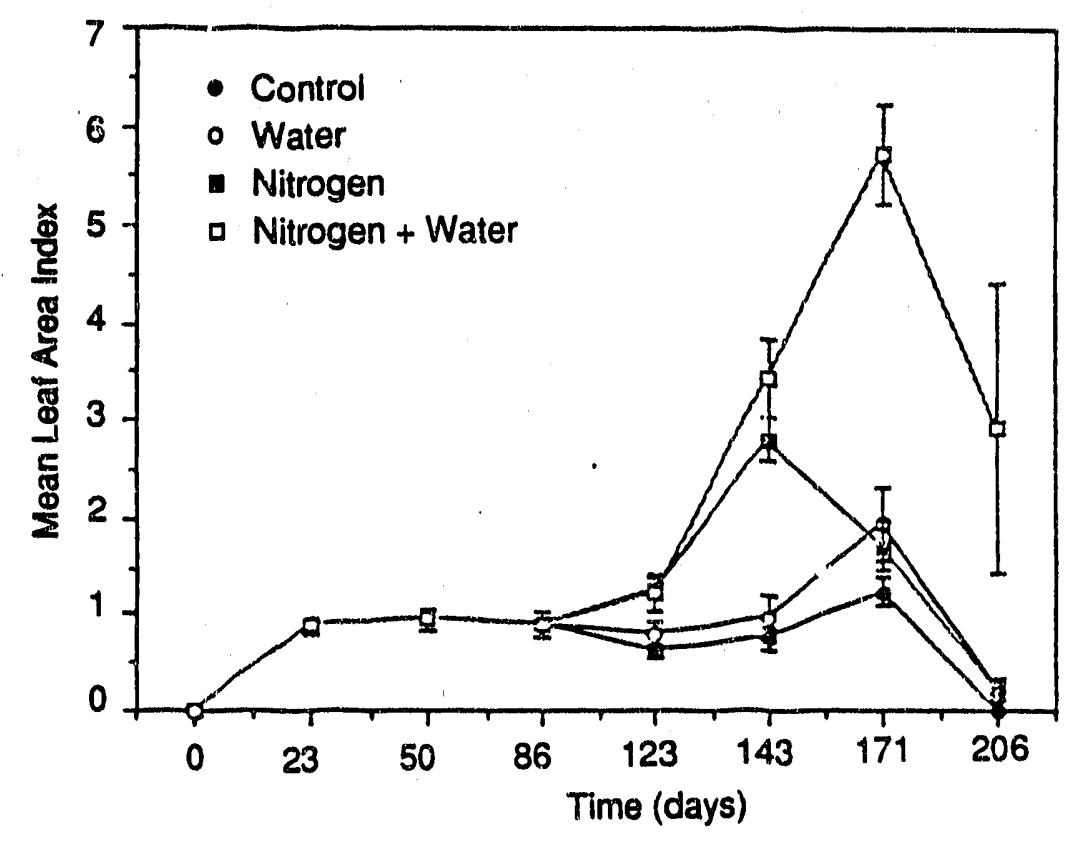

FIGURE 3.4. The Effect of Water and Nitrogen Treatments on Bromus tectorum GreenLeaf-Area Index. Bars are one standard error of the mean $(n=5)$ 


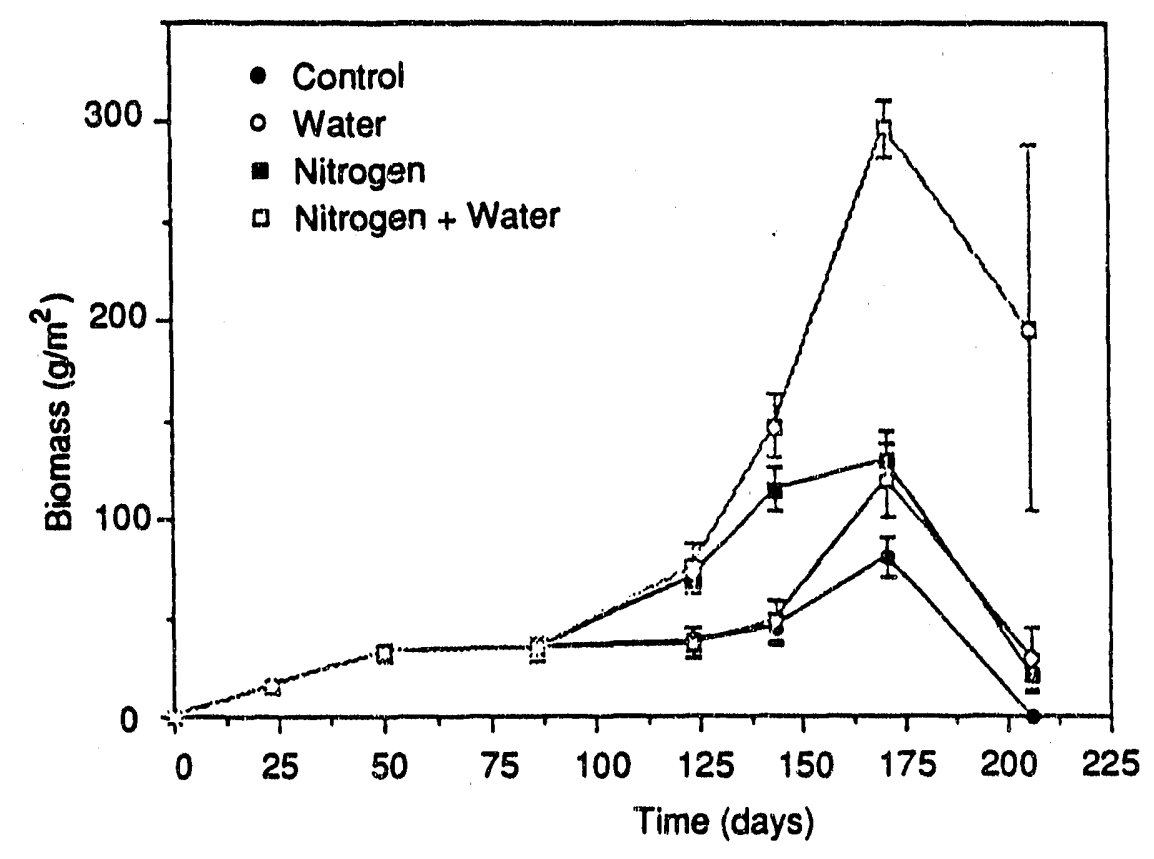

FIGURE 3.5. The Effect of Water and Nitrogen Treatments on Bromus tecterum GreenShoot-Biomass Development. Bars are one standard error of the mean $(n=5)$. 


\subsection{SNIVELY CANYON}

Predictive models for stomatal conductance and thus transpiration and net photosynthesis were developed by first estimating parameters for univariate relationships between the processes and the driving variables. Statistical characteristics of the regressions for Equations (2.1) through (2.10) are presented in Table 3.1.

TABLE 3.1 Statistical Characteristics of the' Regressions for Equations (2.1) Through (2.10), Parameter Estimates, and Associated Asymptotic Standard Errors

\begin{tabular}{|c|c|c|c|c|}
\hline Equation & $R^{2}$ & Parameter & $\begin{array}{l}\text { Parameter } \\
\text { Estimate }\end{array}$ & $\begin{array}{c}\text { Asymptotic } \\
\text { Standard } \\
\text { Error }\end{array}$ \\
\hline \multirow[t]{2}{*}{$(2.1)$} & 0.993 & $\begin{array}{l}\text { gvpgmin } \\
\text { gvpgmax }\end{array}$ & $\begin{array}{l}31.0 \\
26.803 \\
1.764\end{array}$ & $\begin{array}{l}\overline{0} \\
0.930 \\
0.037\end{array}$ \\
\hline & & $n$ & 6.661 & 0.702 \\
\hline (2.2) & 0.996 & $\begin{array}{l}\text { gparmin } \\
\text { 9parmax } \\
c\end{array}$ & $\begin{array}{c}9.693 \\
36.987 \\
0.0514\end{array}$ & $\begin{array}{l}\overline{1} .089 \\
0.0024\end{array}$ \\
\hline (2.3) & & $\begin{array}{l}b 0 \\
b 1\end{array}$ & $\begin{array}{r}-76.32 \\
0.28\end{array}$ & $\begin{array}{r}37.81 \\
0.13\end{array}$ \\
\hline (2.5) & 0.766 & gpmax & $\begin{array}{l}181.26 \\
-21.93\end{array}$ & $\begin{array}{r}20.94 \\
6.07\end{array}$ \\
\hline$(2.8)$ & 0.998 & $\begin{array}{c}\text { Pceif } \\
c\end{array}$ & $\begin{array}{l}9.4050 \\
5.455\end{array}$ & $\begin{array}{l}264 \\
0.373\end{array}$ \\
\hline (2.9) & 0.977 & $\stackrel{r}{E}$ & $\begin{array}{l}8.623 \times 10^{7} \\
4.3651 \times 10^{4}\end{array}$ & $4004^{1.363 \times 10^{8}}$ \\
\hline$(2.10)$ & 0.980 & $\begin{array}{l}\text { b0 } \\
\text { b1 } \\
\text { b2 } \\
\text { b3 }\end{array}$ & $\begin{array}{l}0.01059 \\
1.491 \\
0.05895 \\
0.000573\end{array}$ & $\begin{array}{l}0.869 \\
0.2257 \\
0.0157 \\
0.000279\end{array}$ \\
\hline
\end{tabular}


The results for the controlled experiments are further depicted in Figures. 3.6 through 3.13. The relationship between stomatal conductance and PAR (Figure 3.6) is described with a saturating curve (Equation [2.2]). Stomatal conductance is apparently saturated with light only under full-sun conditions $\left(2000 \mu \mathrm{mol} \mathrm{m}^{-2} \mathrm{~s}^{-1}\right)$. The estimated maximum stomatal conductance is obtained by summing gparmin and gparmax, yielding a value of $46.7 \mathrm{mmol} \mathrm{m}^{-2} \mathrm{~s}^{-1}$, as can be seen graphically.

The relationship between stomatal conductance and VPG (Figure 3.7) shows the typical curvilinear (Equation [2.1]) decrease from maximum stomatal conductance at low VPG (humid) to high VPG (dry). Maximal stumatal conductance is obtained by summing gvpgmin and gvpgmax, yielding a value of $57.8 \mathrm{mmol} \mathrm{m}^{-2} \mathrm{~s}^{-1}$, as can be seen graphically. The region most sensitive to VPG is that between values of 1 and $2 \mathrm{kPa}$.

The relationship between stomatal conductance and temperature (Figure 3.8) shows a curvilinear (Equation [2.4]) decrease from maximum stomatal conductance at low temperature and low VPG to low values at high temperature and high VPG. The marginal relationship for stomatal conductance as a function of temperature was derived from Equation (2.4) and was linear (Equation [2.3]).

The relationship between stomatal conductance and xylem pressure potential (Figure 3.9) was linear, with decreasing stomatal conductance at lower values of xylem pressure potential (Equation [2.5]). This data set is restricted to relatively low values of the xylem pressure potential. A complete description of the relationship ivould require data closer to $0 \mathrm{MPa}$.

The relationship between carboxylation and PAR (Figure 3.10) is described with a saturating curve (Equation [2.8]). Carboxylation is apparently light-saturated near $1000 \mu \mathrm{mol} \mathrm{m}-2 \mathrm{~s}^{-1}$. The estimated maximum carboxylation rate $\left(\mathrm{Pc}_{\max }\right)$ is obtained as follows:

$$
P_{c_{\text {max }}}=P_{c_{e f f}} / V_{c}
$$

yielding a value of $4.02 \mu \mathrm{mol} \mathrm{m}-2 \mathrm{~s}^{-1}$, as can be seen graphically. Subtracting dark respiration from carboxylation results in net photosynthesis, shown in Figure 3.11. The light-compensation point is $200 \mu \mathrm{mol} \mathrm{m}-2 \mathrm{~s}^{-1}$. 


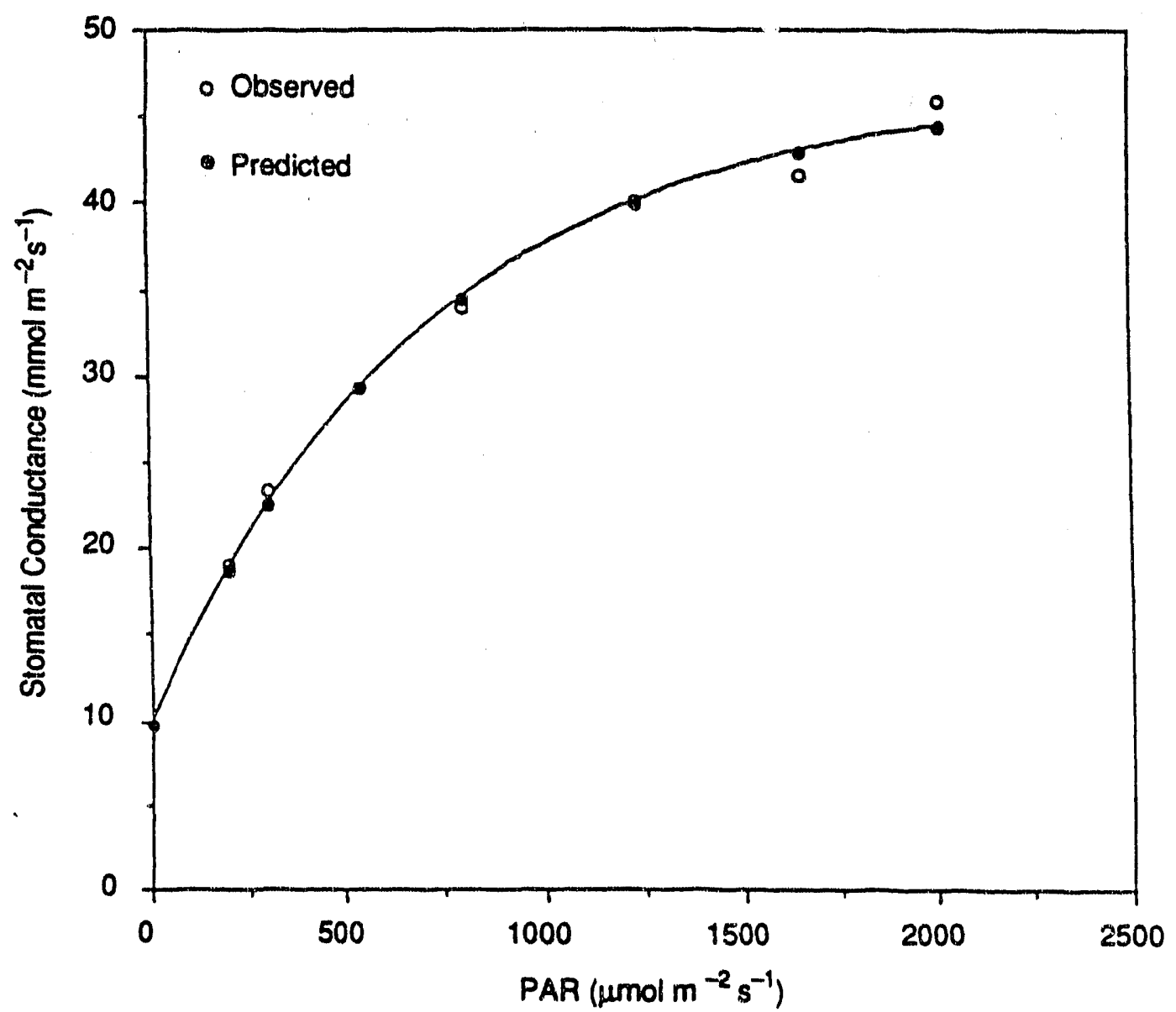

FIGURE 3.6. The Relationship Between Stomatal Conductance and Photosynthetically Active Radiation. The open symbols are observed data. The closed symbols are values predicted by Equation (2.2). 


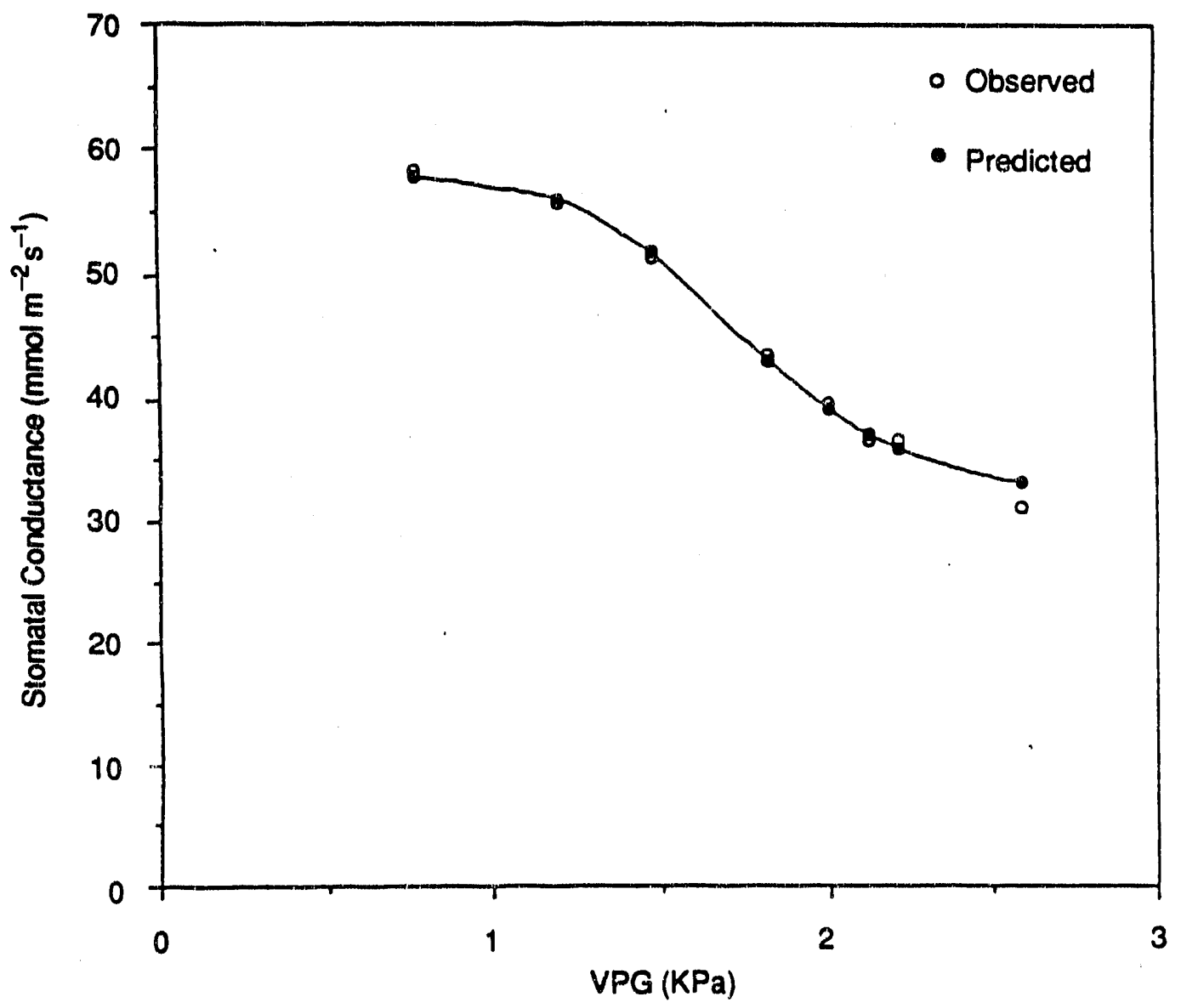

FIGURE 3.7. The Relationship Between Stomatal Conductance and Vapor Pressure Gradient. The open symbols are observed data. The closed symbols are values predicted by Equation (2.1). 


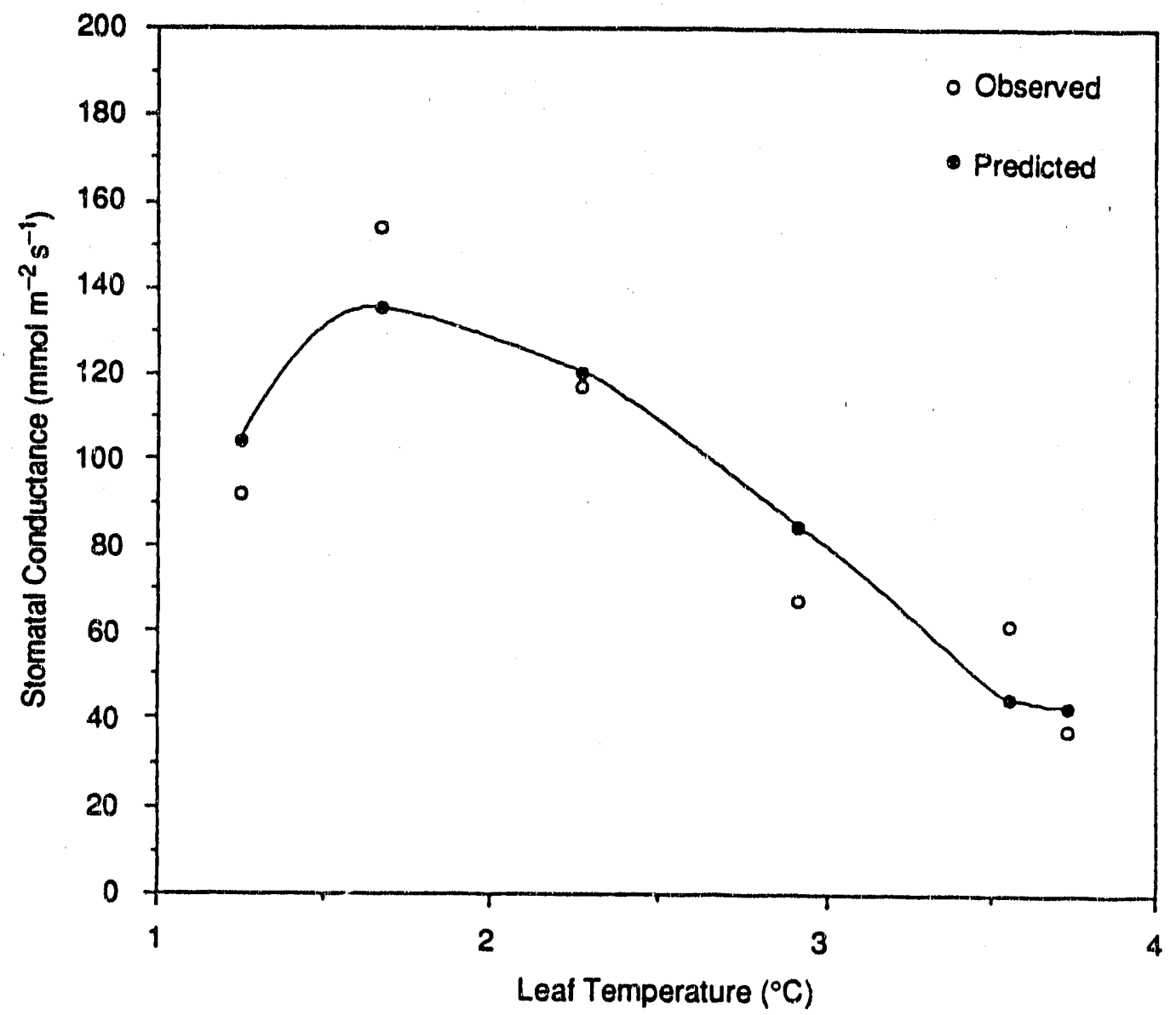

FIGURE 3.8. The Relationship Between Stomatal Conductance and Leaf Temperature. The open symbols are observed data. The closed symbols are values predicted by Equation (2.4). 


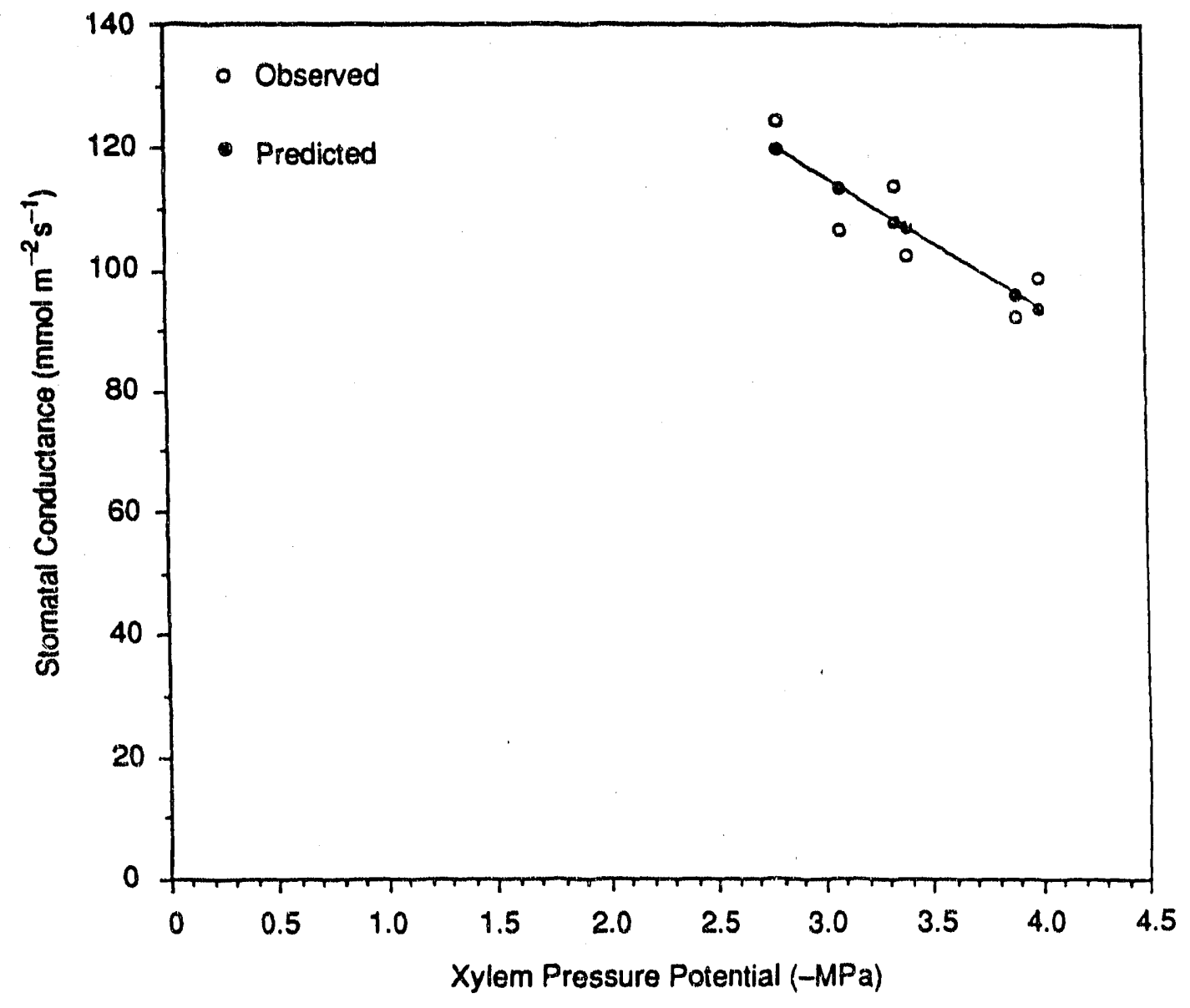

FIGURE 3.9. The Relationship Between Stomatal Conductance and Xylem Pressure Potential. The open symbols are observed data. The closed symbols are values predicted by Equation (2.5). 


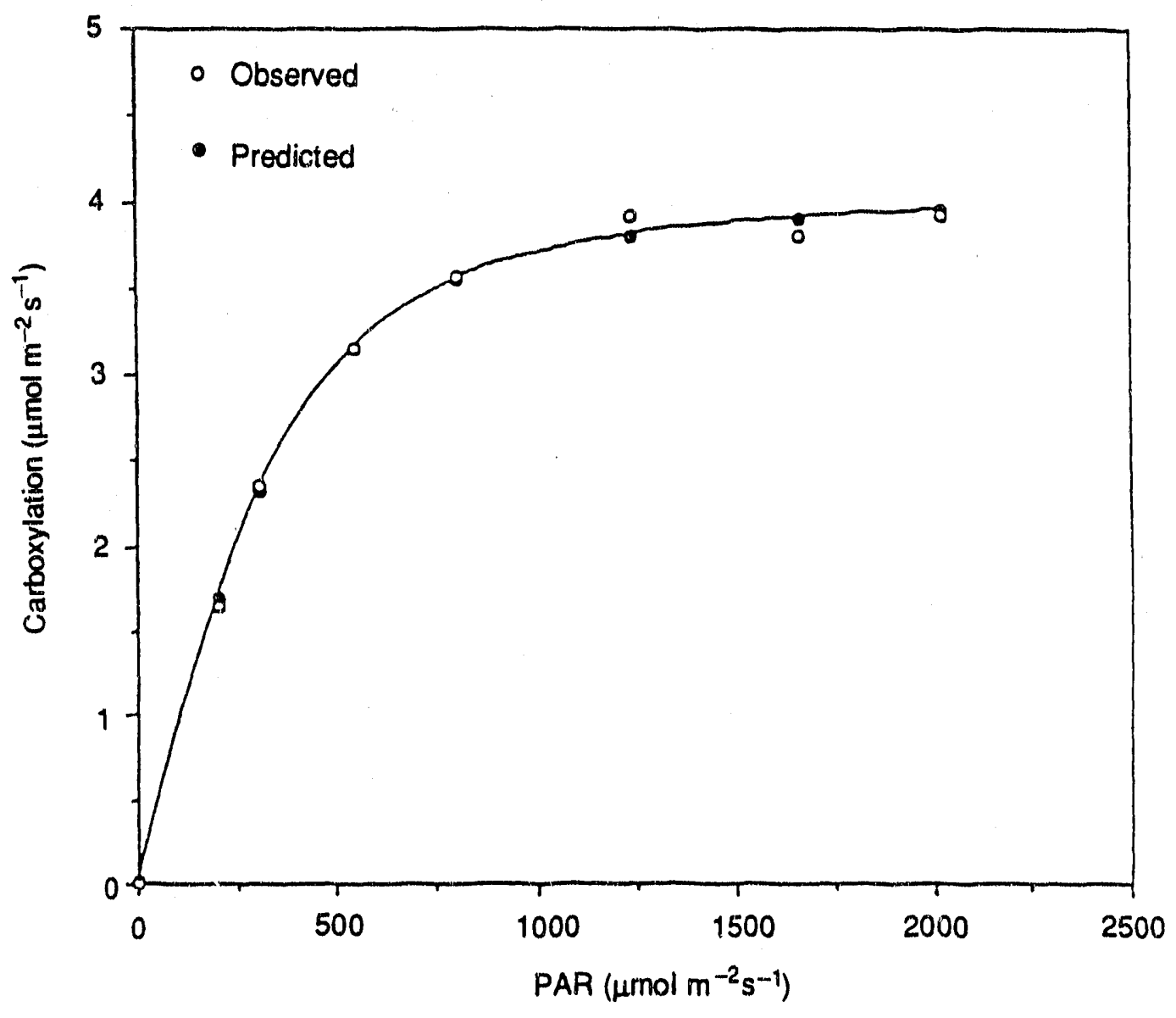

FIGURE 3.10. The Relationship Between Carboxylation and Photosynthetically Active Radiation. The open symbols are observed data. The closed symbols are values predicted by Equation (2.8). 


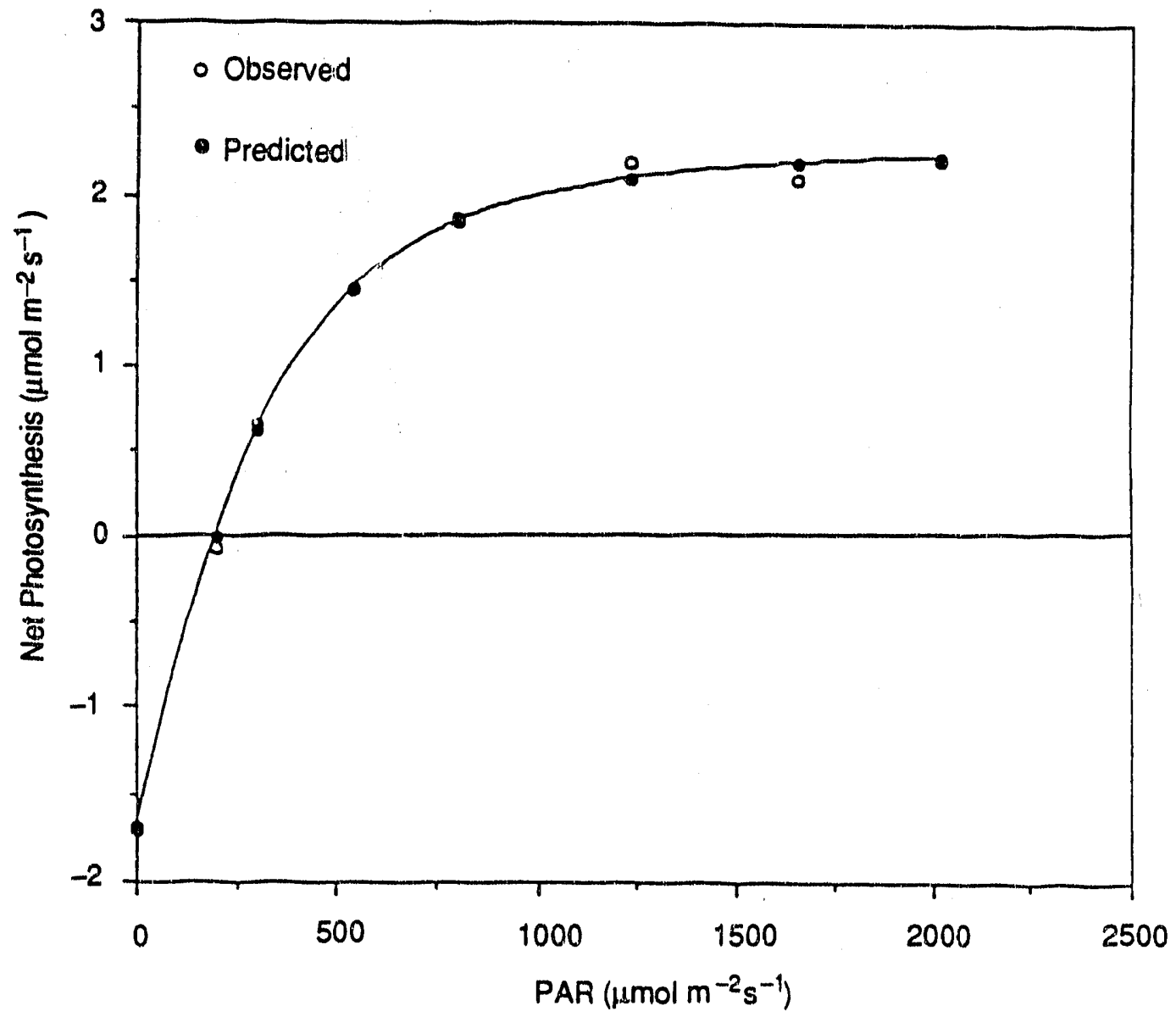

FIGURE 3.11. The Relationship Between Net Photosynthesis and Photosynthetically Active Radiation. The open symbols are observed data. The closed symbols are values predicted by Equation (2.8) after subtraction of dark respiration. 
The relationship between dark respiration and temperature (Figure 3.12) shows a typical Q10 exponential curve (Equation [2.9]), with higher dark respiration rates at the highest temperatures.

The relationship between carboxylation and temperature (Figure 3.13) shows a decrease in carboxylation rate with increasing temperatures after approximately $17^{\circ} \mathrm{C}$, the optimum temperature for carboxylation. The value of $0 \mu \mathrm{mol} \mathrm{m}-2 \mathrm{~s}^{-1}$ at $0^{\circ} \mathrm{C}$ is an assumed value included for curve fitting. At $37^{\circ} \mathrm{C}$ the carboxylation rate drops to less than $25 \%$ of its maximum rate.

After the univariate relationships described above were developed, it was then possible to estimate the scaling parameters for Equations (2.6) and (2.11). The purpose of this estimate was to scale the absolute predicted values of the univariate relationships and their interaction to produce a "best" fit to the diurnal data collected on June 8 and June 16. Statistical characteristics for the scalar parameterization of stomatal conductance using Equation (2.6) for the diurnal data sets are presented in Table 3.2.

IABLE 3.2. Statistical Characteristics for Scalar Parameterization of Stomatal Conductance Given in Equation (2.6)

\begin{tabular}{|c|c|c|c|c|}
\hline Date & $R^{2}$ & Parameter & $\begin{array}{c}\text { Parameter } \\
\text { Estimate }\end{array}$ & $\begin{array}{c}\text { Asymptotic } \\
\text { Standard } \\
\text { Error }\end{array}$ \\
\hline \multirow[t]{2}{*}{ June 8} & 0.888 & $\begin{array}{l}a \\
b \\
c \\
d\end{array}$ & $\begin{array}{c}-22.410 \\
-0.05137 \\
5.0506 \\
3.0461\end{array}$ & $\begin{array}{l}1.3051 \\
0.1204 \\
0.4794 \\
0.2161\end{array}$ \\
\hline & & $\theta$ & $-2.133 \times 10^{-5}$ & $1.292 \times 10^{-5}$ \\
\hline \multirow[t]{2}{*}{ June 16} & 0.734 & $\begin{array}{l}a \\
b \\
c \\
d\end{array}$ & $\begin{array}{l}-6.4296 \\
-0.7682 \\
-0.6543 \\
2.8112\end{array}$ & $\begin{array}{l}2.0419 \\
0.1917 \\
0.5047 \\
0.3555\end{array}$ \\
\hline & & $\theta$ & 0.0001475 & $1.589 \times 10^{-5}$ \\
\hline
\end{tabular}

3.15 


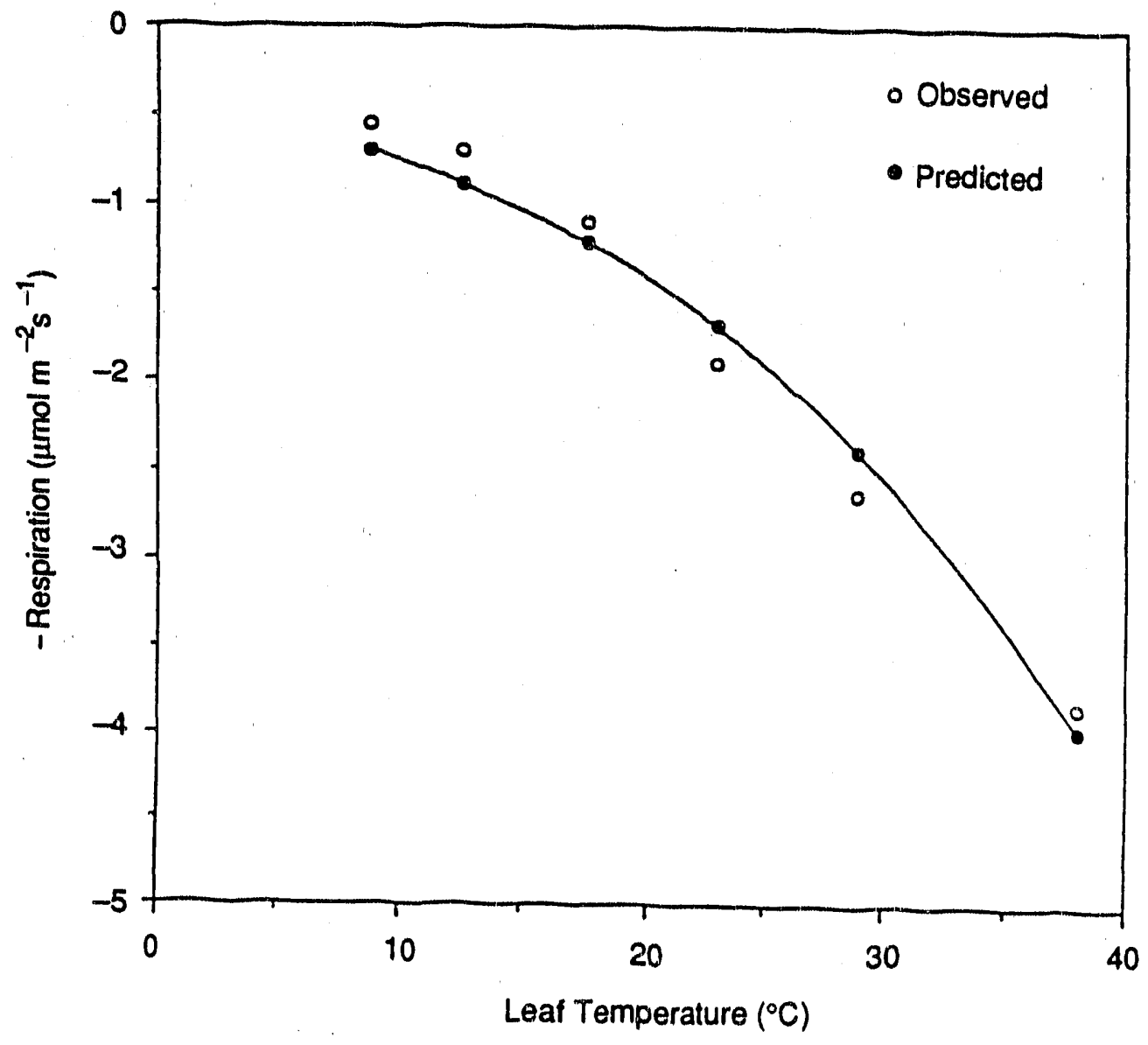

FIGURE 3.12. The Relationship Between Dark Respiration and Leaf Temperature. The Open Symbols Are Observed Data. The closed symbols are predicted values by Equation (2.9). 


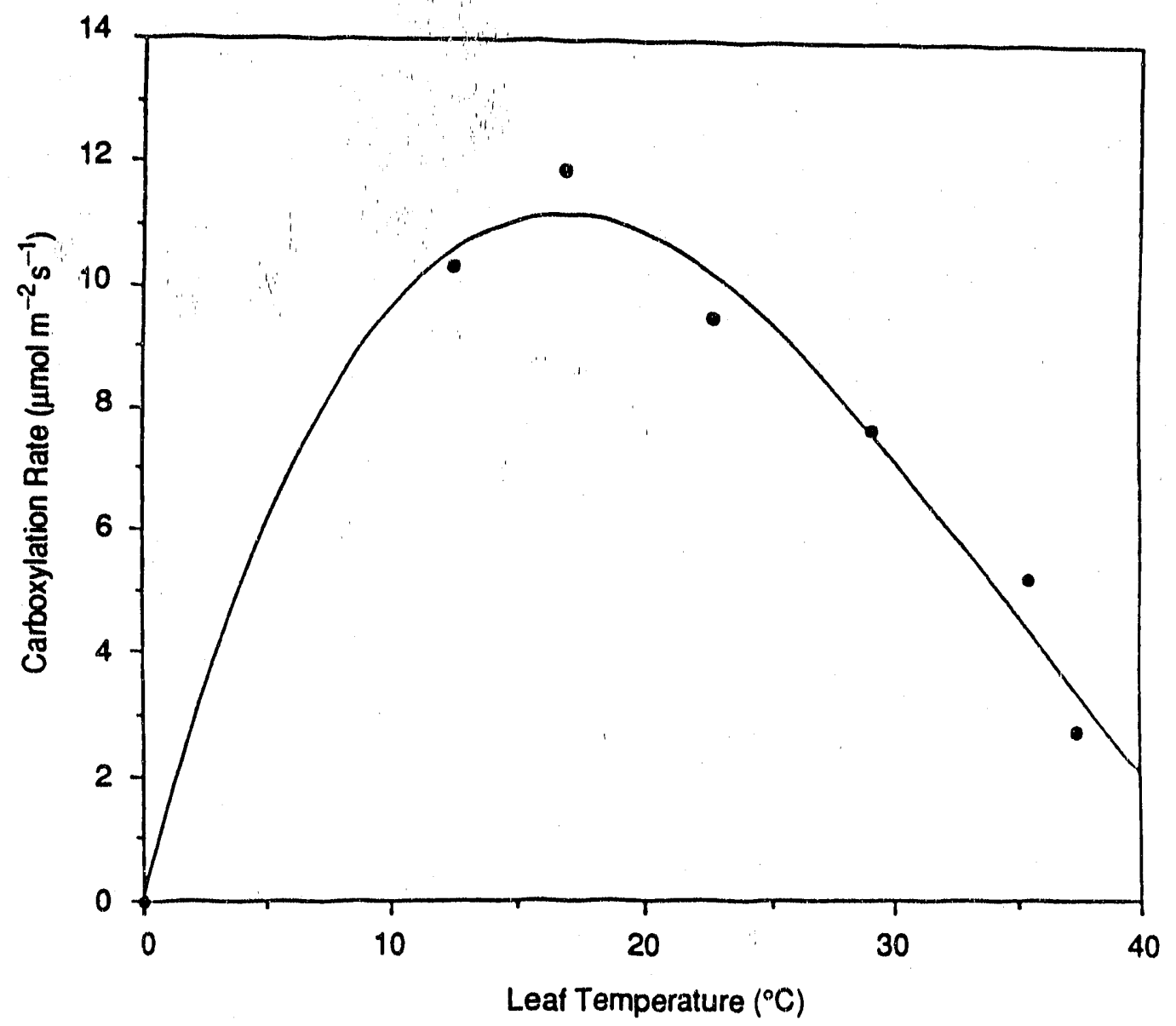

FIGURE 3.13. The Relationship Between Carboxylation and Leaf Temperature. The closed symbols are observed data. The line represents predicted values by Equation (2.10). 
Statistical characteristics for the scalar parameterization of net photosynthesis using Equation (2.11) for the diurnal data sets are presented in Table 3.3. Figures 3.14 through 3.25 present the diurnal data sets for June 8 , and Figures 3.27 through 3.39 present those for June 16.

June 8 was cloudy in the morning with clearing at midday, as can be seen from the PAR data in Figure 3.14 . Temperatures rose to about $27^{\circ} \mathrm{C}$ by 1600 from a low of $16.5^{\circ} \mathrm{C}$ at pre-dawn (Figure 3.15). Chamber temperatures tracked outside temperature closely through the day, staying within $0.5^{\circ} \mathrm{C}$. Leaf temperatures were about $0.5^{\circ} \mathrm{C}$ less than chamber temperatures in the morning, and this difference decreased with increasing temperatures. Chamber humidity control as measured by dewpoint temperature is depicted in Figure 3.16. Humidity control was good through the day, although chamber dewpoint temperature was consistently up to $1^{\circ} \mathrm{C}$ greater than the dewpoint temperature of the outside ai $i$. Dewpoint temperatures rose to about $12^{\circ} \mathrm{C}$ at 1500 , meaning that humidity was increasing, and then humidity decreased after that. The vapor pressure gradient remained near $1 \mathrm{kPa}$ until the sun came out near 1300 , after which the gradient increased to over $2 \mathrm{kPa}$ (Figure 3.17). The xylem pressure potential gradually decreased from -2.1 MPa at pre-dawn to -3.3 MPa in the late afternoon (Figure 3.18). The pattern and the absolute value of stomatal conductance were well predicted by the model (Figure 3.19). A linear regression of observed and predicted values of transpiration had an $R^{2}$

IABLE 3.3. Statistical Characteristics for Scalar Parameterization of Net Photosynthesis Given in Equation (2.11)

\begin{tabular}{|c|c|c|c|c|}
\hline Date & $R^{2}$ & Parameter & $\begin{array}{l}\text { Parameter } \\
\text { estimate }\end{array}$ & $\begin{array}{l}\text { Asymptotic } \\
\text { standard } \\
\text { error }\end{array}$ \\
\hline June 8 & 0.984 & $\begin{array}{l}a \\
b \\
c \\
d\end{array}$ & $\begin{array}{l}-0.02443 \\
2.105 \\
0.08666 \\
2.102\end{array}$ & $\begin{array}{l}0.03138 \\
0.4319 \\
0.03877 \\
0.3030\end{array}$ \\
\hline June 16 & 0.941 & $\begin{array}{l}a \\
b \\
c \\
d\end{array}$ & $\begin{array}{l}-0.03431 \\
1.549 \\
0.1334 \\
1.868\end{array}$ & $\begin{array}{l}0.05156 \\
0.6069 \\
0.05344 \\
0.4732\end{array}$ \\
\hline
\end{tabular}




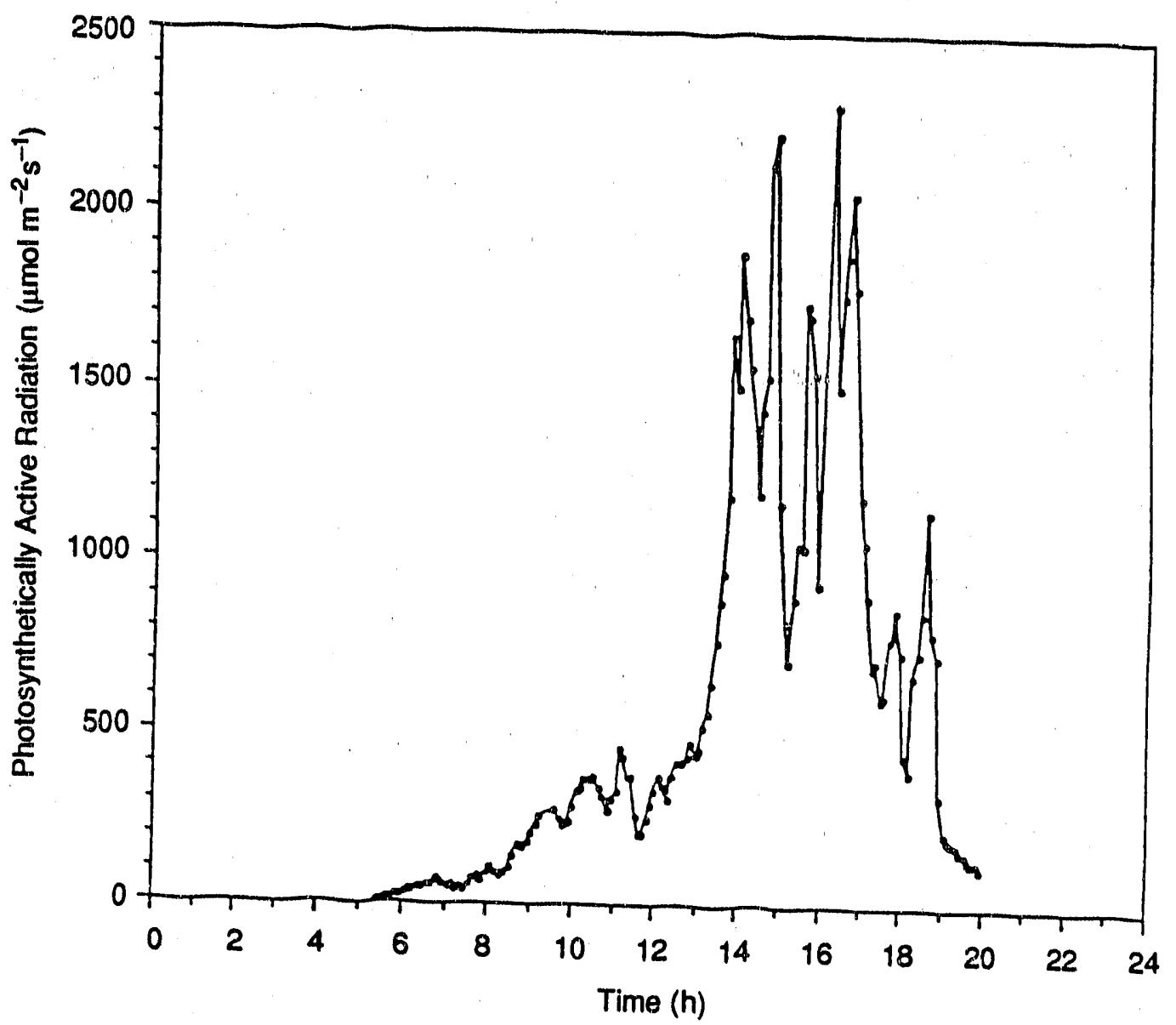

FIGURE 3.14. Photosynthetically Active Radiation at Snively Canyon on June 8, 1990 


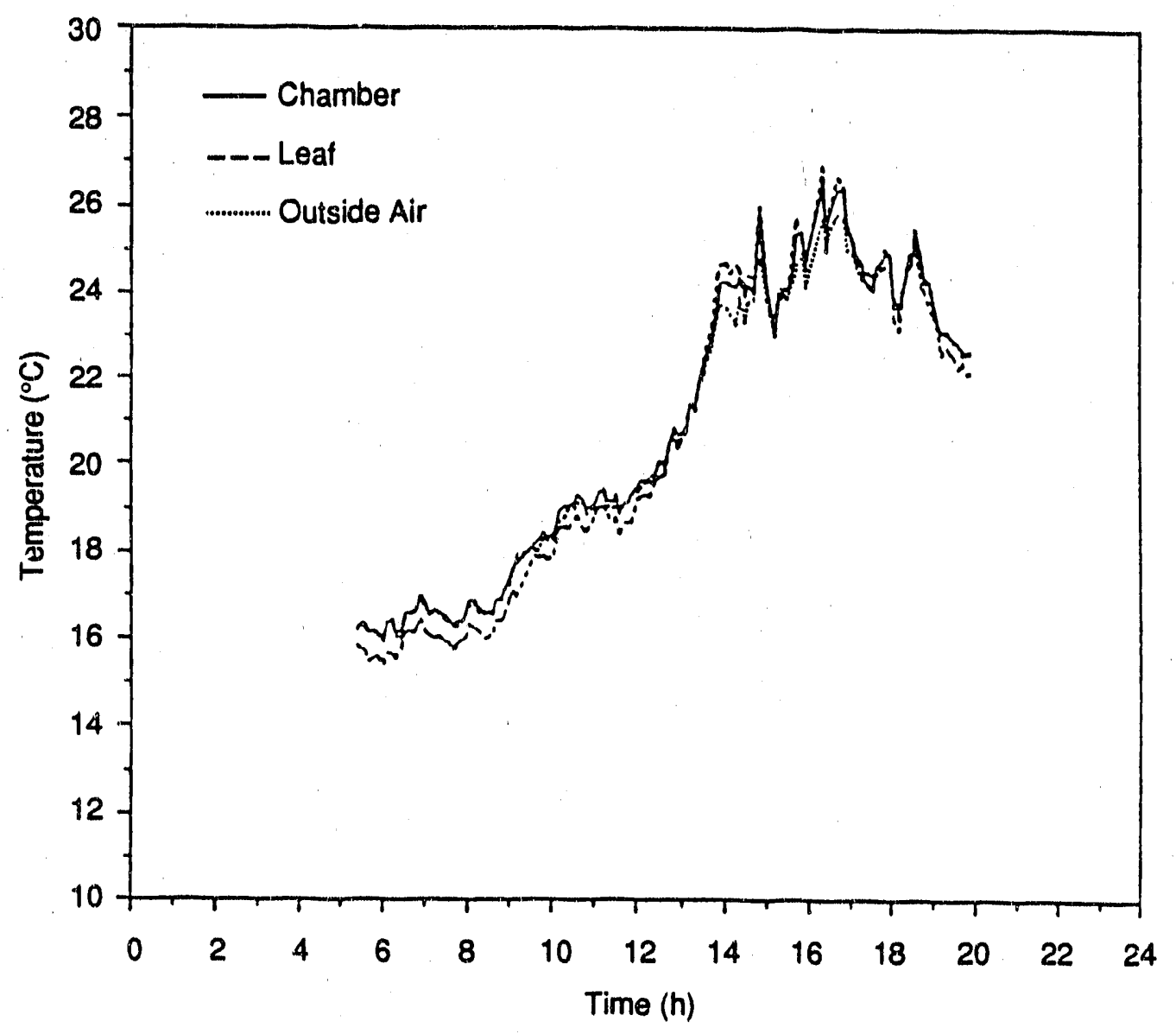

EIGURE 3.15. Chamber-Air, Leat, and Outside-Air (2 m) Temperatures at Snively Canyon on June 8, 1990 


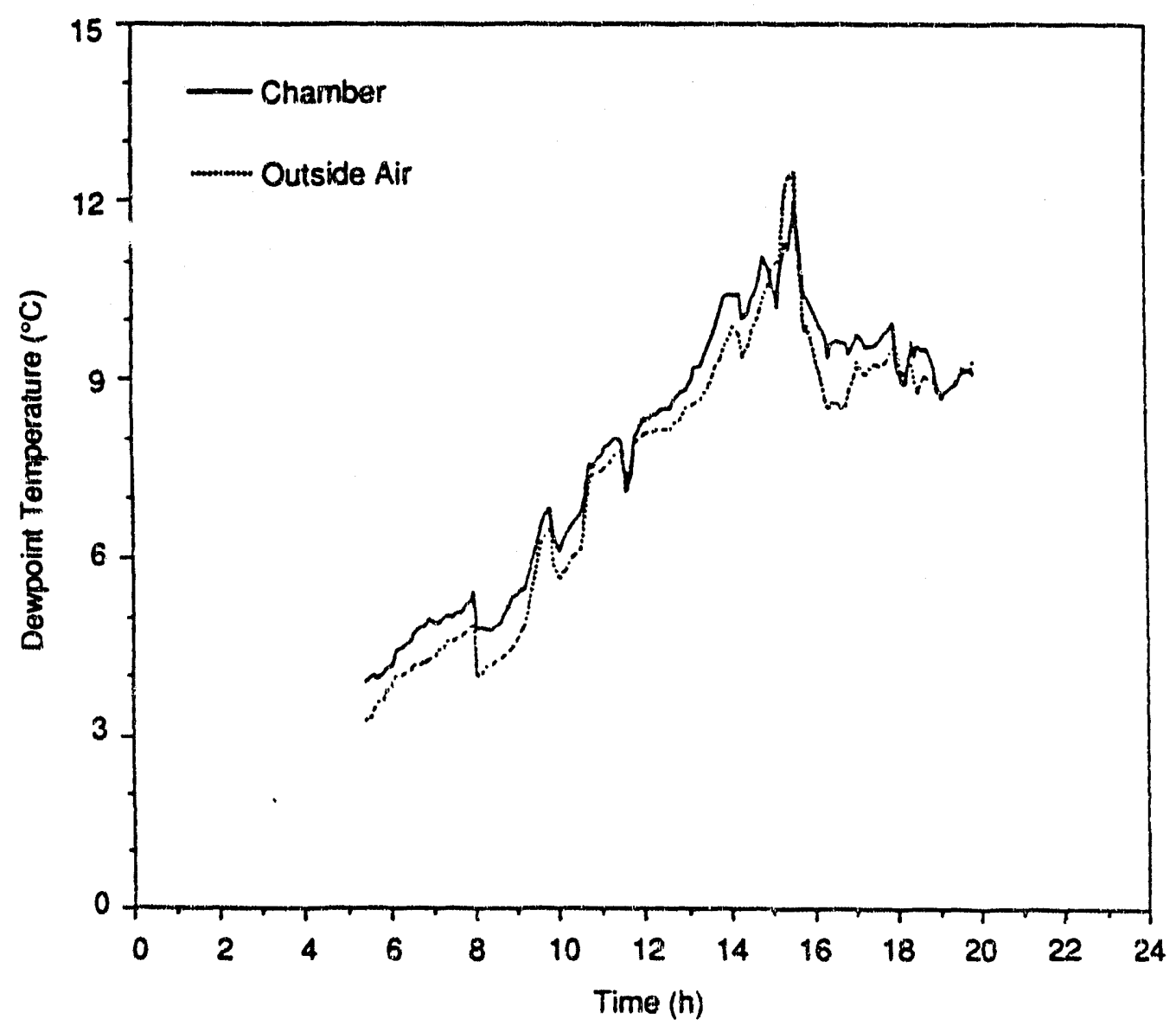

ElGURE 3.16. Dewpoint Temperature of Chamber Air and Outside Air at Snively Canyon on June 8. 1990 


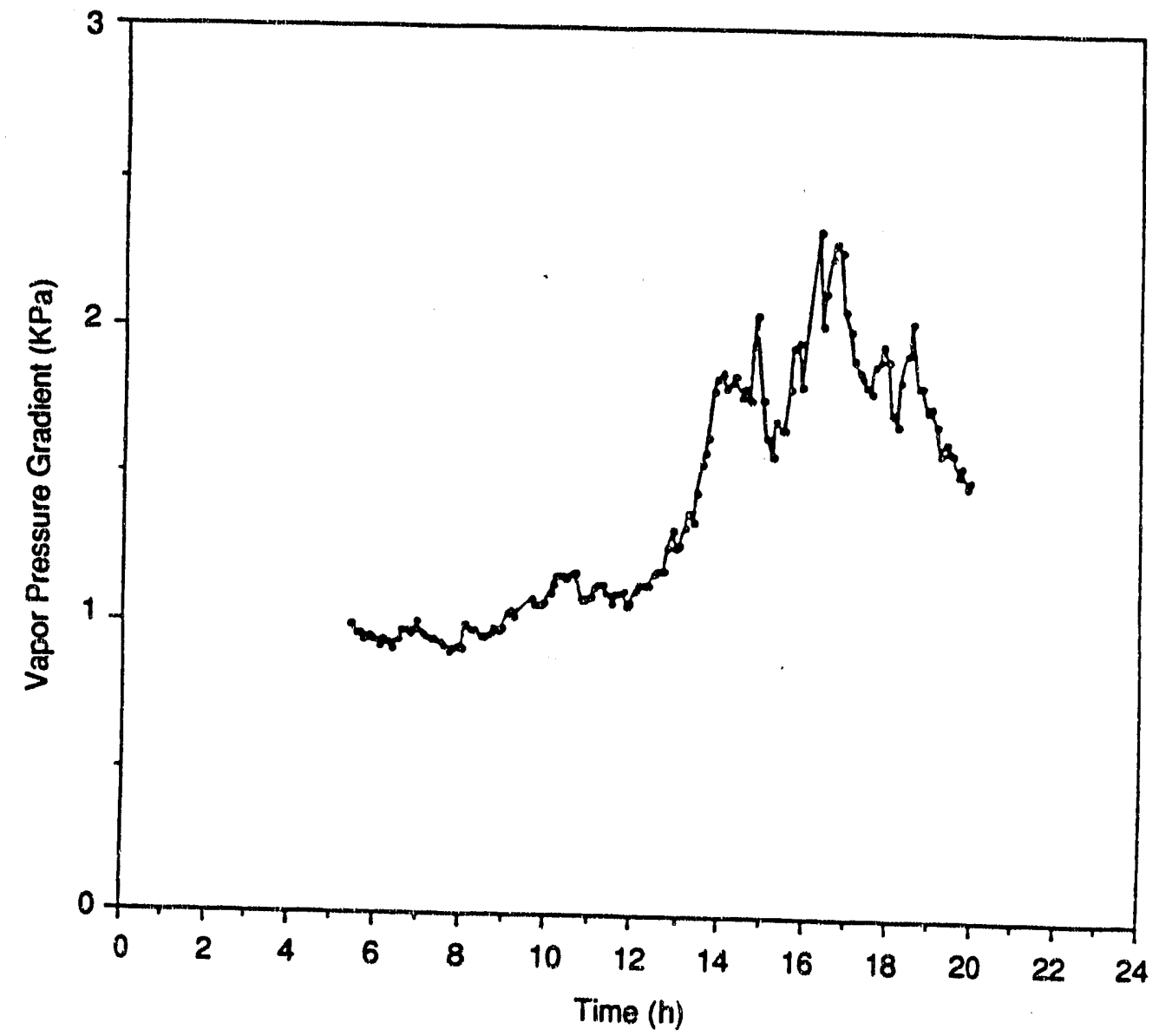

FIGURE 3.17. Vapor Pressure Gradient Inside the Chamber at Snively Canyon on June 8, 1990 
value of 0.89 . The calculation of transpiration from the predicted stomatal conductance described in Figure 3.19 is depicted in Figure 3.20 along with the observed values of transpiration. The pattern and the absolute value of transpiration were well-predicted by the model. A linear regression of observed and predicted values of transpiration had an $R^{2}$ value of 0.96 . Net photosynthesis (Figure 3.21) was described well using the parameters for June 8 in Table 3. A linear regression of observed and predicted values of net photosynthesis had an $R^{2}$ value of 0.98 . Dark respiration occurred until 0800 , after which net photosynthetic rates rapidly increased to a maximum at near 1300. Rapid change in the rates of net photosynthesis are associated with rapid changes in PAR in the morning and late afternoon. Internal $\mathrm{CO}_{2}$ showed a pattern that is a near mirror image of the pattern for net photosynthesis (Figure 3.22), with minimal values occurring from 1400 until 1830. Water-use efficiency (Figure 3.23) showed rapid changes in the early morning and late afternoon associated with rapid changes in PAR. Water-use efficiency was essentially constant from 0900 until 1830. Using empirical scaling parameters estimated with data collected on June 16, we were able to predict stomatal conductance on June 8 reasonably well, but stomatal conductance was underpredicted before 1000 and overpredicted at midday. A linear regression of observed and predicted values of transpiration had an $R^{2}$ value of 0.65 . Using empirical scaling parameters estimated with data collected on June 16, we were able to predict transpiration rates on June 8 correctly in terms of pattern and absolute value (Figure 3.25). A linear regression of observed and predicted values of transpiration had an $R^{2}$ value of 0.91 . We were able to predict net photosynthesis rates on June 8 correctly in terms of pattern and absolute value using empirical scaling parameters estimated with data collected on June 16 (Figure 3.26). A linear regression of observed and predicted values of net photosynthesis had an $R^{2}$ value of 0.98 . 


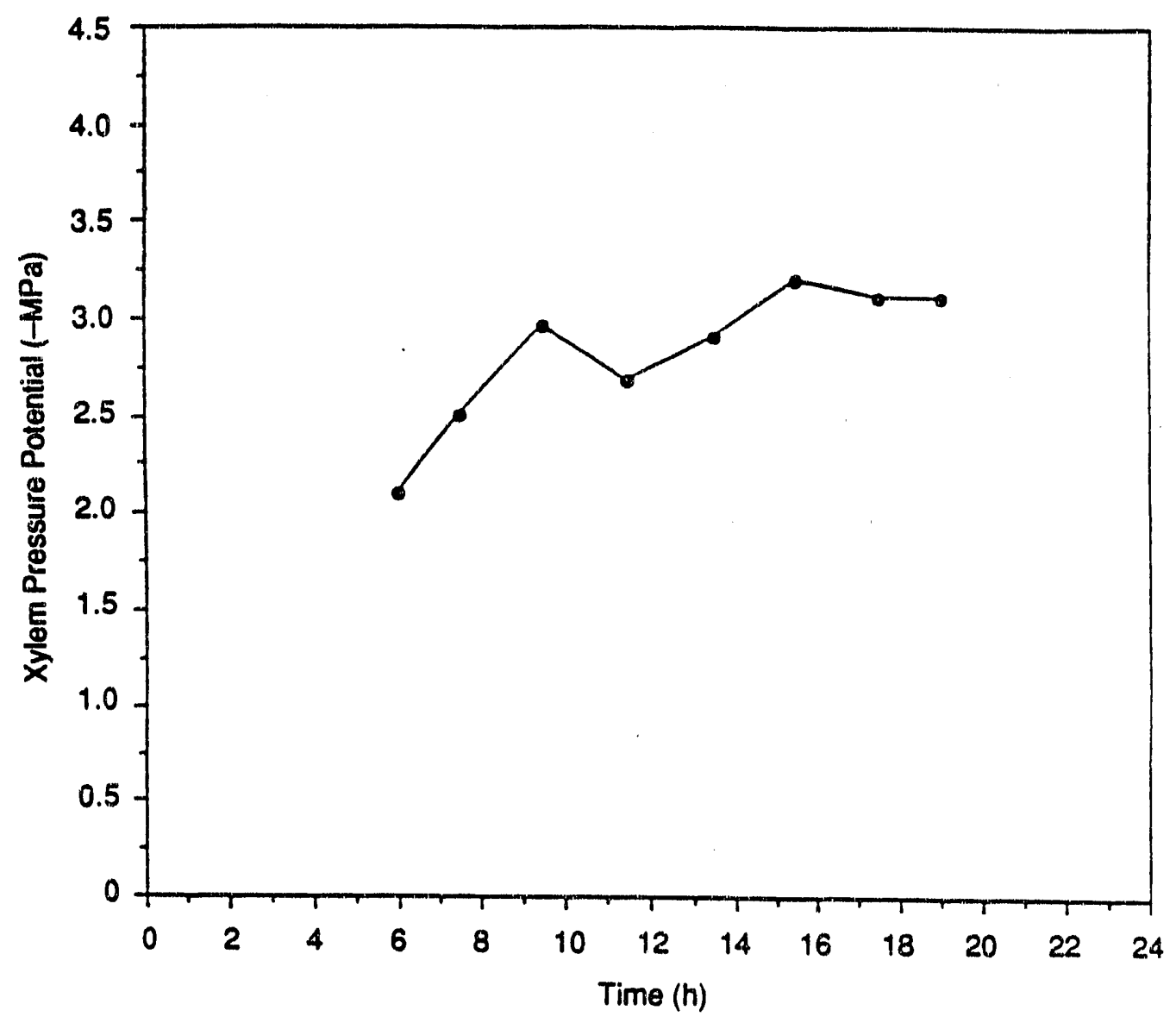

EIGURE 318. Xylem Pressure Potential of Bromus tectorum at Snively Canyon on June 8, 1990 


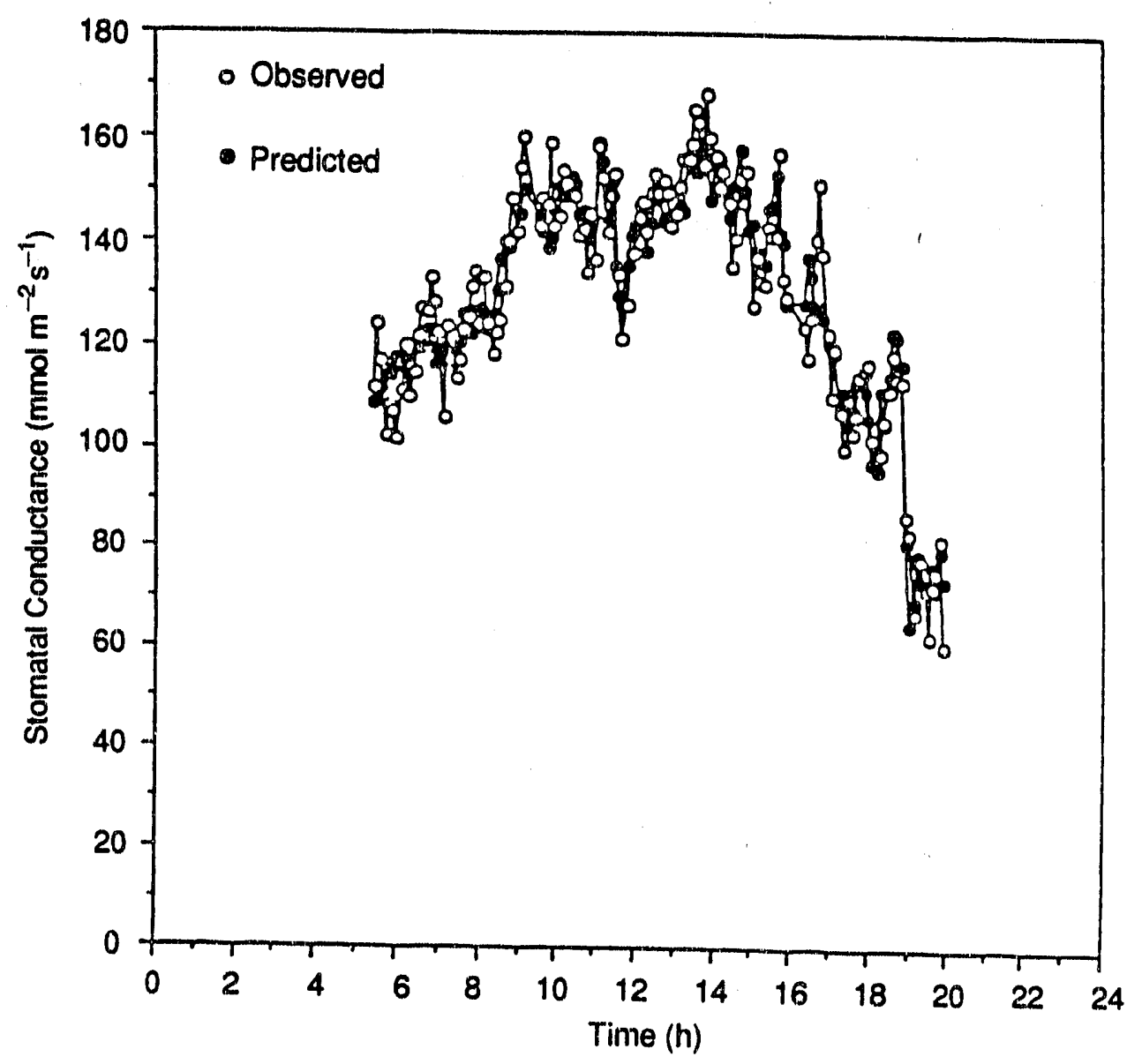

FIGURE 3.19. Predicted and Observed Stomatal Conductance of Bromus tectorum at Snively Canyon on June 8, 1990 


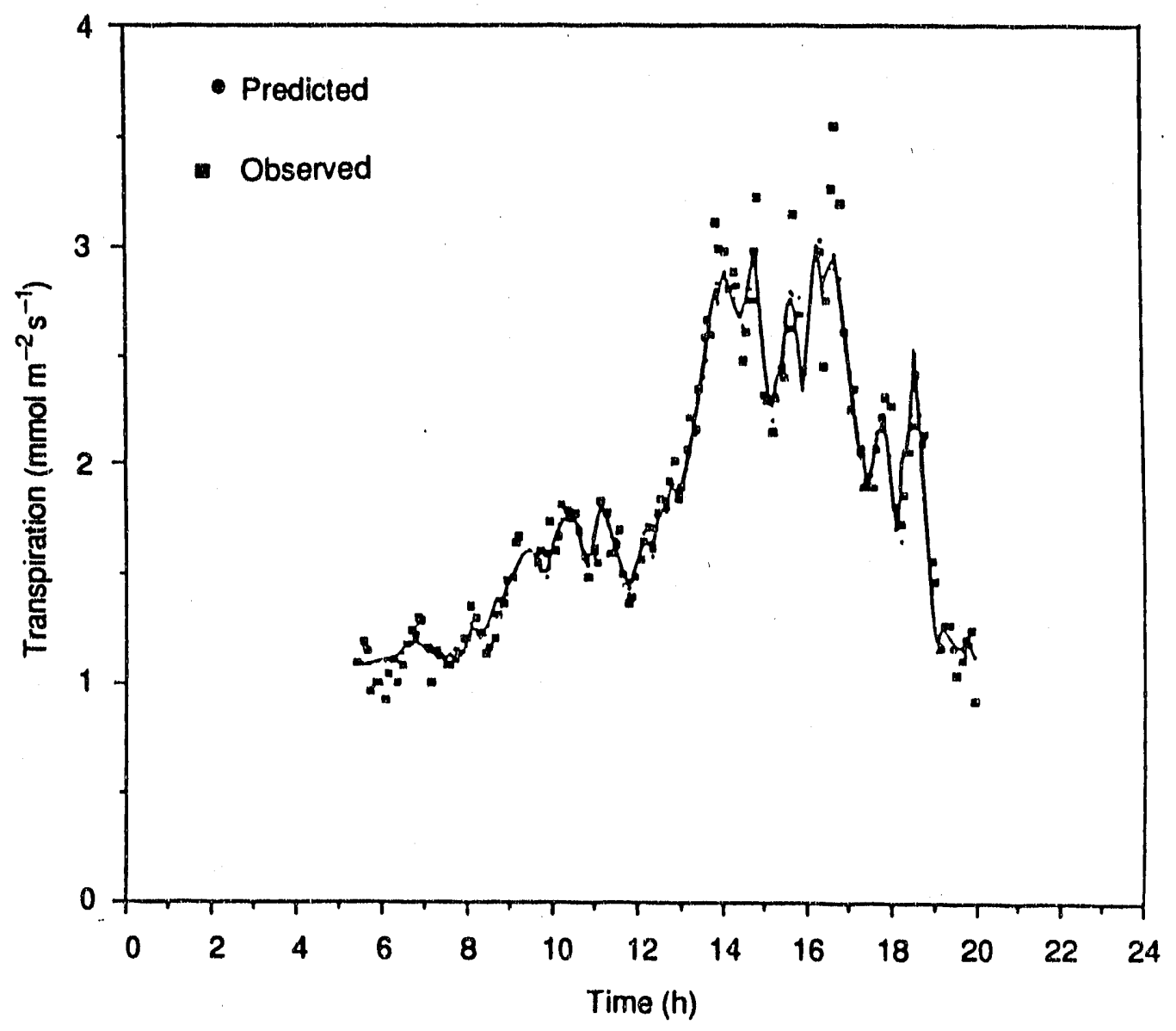

FIGURE 3.20. Predicted and Observed Transpiration of Bromus tectorum at Snively Canyon on June 8, 1990 


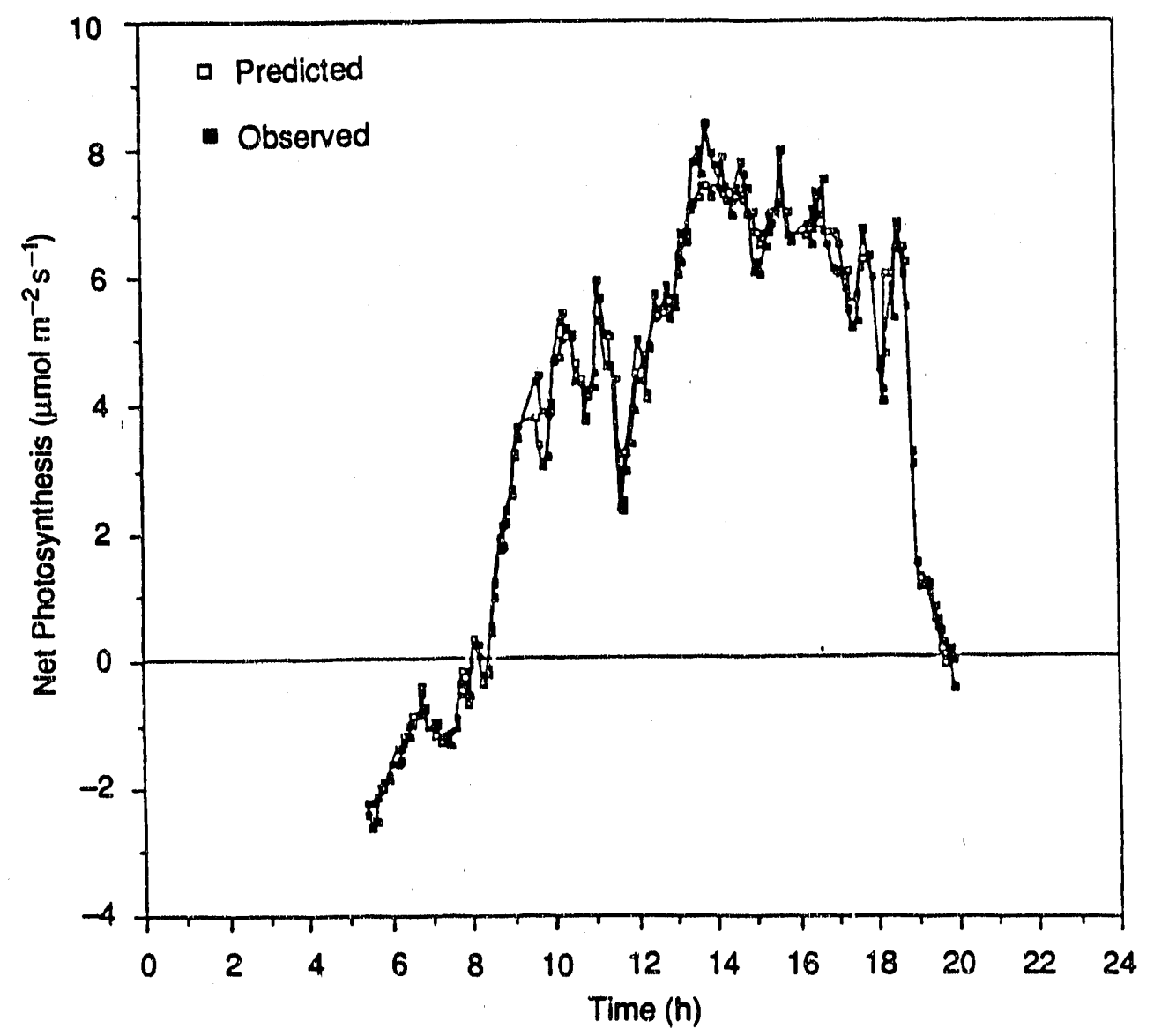

FIGURE 3.21. Predicted and Observed Net Photosynthesis of Bromus tectorum at Snively Canyon on June 8, 1990 


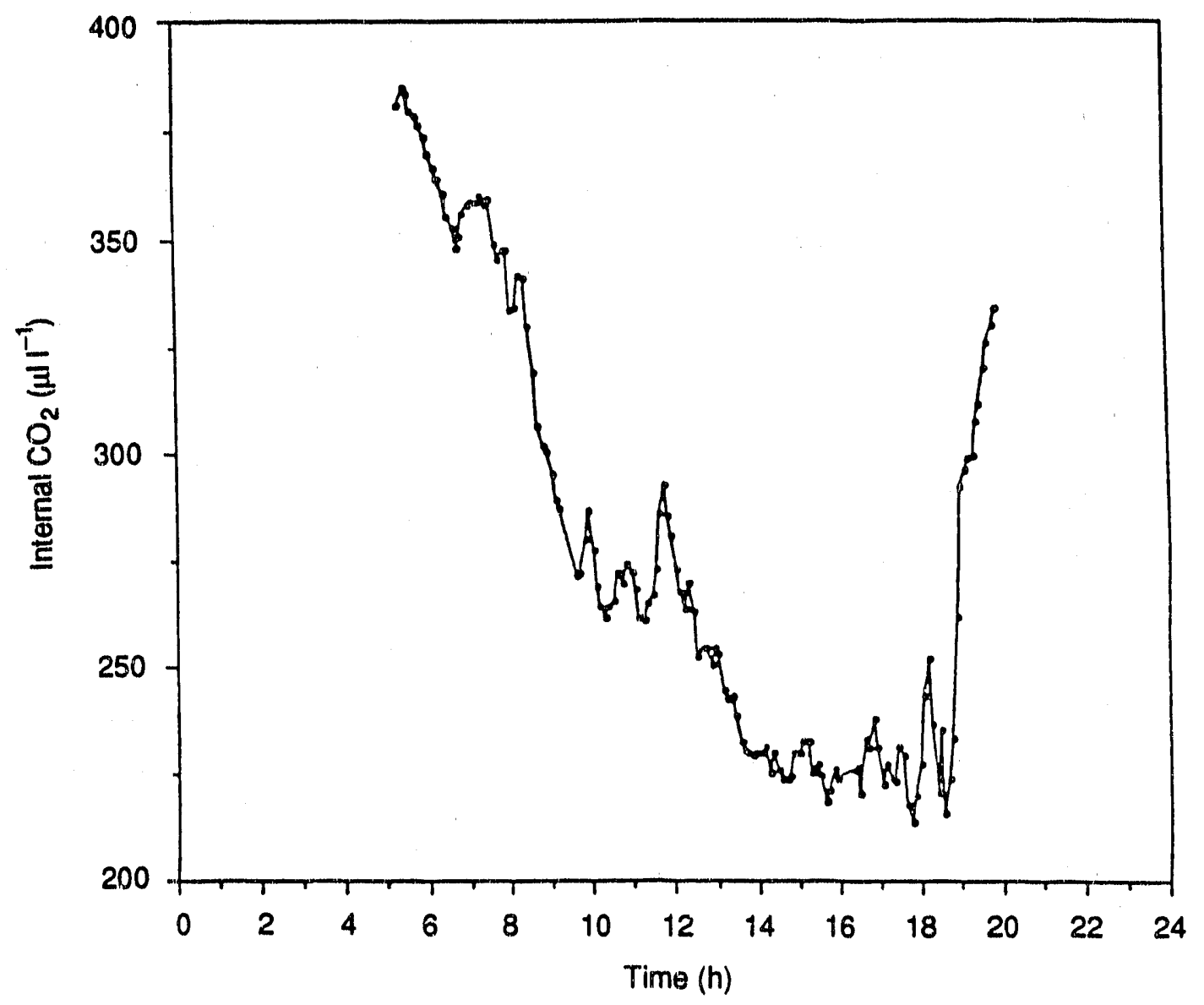

FIGURE 3.22. Internal $\mathrm{CO}_{2}$ Concentration of Bromus tectorum at Snively Canyon on June 8,1990 


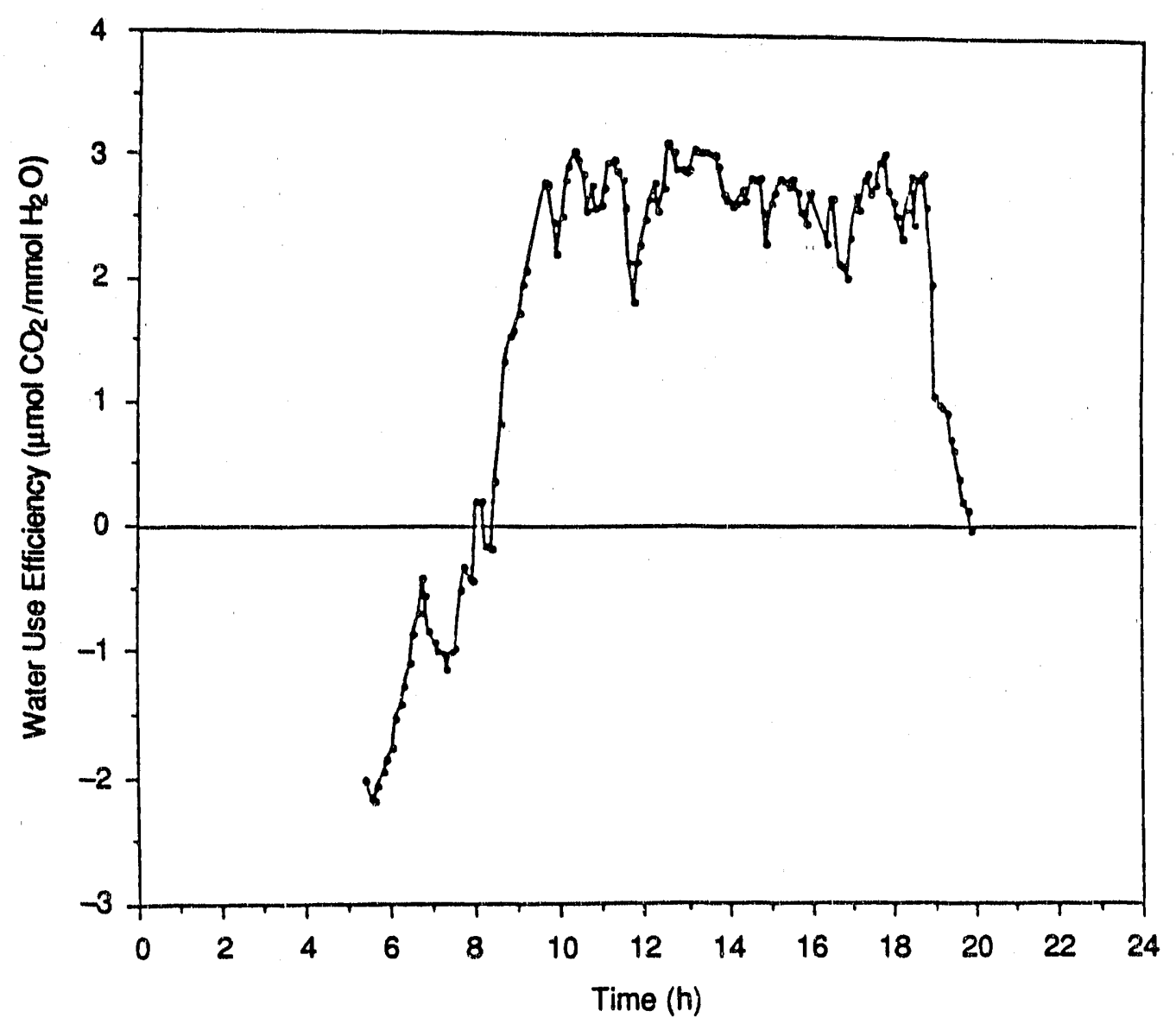

FIGURE 3.23. Water-Use Efficiency of Bromus tectorum at Snively Canyon on June 8, 1990 


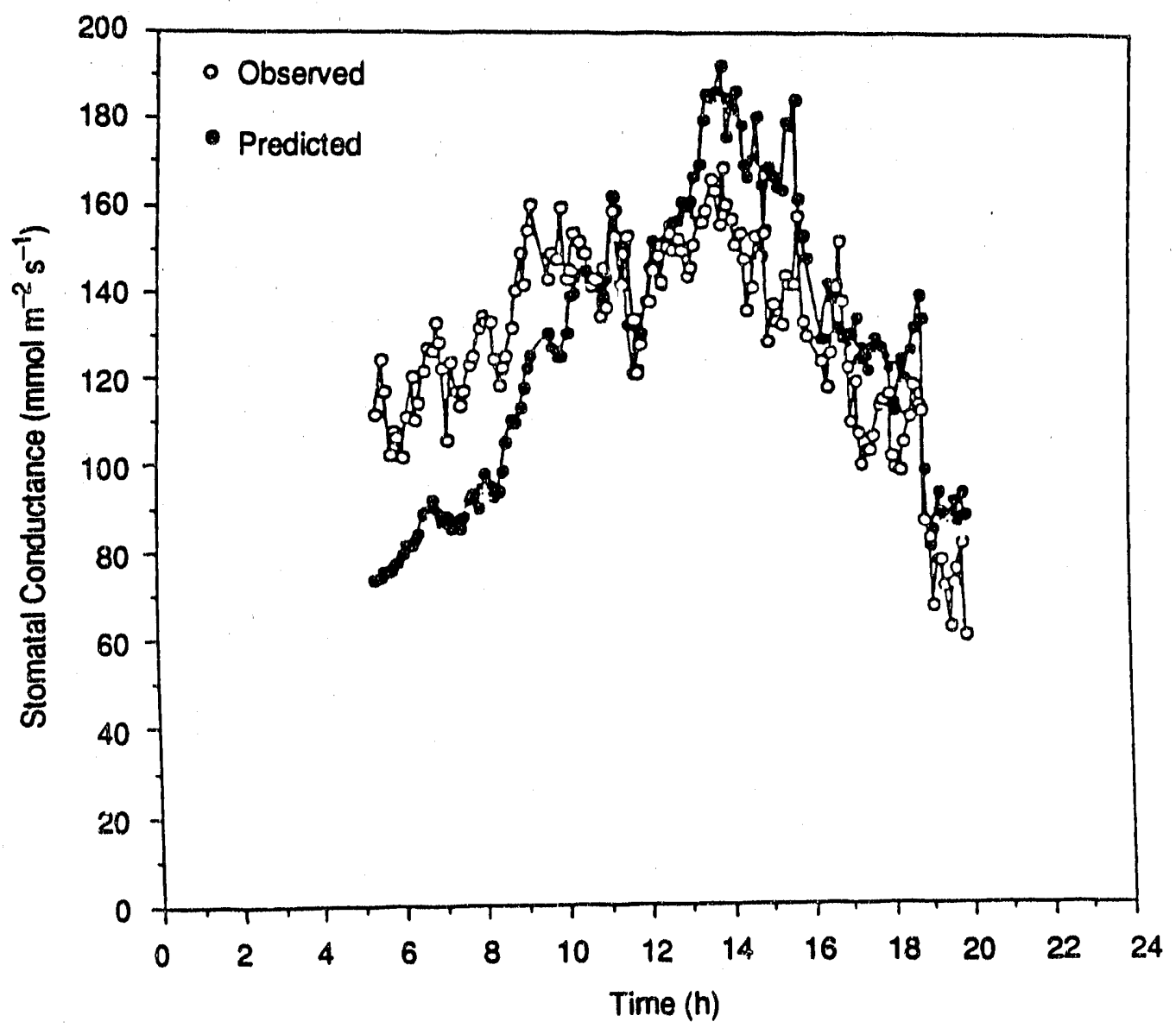

FIGURE 3.24. Predicted and Observed Stomatal Conductance of Bromus tectorum at Snively Canyon on June 8, 1990 Using Scaling Parameters Estimated with Data Collected on June 16, 1990 


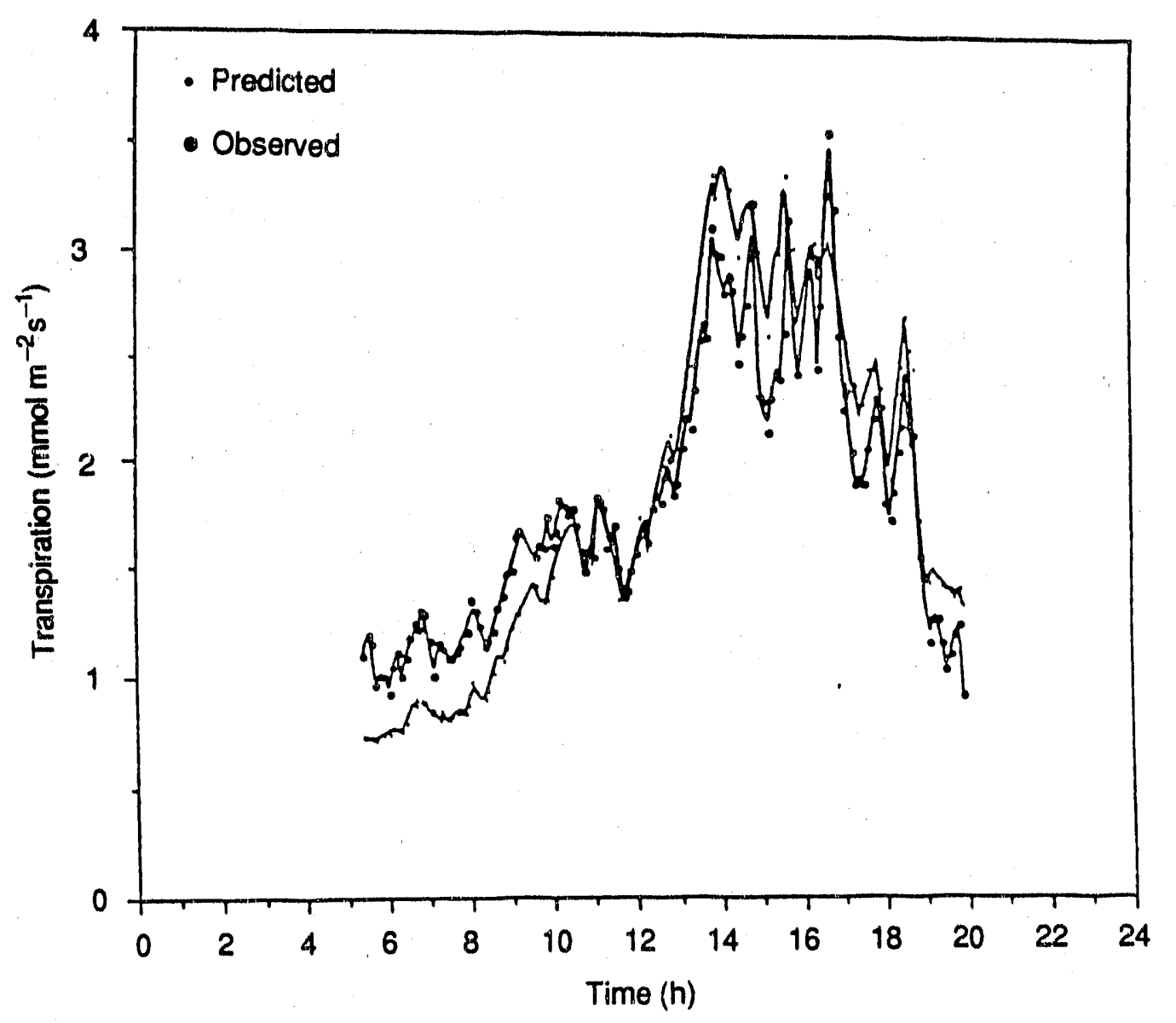

FIGURE 3.25. Predicted and Observed Transpiration of Bromus tectorum at Snively Canyon on June 8, 1990, Using Scaling Parameters Estimated with Data collected on June 16, 1990 
June 16 was generally clear all day, but periods of high thin clouds reduced PAR levels (Figure 3.27). Temperatures rose to about $31^{\circ} \mathrm{C}$ by 1600 from a low of $16.5^{\circ} \mathrm{C}$ at pre-dawn (Figure 3.28 ). Chamber temperatures tracked outside temperature closely through the day, staying within $0.5^{\circ} \mathrm{C}$. Leaf temperatures were generally about $0.5^{\circ} \mathrm{C}$ less than chamber temperatures, except in the late afternoon, when leaf temperatures were about $1^{\circ} \mathrm{C}$ less than chamber temperatures. Chamber humidity control as measured by dewpoint temperature is depicted in Figure 3.29. Humidity control was good through most of the day, although chamber dewpoint temperature was consistently up to $1^{\circ} \mathrm{C}$ greater than the dewpoint temperature of the outside air. Instrumentation problems associated inadequate air-compressor capacity caused dewpoint temperature differences to exceed $2^{\circ} \mathrm{C}$ from 1500 until 1700 . The vapor pressure gradient increased from near $1 \mathrm{kPa}$ in the early morning to $3.2 \mathrm{kPa}$ at 1600 (Figure 3.30). The xylem pressure potential gradually decreased from $-1.7 \mathrm{MPa}$ at pre-dawn to $-4.8 \mathrm{MPa}$ in the late afternoon, and then increased again to $-3.7 \mathrm{MPa}$ at sundown (Figure 3.31). Stomatal conductance was maximum near 0700 and decreased after that (Figure 3.32). The model performed well, with the exception of an underprediction near 0700 and again near 1700. A linear regression of observed and predicted values of transpiration had an $R^{2}$ value of 0.73 . The calculation of transpiration from the predicted stomatal conductance described in Figure 3.32 is depicted in Figure 3.33 along with the observed values of transpiration. The pattern and absolute value of transpiration were well predicted by the model, except for an overprediction at around 1700. A linear regression of obsened and predicted values of transpiration had an $R^{2}$ value of 0.96. Net photosynthesis (Figure 3.34) was described well using the parameters for June 16 in Table 3. A linear regression of observed and predicted values of net photosynthesis had an $R^{2}$ value of 0.94. Dark respiration occurred until 0600 , after which net photosynthetic rates rapidly increased to a maximum at near 0900, after which net photosynthesis gradually declined until sunset, when rates declined rapidly. Internal $\mathrm{CO}_{2}$ showed a pattern that is a near mirror image of the pattern for net photosynthesis (Figure 3.35), with minimal values occurring near 1700. Water-use efficiency (Figure 3.36) showed rapid changes in the early morning and late afternoon, associated with rapid changes in PAR. Water-use efficiency was essentially constant from 0700 until 1700. We were less able to predict stomatal conductance on June 16 using empirical scaling parameters estimated with data collected on June 8 than we were using June 16 parameters to predict June 8 
data (Figure 3.37). A linear regression of observed and predicted values of stomatal conductance had an $R^{2}$ value of 0.41 , which is still significant $(F=78.45 ; p=0.0001$ ). We were less able to predict transpiration on June 16 using empirical scaling parameters estimated with data collected on June 8 than we were using June 16 parameters to predict June 8 data (Figure 3.38). A linear regression of observed and predicted values of transpiration had an $R^{2}$ value of 0.53 . Using empirical scaling parameters estimated with data collected on June 8, we were able to predict net photosynthesis rates on June 16 correctly in terms of pattern and absolute value (Figure 3.39). A linear regression of observed and predicted values of transpiration had an $R^{2}$ value of 0.94 . 


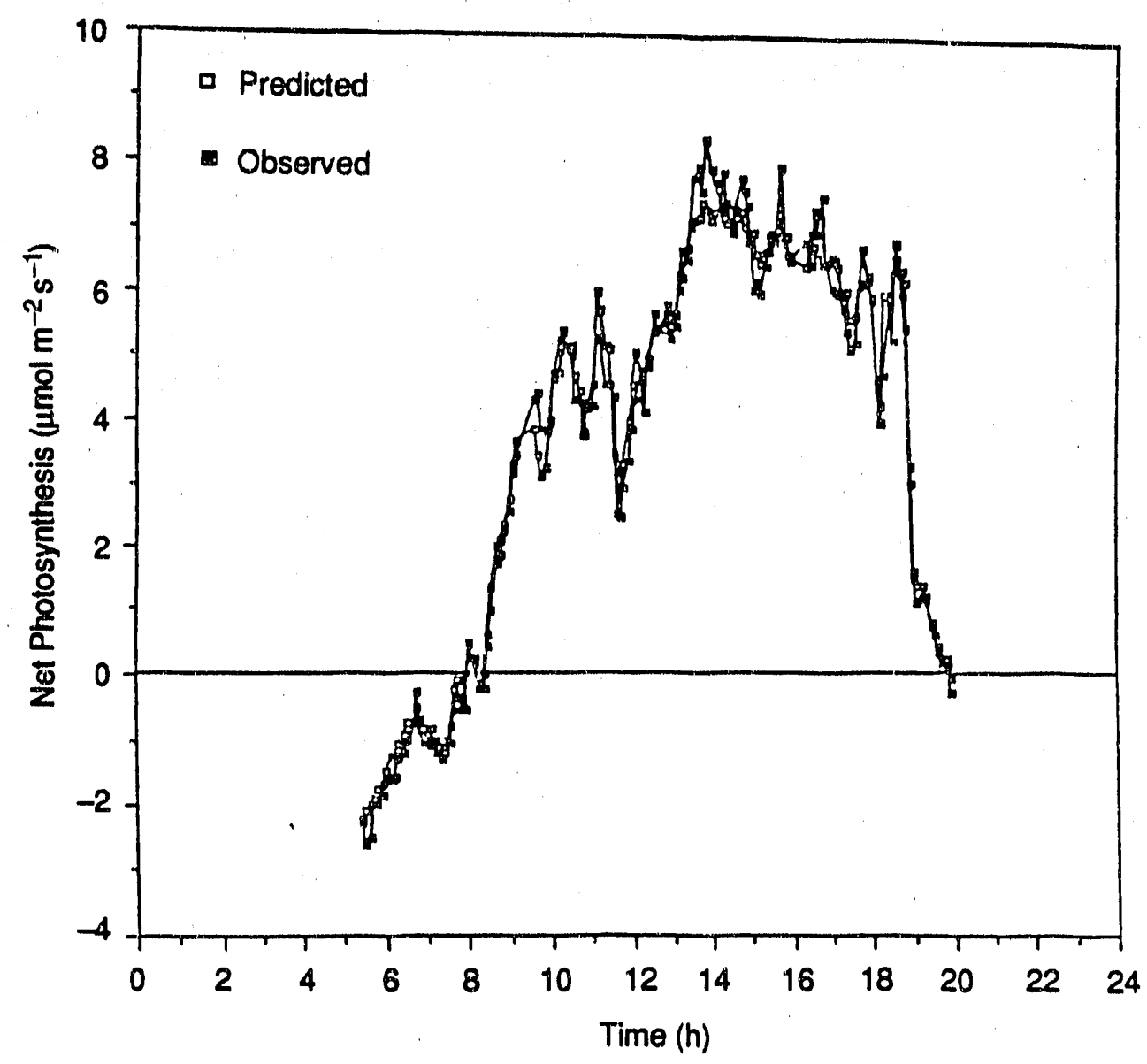

FIGURE 3.26. Predicted and Observed Net Photosynthesis of Bromus tectorum at Snively Canyon on June 8, 1990, Using Scaling Parameters Estimated with Data Collected on June 16, 1990 


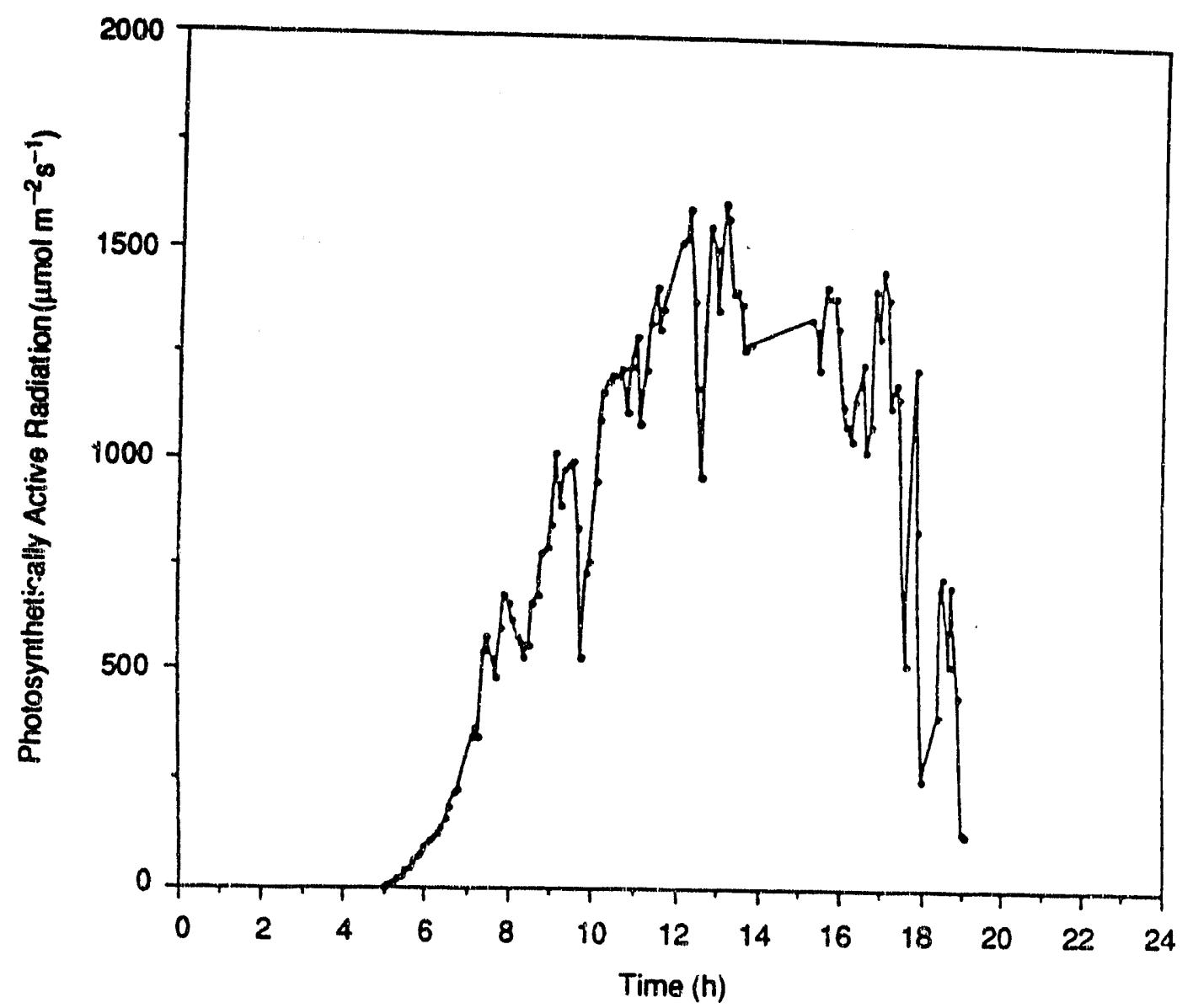

FIGURE 3.27. Photosynthetically Active Radiation at Snively Canyon on June 16, 1990 


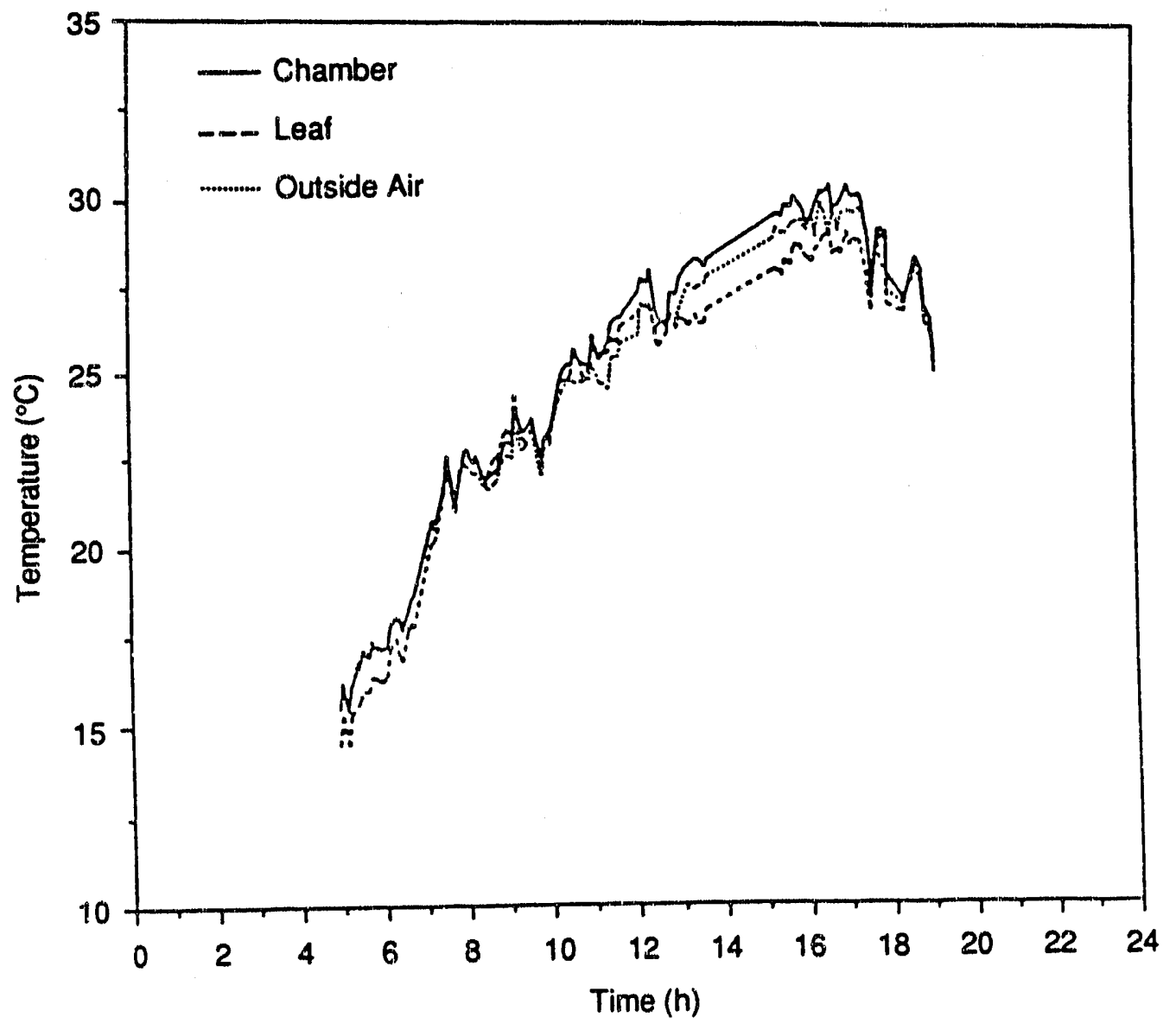

FIGURE 3.28. Chamber-Air, Leaf, and Outside-Air $(2 \mathrm{~m})$ Temperatures at Snively Canyon on June 16, 1990 


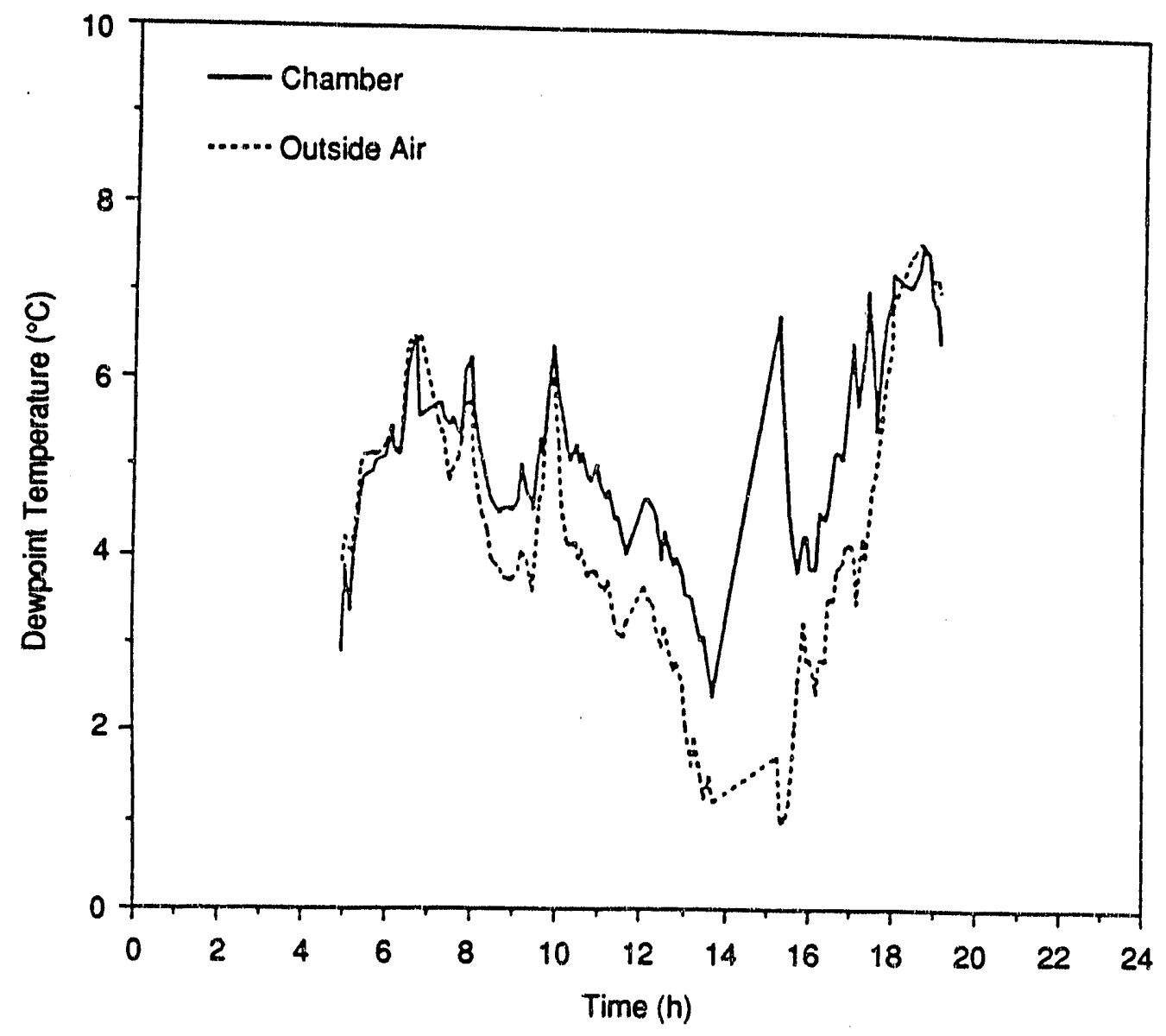

FIGURE 3.29. Dewpoint Temperature of Chamber Air and Outside Air at Snively Canyon on June 16, 1990 


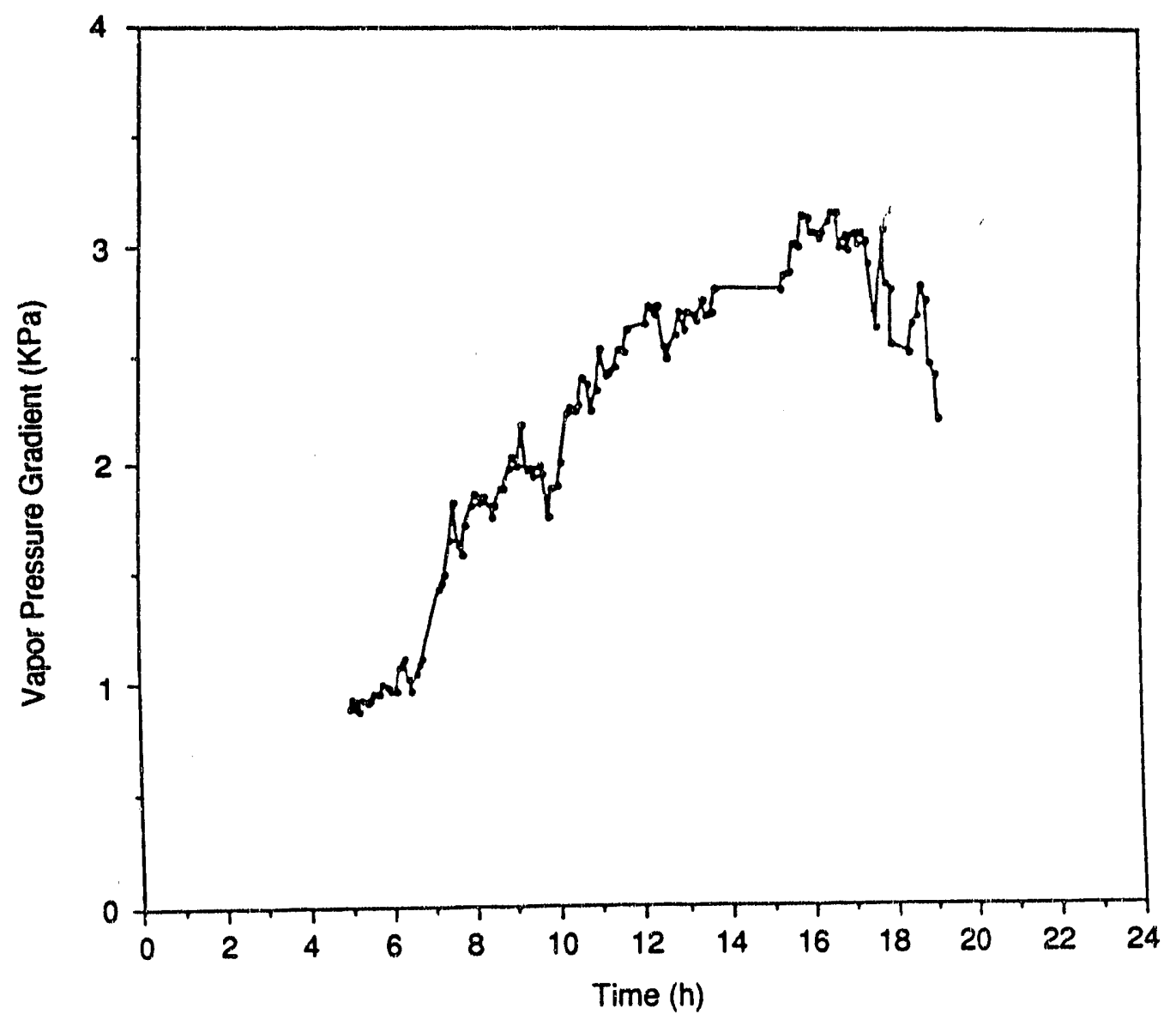

FIGURE 3.30. Vapor Pressure Gradient Inside the Chamber at Snively Canyon on June 16, 1990 


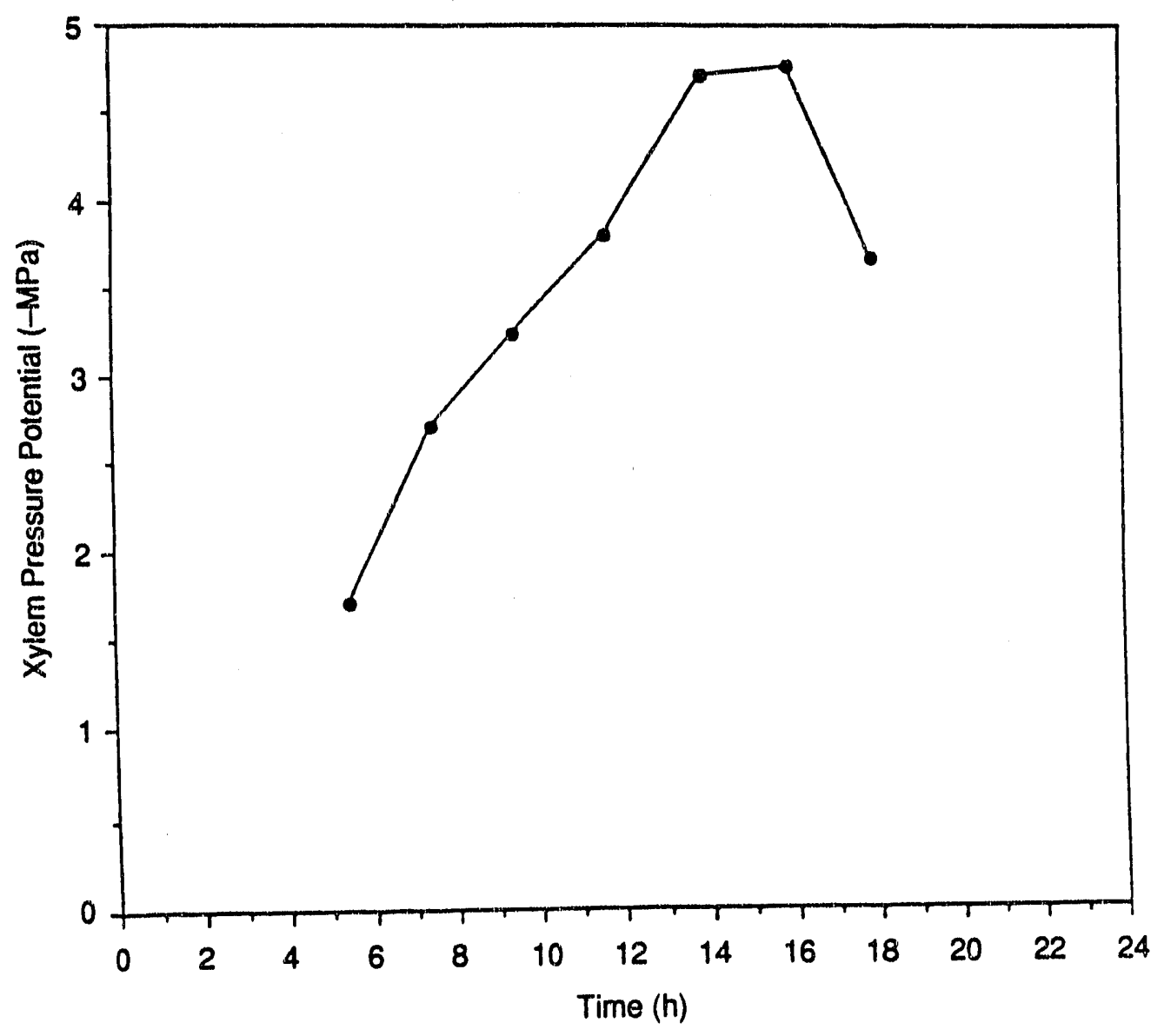

EIGURE 3.31. Xylem Pressure Potential of Bromus tectorum at Snively Canyon on June 16, 1990 


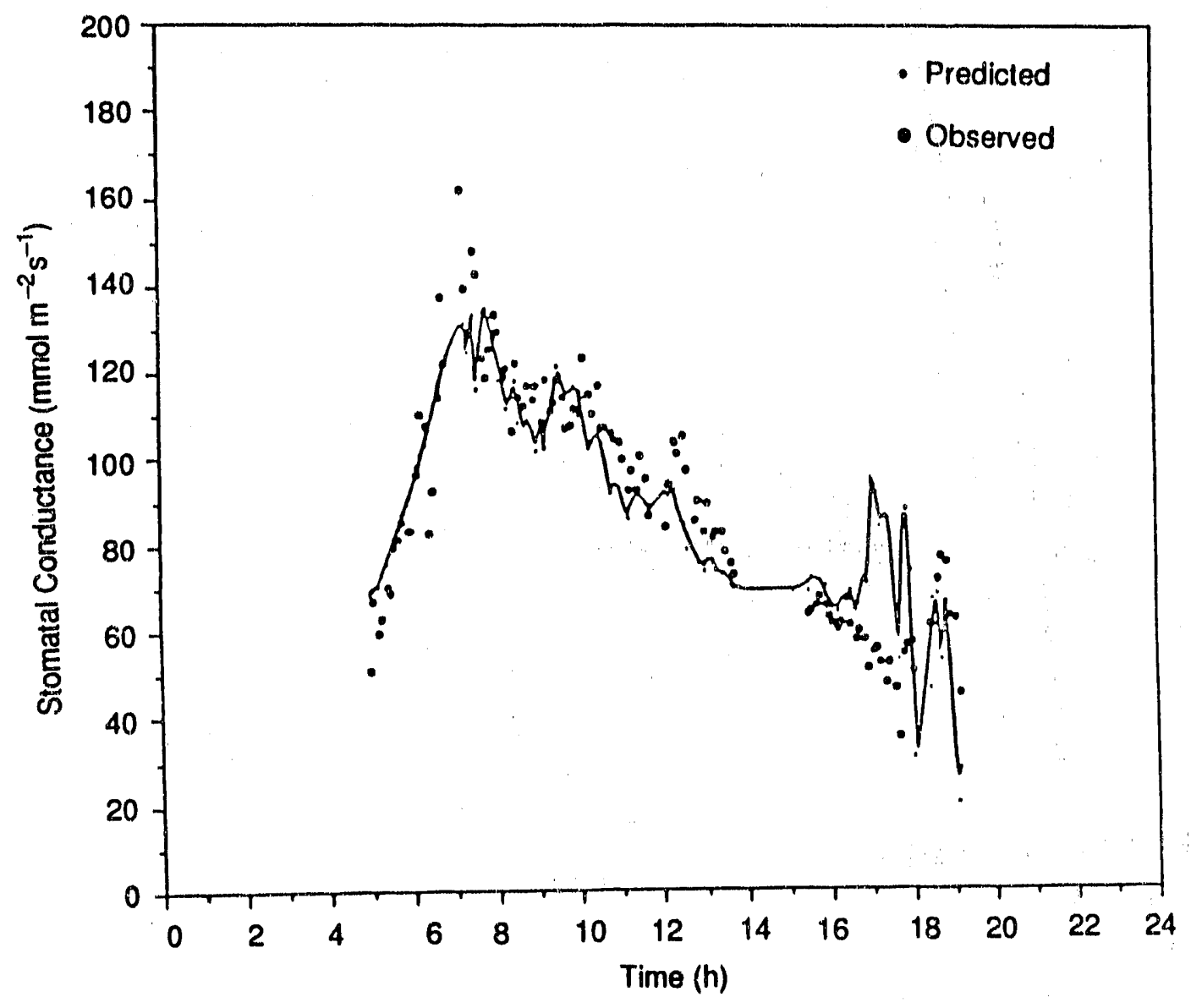

FIGURE 3.32. Predicted and Observed Stomatal Conductance of Bromus tectorum at Snively Canyon on June 16, 1990 


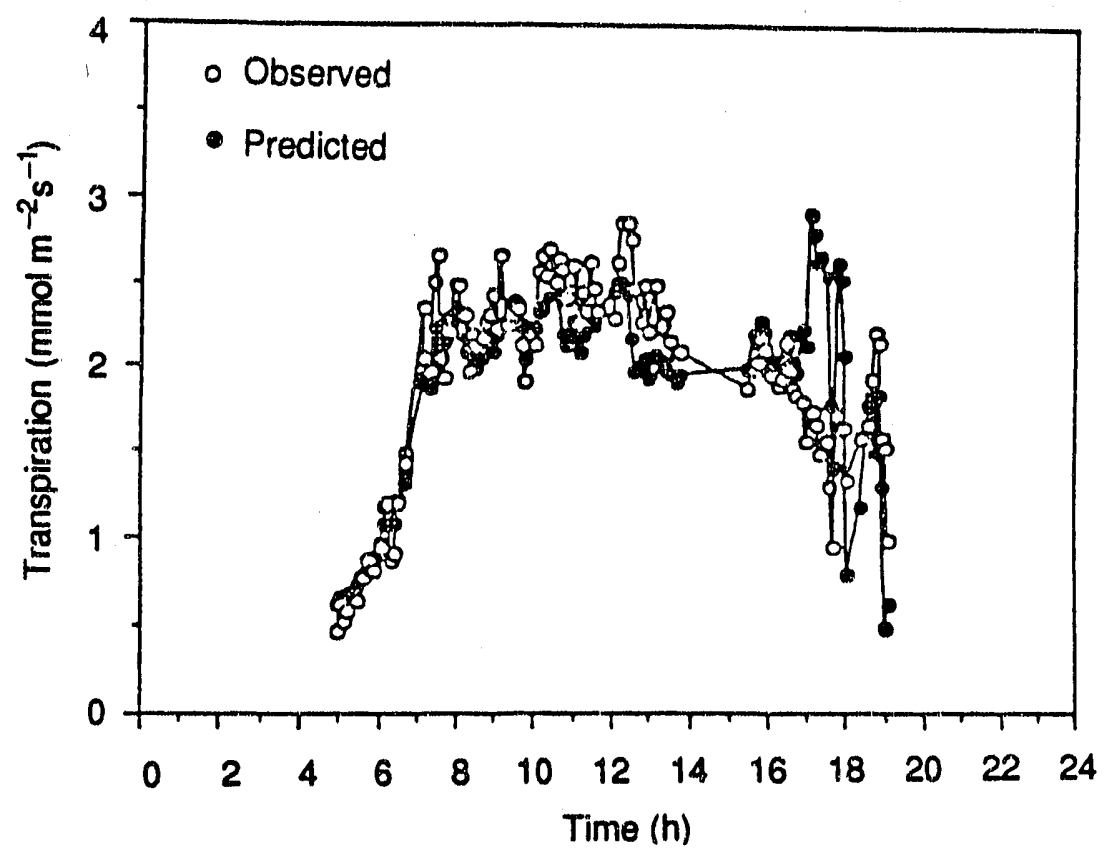

EIGURE 3.33. Predicted and Observed Transpiration of Bromus tectorum at Snively Canyon on June 16, 1990 


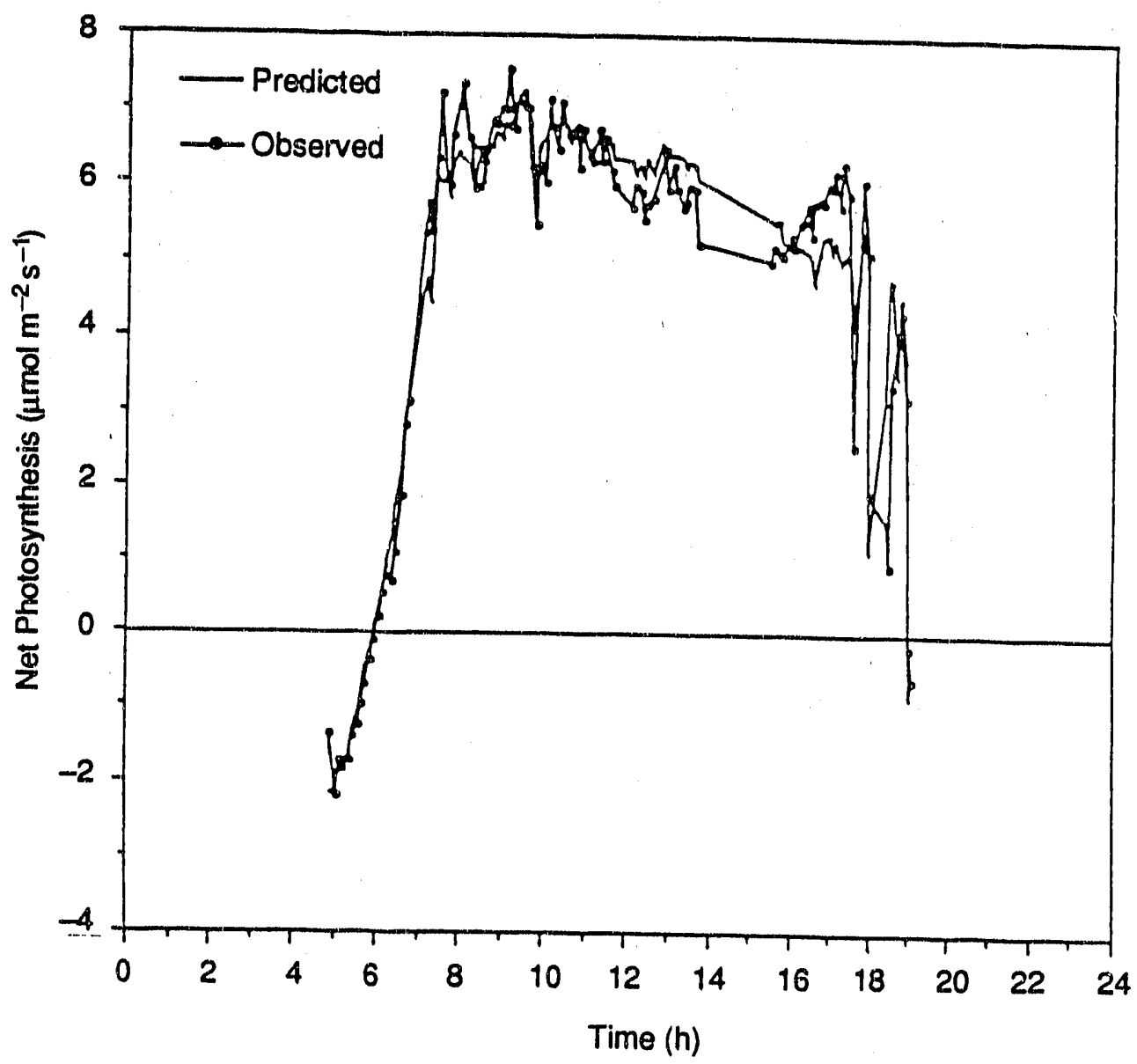

FIGURE 3.34. Predicted and Observed Net Photosynthesis of Bromus tectorum at Snively Canyon on June 16, 1990 


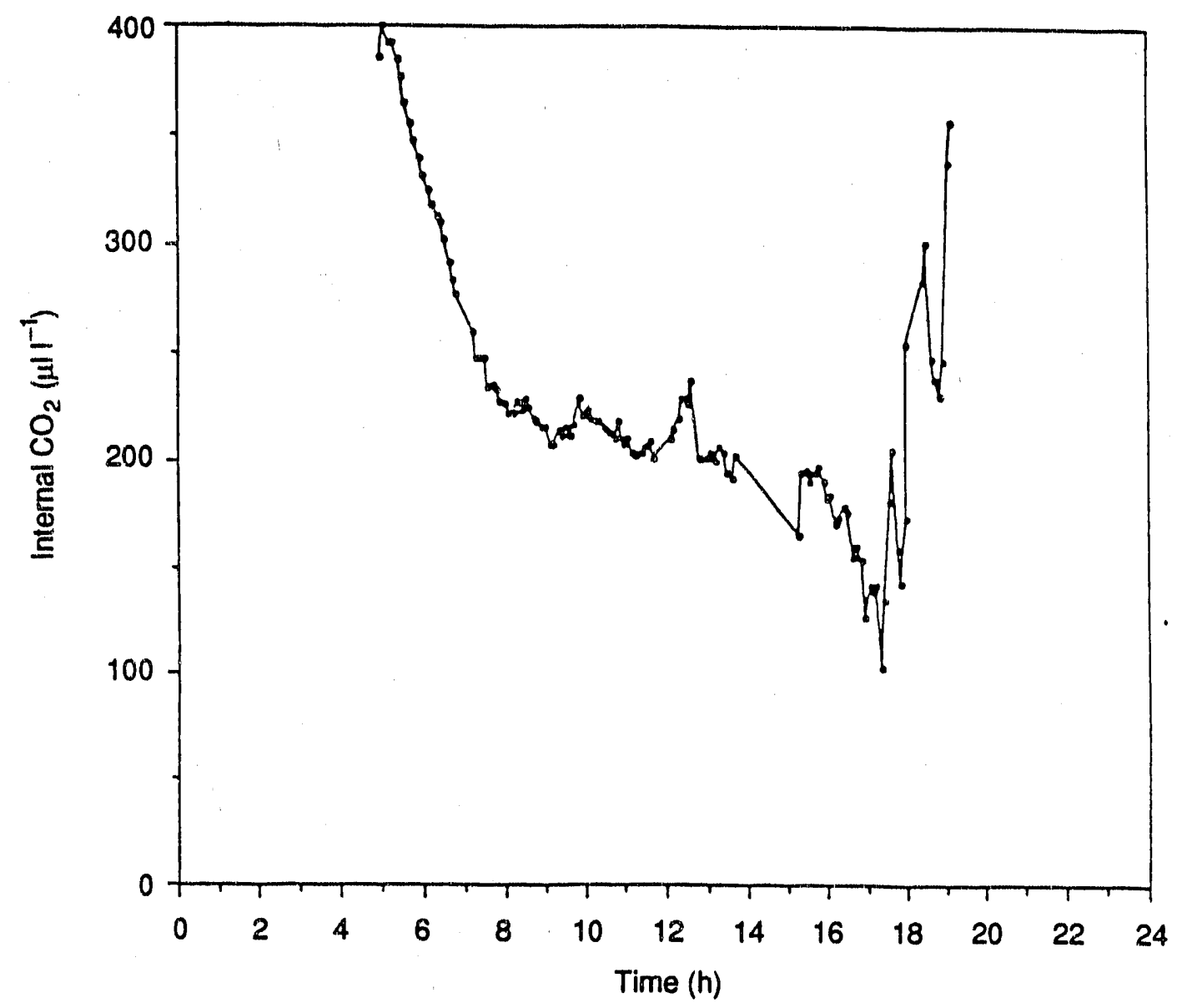

FIGURE 3.35. Internal $\mathrm{CO}_{2}$ Concentration of Bromus tectorum at Snively Canyon on June 16, 1990 


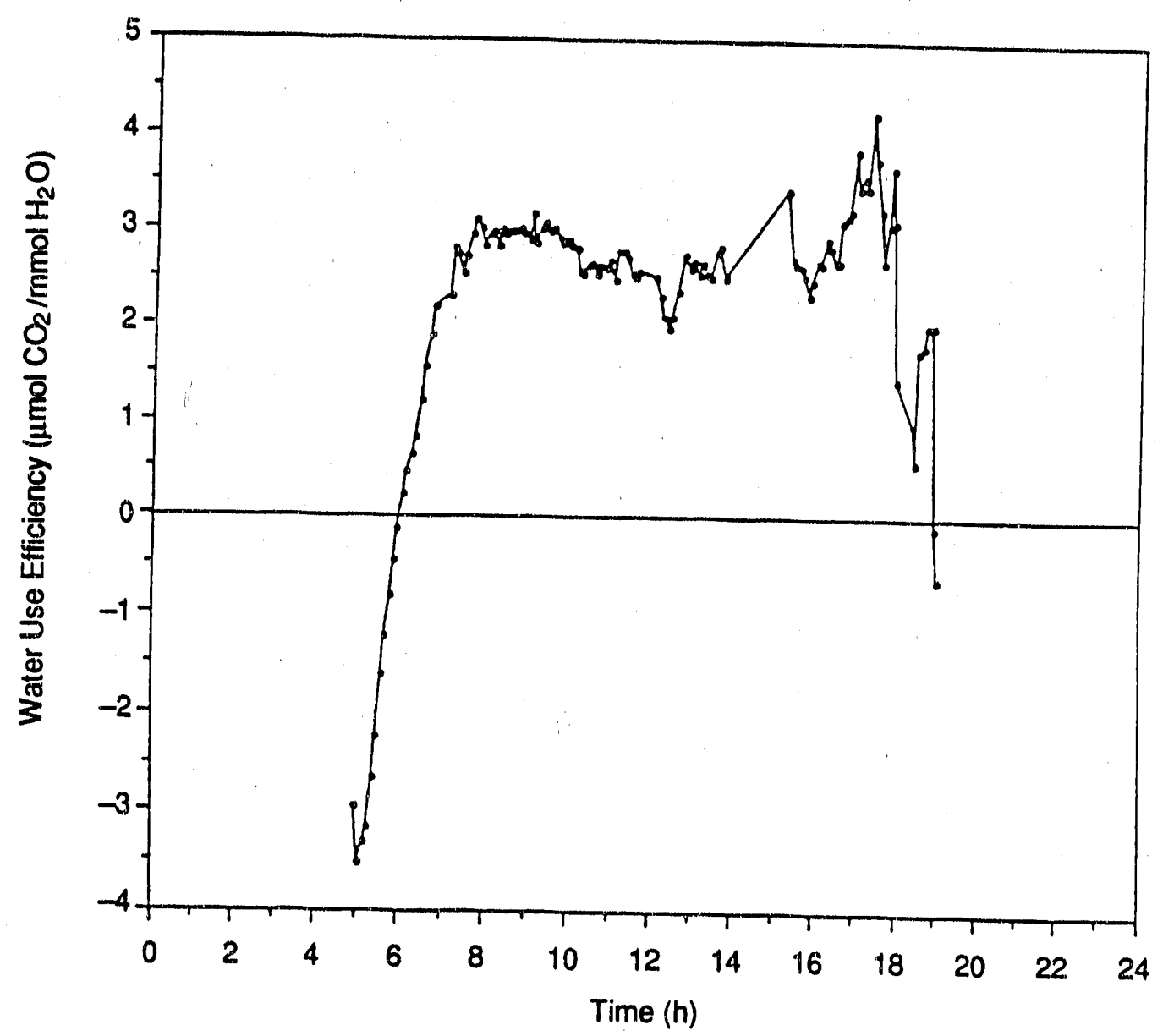

FIGURE 3.36. Water-Use Efficiency of Bromus tectorum at Snively Canyon on June 16, 1990 


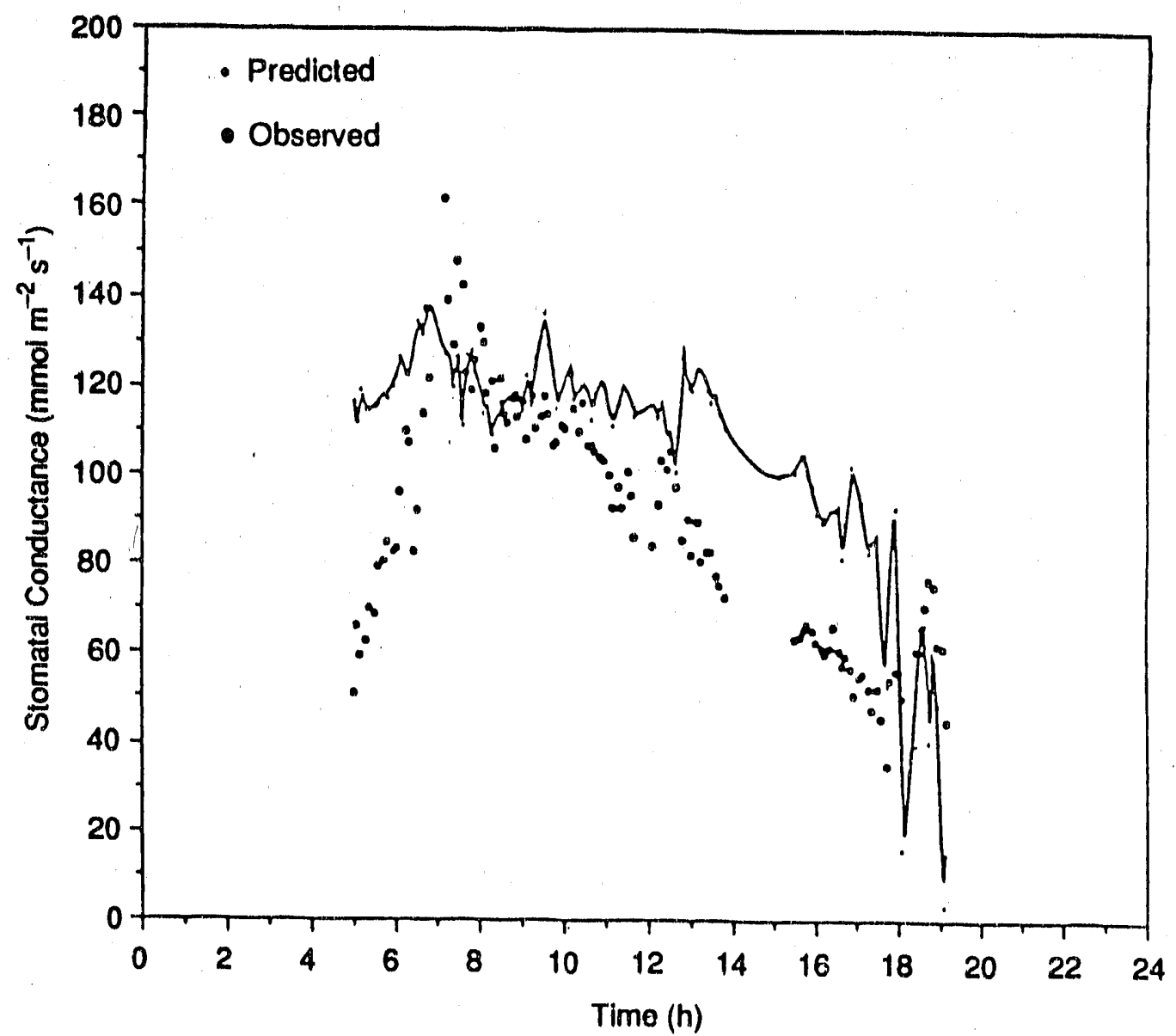

FIGURE 3.37. Predicted and Observed Stomatal Conductance of Bromus tectorum at Snively Canyon on June 16, 1990, Using Scaling Parameters Estimated with Data Collected on June 8, 1990 


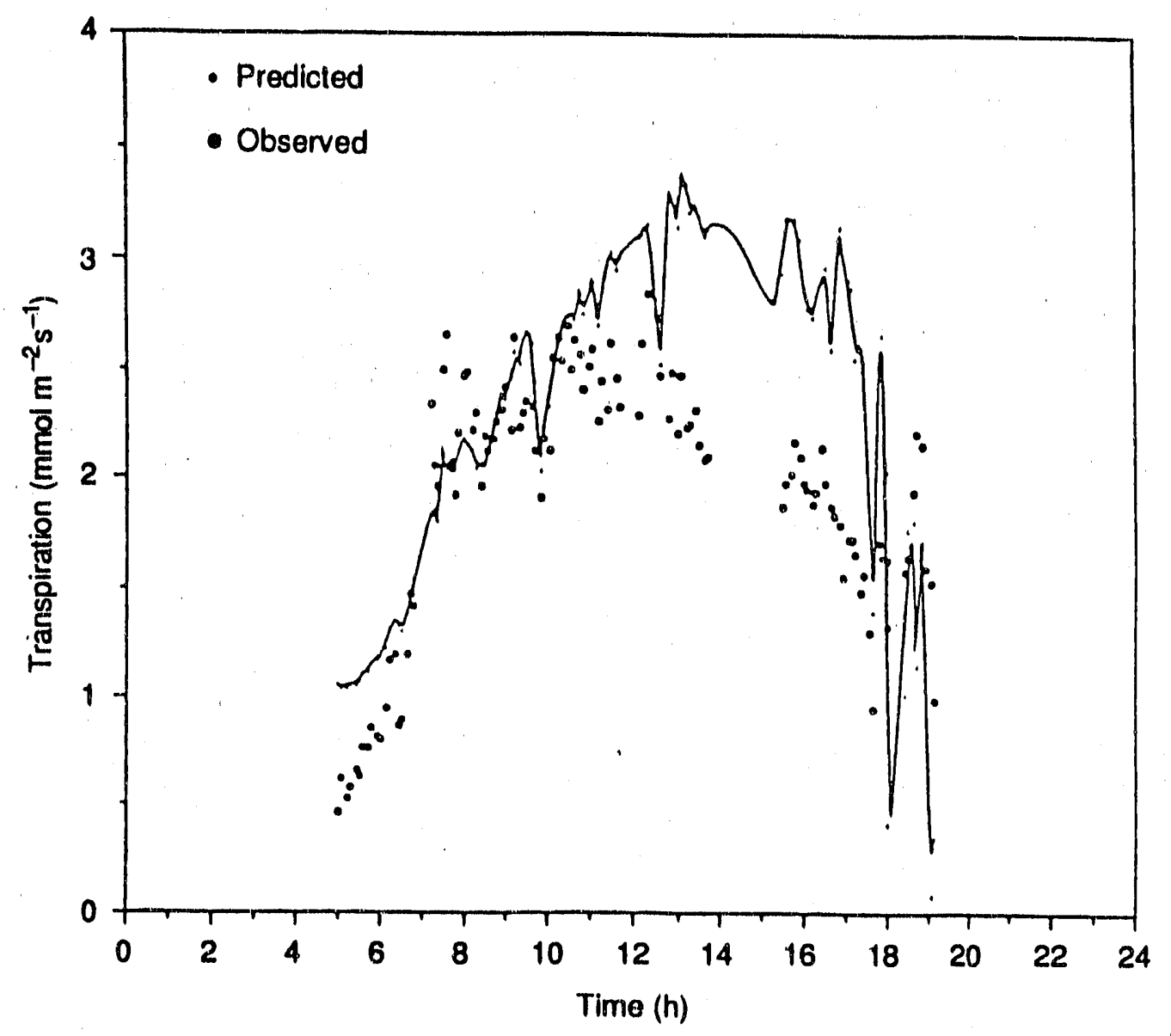

FIGURE 3.38. Predicted and Observed Transpiration of Bromus tectorum at Snively Canyon on June 16,1990, Using Scaling Parameters Estimated with Data Collected on June 8, 1990 


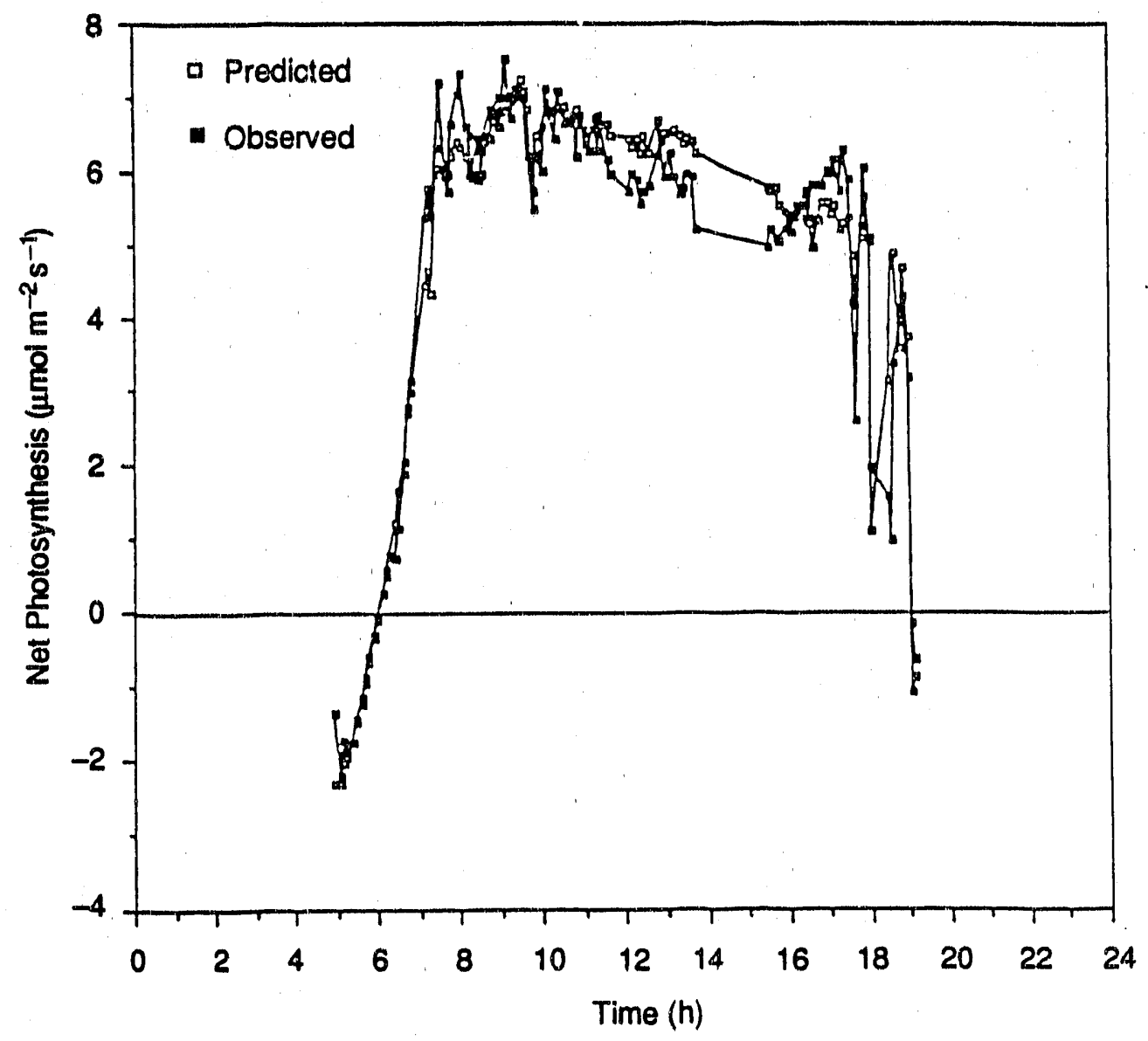

FIGURE 3.39. Predicted and Observed Net Photosynthesis of Bromus tectorum at Snively Canyon on June 16,1990, Using Scaling Parameters Estimated with Data Collected on June 8, 1990 


\subsection{DISCUSSION}

The purposes of the work done in FY 1990 were 1) to develop and test an environmentally controlled whole-plant gas exchange system, 2) to collect evapotranspiration data at the whole-plant level on the small-tube lysimeters, 3) to collect transpiration data on shrubs at McGee Ranch, and 4) to collect data necessary to parameterize the plant component of the UNSAT-H code. These were successfully accomplished.

Instrumentation development entailed the construction of three additional air conditioning units for a total of four gas exchange systems. The purpose of the additional chambers is to allow for replicated experiments in time. Remaining work to be done on this instrumentation upgrade is to integrate the new chambers into the system.

At the STLF site we measured evaporation, evapotranspiration, and carbon dioxide exchange rates from the lysimeters in the soil surface treatment with and without $\mathrm{B}$. tectorum growing on the surface. Evapotranspiration was apparently higher on the lysimeters with $\mathrm{B}$. tecterum than on the lysimeters with bare soil. As discussed in the results section, when plant factors are not taken into account in the computation of evapotranspiration rates, error terms increase. As a consequent, statistical tests are less efficient. Leaf area of $\mathrm{B}$. tectorum was positively correlated with evapotranspiration rates. The problem with comparing bare soil surfaces with surfaces covered with plants is that the two conditions are not truly comparable except at a gross scale. More adequately comparing such conditions requires considering plant and soil processes separately. The other process measured was carbon flux. Carbon flux was measured because it is an integral component of growth models needed to predict transpiration rates as they relate to plant size.

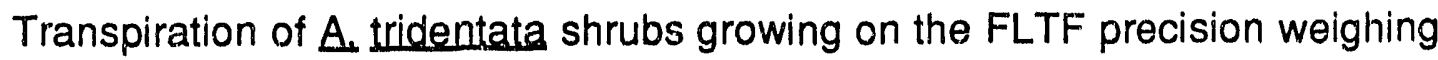
lysimeters at McGee Ranch was measured using the stem flow device. The results are presented and discussed in the Appendix. 
Growth data for B tecterum at Lower Snively Field were collected for parameterizing the plant component of UNSAT-H. Our results suggest that leaf area index and mean biomass increase significantly in response to additional nitrogen and/or water. Plants in the treatment plots receiving nitrogen increased growth rates earlier in the season than did plants receiving only additional water. Increases in plant growth resulting from water application were apparent later in the growing season. In April, as transpirational demand increased and available soil water became limiting, plants receiving additional water had significantly greater biomass arid leaf area than did plants in the control plots. Plants receiving additional nitrogen but no additional water also appeared to respond to limiting soil-water conditions between March and April by decreasing both biomass and leaf area. Plants receiving nitrogen and additional water continue to increase biomass and leaf area between March and April. These results suggest that the growth of $B$. tecterum may be limited by nitrogen availability in the soils early in the spring growing season or when sufficient water is available. As soil water availability decreases, LAI and biomass decrease.

For further parameterizing UNSAT-H, data also were collected at Snively Canyon to develop gas exchange models for $B$ _tectorum. This effort was successful. We demonstrated that it is possible to parameterize the driving relationships for transpiration and net photosynthesis by controlled experimentation in a field setting. We further demonstrated that it is possible to formulate a model for these processes that can effectively predict diurnal rates. This was demonstrated in a simple way by predicting data on June 16 with parameters estimated from data collected on June 8 and predicting data on June 8 with parameters estimated from data collected on June 16. The prediction of net photosynthesis worked well for both days. The prediction of transpiration was better when applying the model developed with June 16 data to the June 8 data than when applying the model developed with June 8 data to the June 16 data, possibly because the values of stomatal conductance measured in the morning of June 8 were relatively high. If the soil was damp, then higher values would be expected than if soils were dry and the control of evapotranspiration was mainly by the plant. In fact, by the end of the day, values of stomatal conductance were half of what they were in the early morning, suggesting the soil had dried. Values of stomatal conductance at the beginning and at the end of the day on June 16 were comparable and were near $40 \mathrm{mmol} \mathrm{m}^{-2} \mathrm{~s}^{-1}$, which was comparable to the ending values of 60 
mmol $\mathrm{m}^{-2} \mathrm{~s}^{-1}$ on June 8 . If soils were damp on the morning of June 8 , then the scaling parameters estimated would be influenced by soil evaporation and would not entirely reflect controlling plant processes, which would account for the relatively poor prediction. 


\subsection{EUTURE WORK}

Future research will entail parameterizing for model development the relationships between evapotranspiration, transpiration, soil evaporation, carbon dioxide exchange, growth, and the abiotic and biotic factors that drive these processes. 


\subsection{BEFERENCES}

Adams, M.R. and N.R. Wing. 1986. Protective Barrier and Warning Marker System Development Plan. RHO-RE-PL-35, Rockwell Hanford Operations, Richland, Washington.

Bloom, A.J., H.A. Mooney, O. Bjorkmman, and J. Berry. 1980. "Materials and Methods for Carbon Dioxide and Water Exchange Analysis." Plant Cell Environ. 3:371-376.

Caldwell, M.C., T.J. Dean, R.S. Nowak, R.S. Dzurec, and J.H. Richards. 1983. "Bunchgrass Architecture, Light Interception, and Water Use Efficiency: Assessment by Fiber Optic Point Quadrats and Gas Exchange." Qecologia 59:178-184.

Gee, G.W., R.R. Kirkham, J.L. Downs, and M.D. Campbell. 1989. The Field Lysimeter Test Facility (FLTF) at the Hanford Site: Installation and Initial Tests. PNL-6810, Pacific Northwest Laboratory, Richland, Washington.

Link, S.O., and W.J. Waugh. 1989. Evapotranspiration Studies for Protective Barriers: Experimental Plans. PNL-6899, Pacific Northwest Laboratory, Richland, Washington.

Link, S.O., M.E. Thiede, R.D. Evans, J.L. Downs, and W.J. Waugh. 1989.

Evapotranspiration Studies for Protective Barriers: FY 1988 Status Report. PNL-6985, Pacific Northwest Laboratory, Richland, Washington.

Link, S.O., G.W. Gee, and J.L. Downs. 1990. "The Effect of Water Stress on Phenological and Ecophysiological Characteristics of Cheatgrass and Sandberg's Bluegrass." ل. Bange Manage. 43(6):506-513.

Relyea, J.F., M.R. Sackschewsky, and W.J.Waugh. 1990. Small-Tube Lvsimeter Eacility Status Report for Fiscal Year 1989, WHC-EP-0297, Westinghouse Hanford Company, Richland, Washington.

Rickard, W.H. 1985. "Shoot Production and Mineral Nutrient Assirnilation in Cheatgrass Communities." Northwest Sci. 59:169-179.

Smith, E.L. 1937. "The Influence of Light and Carbon Dioxide on Photosynthesis." Gen. Phys. 20:807-830.

U.S. Department of Energy (USDOE). 1987. Dispesal of Hanford Defense HighLevel. Transuranic and Tank Wastes. DOE/EIS-0113, U.S. Department of Energy, Washington, D.C.

Waugh, W.J. and S.O. Link. 1989. Barrier Erosion Control Test Plan: Gravel Mulch Vegetation and Soil Water Interactions. WHC-EP-0067, Westinghouse Hanford Company, Richland, Washington. 


\section{APPENDIX}

MEASUREMENT OF SHRUB IRANSPIRATION USSING

IHE STEM HEAT ELUX IECHNIQUE 


\section{APPENDIX A}

\section{MEASUREMENT OF SHRUB TRANSPIRATION USING THE STEM HEAT FLUX TECHNIQUE}

\section{A. 1 INTRODUCTION}

The development of energy and water budgets or models of productivity are dependent on measurements of gas exchange, data that are often difficult to obtain at remote sites. In addition, integrative measurements of large plant canopies are necessary for understanding exchange processes of surfaces, particularly the exchange of water. However, these data are difficult to collect because of the inherent size of, and variability within, most plant canopies. Direct measurement of water flow through the stem of a plant is one method of cbtaining an integrated measure of plant water loss. The direct measurement of the mass flow of water through plant stems was first reported by Daum (1967) and further developed for woody and herbaceous plants by a series of authors over a period of 20 years (Baker and van Bavel 1987; Cermak et al. 1976; Cermak and Kucera 1981; Kucera et al. 1977; and Schulze et al. 1985). The application of the stem flow technique represents an advance over other conventional techniques for measuring transpiration (e.g., cuvette systems, porometers, heat pulse methods) because it is relatively noninvasive, it does not alter the plant microenvironment, it can be datalogged easily for continuous monitoring, and it is relatively inexpensive.

Cuvette and porometer systems enclose the plant, requiring power inputs and elaborate control systems to minimize changes in the microenvironment (Bingham et al. 1980). In the stem flow system, only the base of the stem is enclosed, eliminating the need for environmental control and leaving the canopy exposed for unimpeded energy and gas exchange. Heat pulse techniques measure only the sap velocities (Swanson 1972) and therefore require assumptions concerning the cross-sectional areas of the conducting elements to calculate volume of flow (Swanson and Whitfield 1981). The stem flow system utilizes steady-state measurements of heat flow dependent only on the volume of water convected through the stem, thereby eliminating errors associated with the estimates of conducting elements. And finally, the development of microprocessor-controlled dataloggers permitted application of the stem flow system for a nominal cost. This relatively inexpensive system permits replication and application of the technique to several plants simultaneously. 
The objective of the proposed research is to collect data on whole-plant transpiration of big sagebrush diurnally and seasonally, in conjunction with the weighing-lysimeter measurements of evapotranspiration. These data will be used to uncouple plant transpiration from evapotranspiration for surface energy budgets, to assess transpiration rates following supplemental watering, and to assess the quantity of water transferred between soil layers by big sagebrush (Artemisia tridentata). 


\section{A.2 METHODS}

The stem flow technique measures water convected through a plant stem using four basic subsystems for operation: 1) a microdatalogger, 2) a power supply, 3) a control board, and 4) a heater and temperature-sensing collar on the plant. The microdatalogger (Campbell Scientific 21X) senses temperature, measures power inputs to the heater, adjusts the power supplied to the heaters, and records data on water flux. The power supply consists of a single 12-volt battery. The control board permits the datalogger to regulate and measure the power supplied to the heater. The heater and sensing collar consists of a series of thermocouples inserted into the bark of the shrub to sense temperature differences before and after the heater coil, the temperature of the heater coil, and the radial temperature gradient. The heater within the sensing collar consists of a coil of resistance wire tightly wrapped around the stem of the shrub.

Control of the system is provided by the datalogger at $1-\mathrm{sec}$ intervals where the datalogger first senses the temperature of the heater relative to the ambient temperature of the stem. Using this temperature, the power supplied to the heater is adjusted to maintain the temperature at $3^{\circ} \mathrm{C}$ above ambient temperature. The temperature gradient before and after the heater, the radial temperature, and the power supplied to the heater are then measured. The heater and sensing collar is insulated with foam pipe insulation and protected with aluminum foil. Data on temperature, power, and flow are collected at $1-\mathrm{sec}$ intervals and averaged at $10-\mathrm{min}$ intervals. Data are stored on tape and returned to Washington State University for analysis. The water flowing through the stem is calculated by the following equation:

$$
\text { FLOW }=\frac{861 \text { (Power }- \text { Radial power loss) }}{\Delta T}
$$

where $\quad$ FLOW $=$ flux of water through the stem in $\mathrm{g} \mathrm{h}^{-1}$

$$
\text { Power }=\text { watts applied to the heater each second }
$$

Radial power loss $=$ a correction for the radial heat loss from the system

$\Delta T=$ the temperature gradient before and after the heater

$861=$ a constant converting the data from watts $\mathrm{s}^{-1}$ to $\mathrm{g} \mathrm{H}_{2} \mathrm{O} \mathrm{h} \mathrm{h}^{-1}$. 
During the summer of 1990 , the stem flow system was constructed and installed on three shrubs associated with the weighing and drainage lysimeters at the Hanford Meteorological Tower. The installation has been collecting data for approximately 30 days, and only preliminary data reduction has occurred. No comparisons between the lysimeter or weather data have been made; however, these comparisons are planned for the next 30 days. 


\section{A.3 BESULTS}

Preliminary analysis of one shrub (the shrub in the weighing lysimeter) shows patterns of stem flow with peaks at approximately $1000 \mathrm{~h}$ declining to undetectable levels by 1300 to $1500 \mathrm{~h}$ (Figure A.1). The mid-afternoon decline in stem flow is followed by a small increase in stem flow at approximately 1500 to $1600 \mathrm{~h}$. This afternoon increase was not always apparent and may be related to the environmental conditions or plant water relations of each day. The apparent sensitivity of the stem flow system is less than $1 \mathrm{~g} \mathrm{~h} \mathrm{~h}^{-1}$, with maximum flows during the measurement period of up to $15 \mathrm{~g} \mathrm{~h}^{-1}$. Because these estimates are preliminary, no confidence limits are available.

Trends in the stem flow between days in the 3-week period of data collection suggest considerable variability in daily water loss (Figure A.2). Large differences in the areas under the daily water loss curves were apparent (see, for example, Julian day 214 and 216). The environmental or physiological control of these differences will be investigated in the future. Future analysis will include daily totals of water loss that can be related directly to the lysimeter data. A tentative relationship has been established between the canopy volume of the stem within the stem flow system and the total volume of the shrub (Table A.1). This relationship will be used to develop estimates of total shrub water loss. No estimates of leaf area for the shrubs studied are currently available, so we did not attempt to calculate transpiration on a leaf-area basis. Similar general patterns, however, are seen between the three shrubs measured, and correlations between them and their relationship to environment are in preparation.

Iable A.1. Estimates of Canopy Volume for Stems Used for Stem Flow Measurements in Relation to the Total Shrub Volume for Plants in the Weighing Lysimeter and Drainage Lysimeters at the Hanford Tower Site

$\begin{array}{ll}\text { Plant and } & \% \text { Canopy } \\ \text { Lecation } & \text { Measured }\end{array}$

Shrub 1

(weighing lysimeter)

Shrub 2

(weighing lysimeter)

Shrub 3

(drainage lysimeter)
Canopy Volume in Flow System $\left(\mathrm{m}^{2}\right)$

Total Shrub Volume $\left(\mathrm{m}^{2}\right)$

\subsection{7}

0.550

0.521 


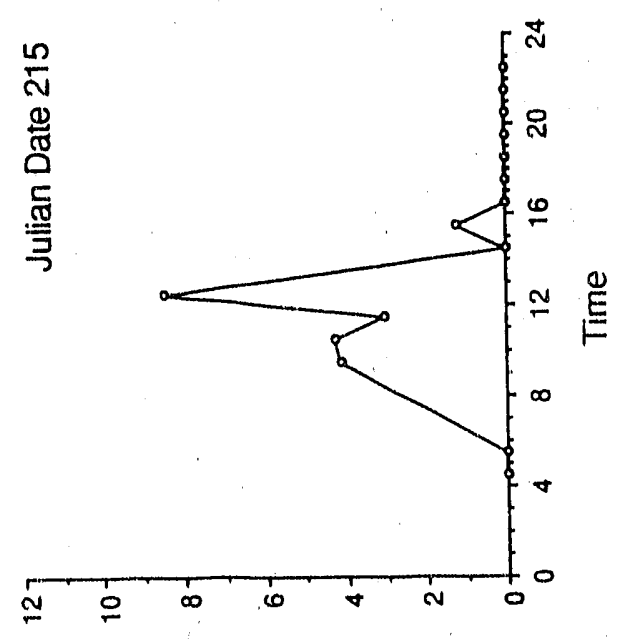

(4/6) Moly

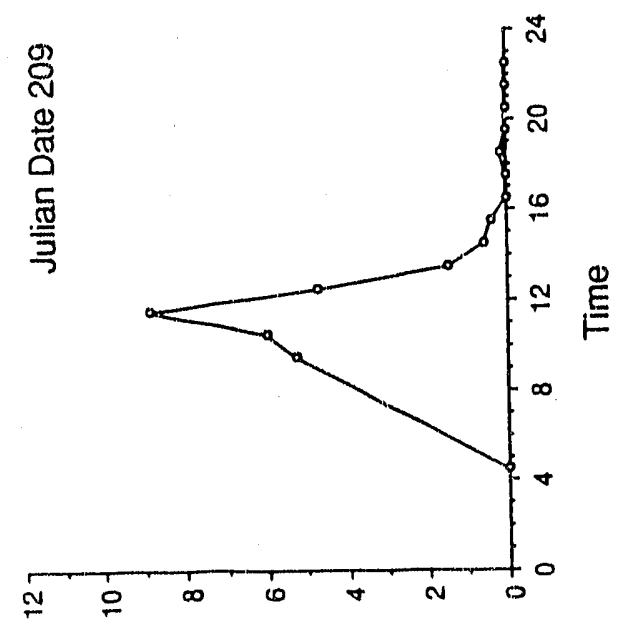

(4/6) M이거

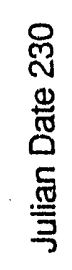

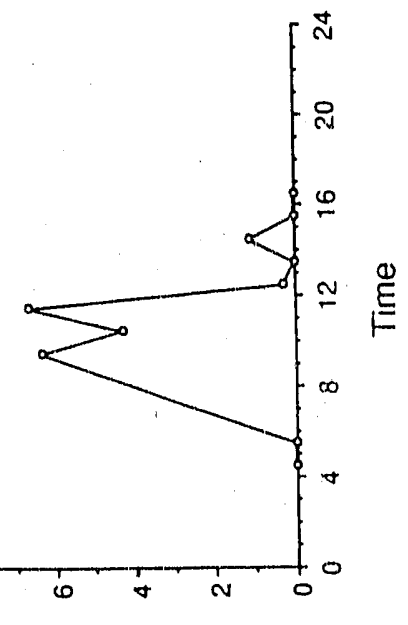

(4/6) M이

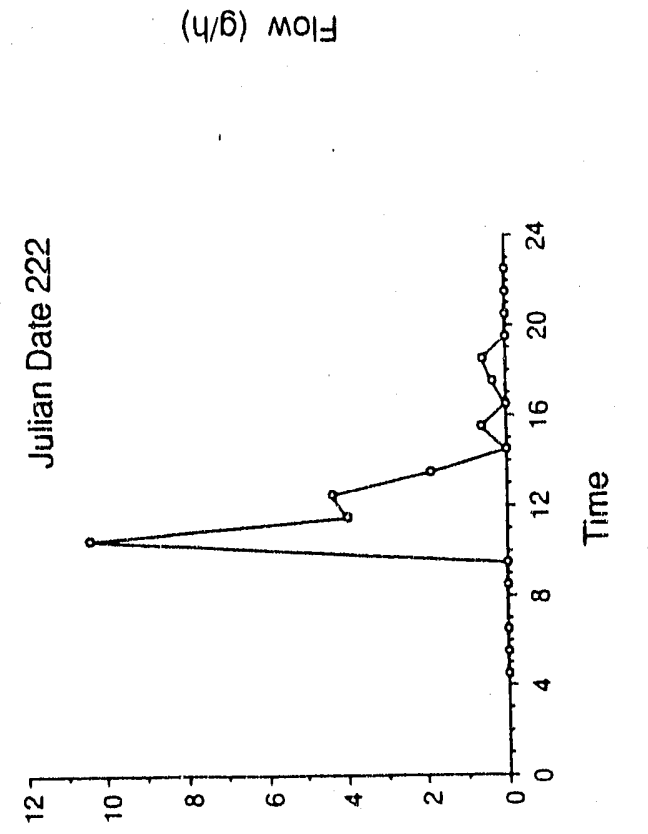

(4/6) M이

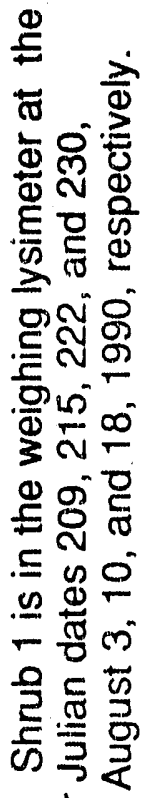

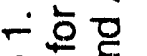

응 站空

흐웛 주

흥

흥 오

는 $\frac{7}{5}$

ह $\frac{\mathbb{d}}{\mathbb{0}}$

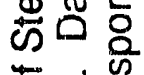
○

है ल

क्ष

สิ $\frac{3}{2}$

주원

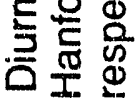

5
$\frac{1}{0}$
$\frac{1}{4}$ 


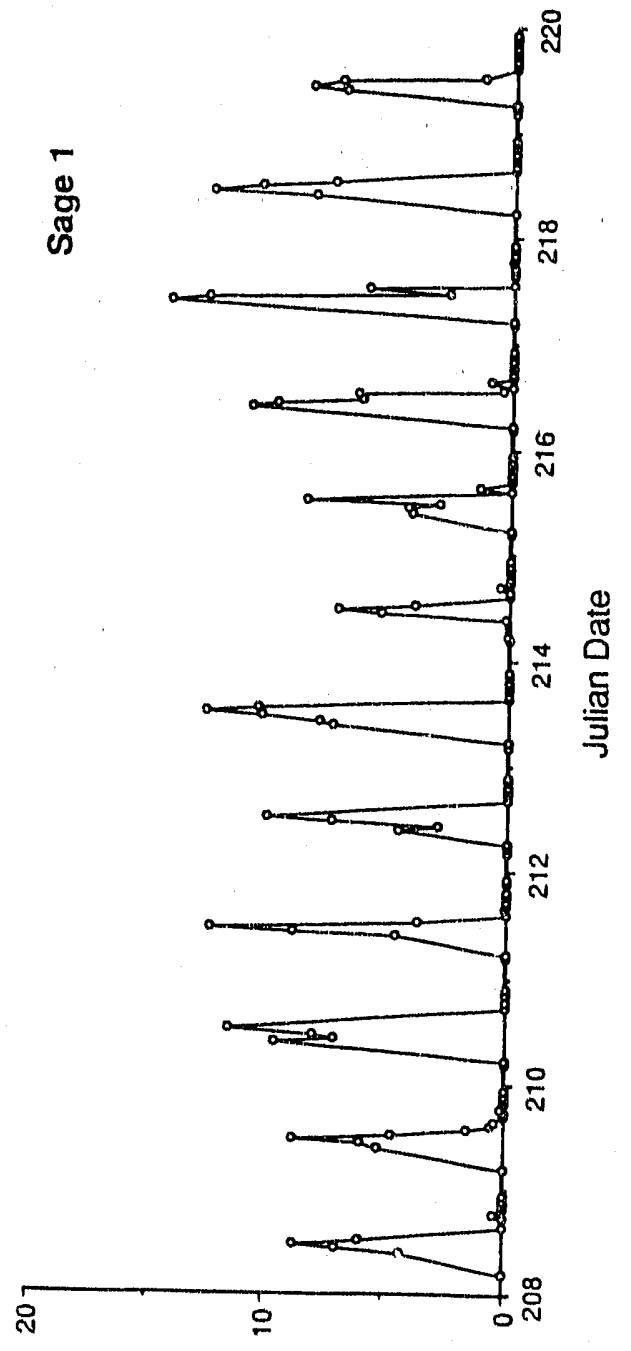

(4/6) MOIJ

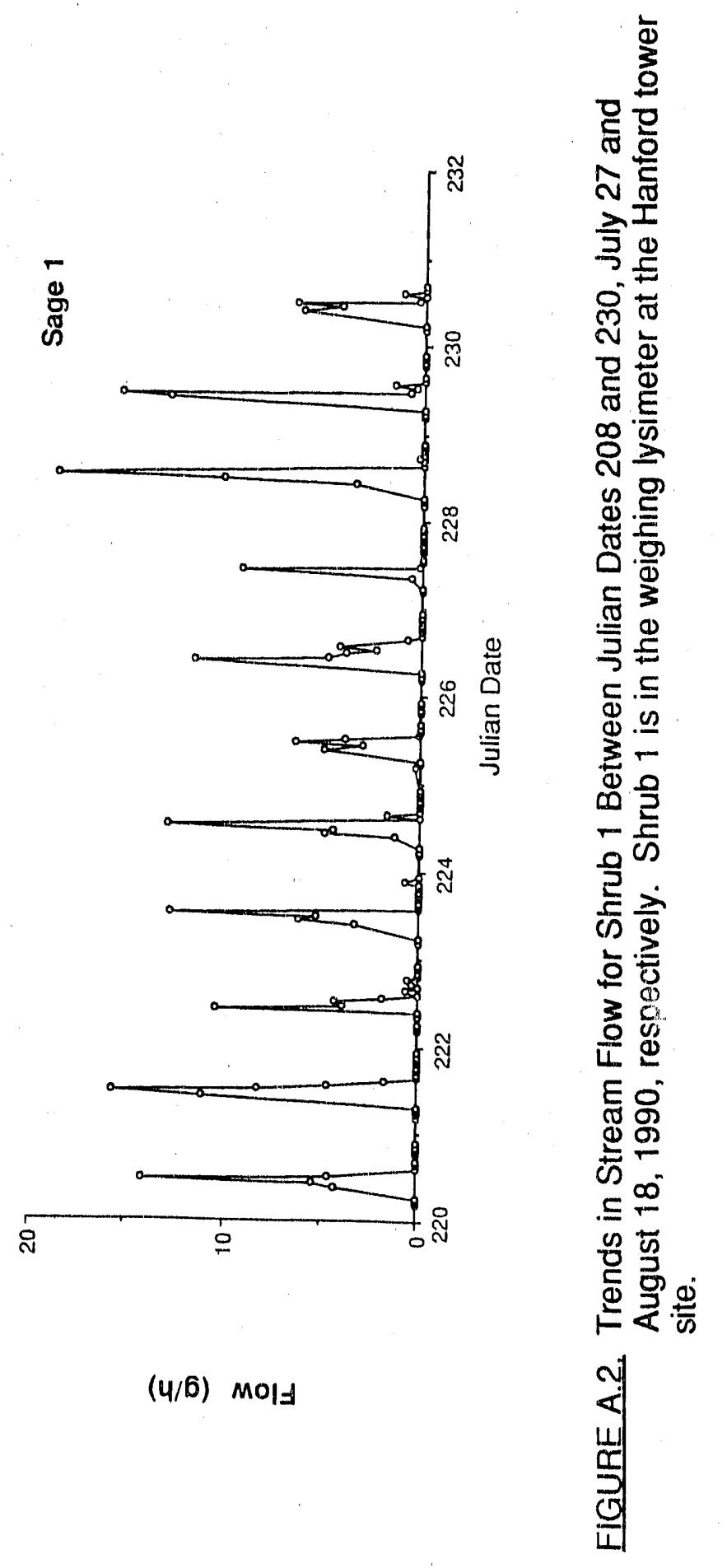




\section{A.4 DISCUSSION}

Trends in water loss measured during the first 3 . weeks of operation of the stem flow systems, were consistent with similar leaf-level measurements at the Arid Lands Ecology (ALE) Reserve in an earlier study (Black and Mack 1986). Mid-morning peaks in transpiration coincide with high stomatal conductance and lower air temperature and evaporative demand. Afternoon declines in transpiration are also commonly measured. The late-afternoon increase in transpiration occasionally seen in the stem flow measurements is less commonly measured. In summary, the measurement trends seen in these preliminary data are consistent with earlier observations. No comparative data have been analyzed to date concerning the magnitude of the stem flow rates or comparisons with the weighing lysimeter, so potential errors in the absolute measurements by system are unknown.

The present stem flow system represents a modification of an earlier design. The modification reduces the error related to radial heat loss and apparently increased the sensitivity of the system. Prior systems were unable to detect flow less than 4 to $5 \mathrm{~g} \mathrm{~h}^{-1}$. The improved sensitivity permits detection of flow less than 1 to $2 \mathrm{~g} \mathrm{~h}^{-1}$, though additional error analysis will be necessary to determine confidence limits of this estimate. The present adaptation to measurement of stem flow in sagebrush also improves on the sensitivity of earlier published methods (Daum 1967; Baker and van Bavel 1987). These methods were based on a constant input of power and are apparently less sensitive at low rates of flow. These published stem flow systems vary considerably from the heater and control designs employed for this project and are not readily adaptable to sagebrush.

Future concerns with regard to these stem flow measurements include 1) comparisons with environmental and lysimeter data, 2) data reduction and data management, and 3) development of additional stem flow systems for other sites on the ALE Reserve. As mentioned above, valuable comparisons with lysimeter data and environmental data are in preparation. These comparisons will not only permit determination of potential errors in the stem flow system, but will also permit separation of plant transpiration from total-evapotranspiration data currently available from the weighing lysimeters. These comparisons will be made available and will become part of a modeling effort currently underway. The current data reduction and management procedure must be modified. During the first three weeks of operation, 
this system collected $500 \mathrm{~K}$ of data, much of it unneeded (for example, data collected at night), that had to be redıced for the figures presented. Modification of the data collection program should eliminate much unneeded data and reduce the effort necessary to analyze the data set. The development of additional stem flow systems will allow extension of current data sets to remote sites on the ALE Reserve. Plans include instrumentation of hop sage and big sagebrush in association with detailed soil water measurements. 


\section{A.5 REFERENCES}

Baker, J. M., and C. H. M. van Bavel. 1987. "Measurement of Mass Flow of Water in the Stems of Herbaceuus Plants." Plant Cell Environ. 10:777-782.

Bingham, G. E., P. I. Coyne, R. B. Kennedy, and W. L. Jackson. 1980. Design and Fabrication of a Portable Minicuvette System for Measuring Leaf Photosynthesis and Stomatal Conductance under Controlled Conditions. Lawrence Livermore Laboratory, University of California, Livermore, CA.

Black, R. A., and R. N. Mack. 1986. "Mount St. Helen's Ash: Recreating its Effects on the Steppe Environment and Ecophysiology." Ecology 67:1289-1302.

Cermak, J., J. Kucera, and M. Penka. 1976. "Improvement of the Method of Sapflow Rate Determination in Full-Grown Trees Based on Heat Balance with Direct Electric Heating of Xylem." Biol. Plant 18:105-110.

Cermak J., and J. Kucera. 1981. "The Compensation of Natural Temperature Gradient at the Measuring Point During the Sap Flow Rate Determination in Trees." Biol. Plant 23:469-471.

Daurn, C. R. 1967. "A Method for Determining Water Transport in Trees." Ecology 48:425-431.

Kucera, J., J. Cermak, and M Penka. 1977. "Improved Thermal Method of Continual Recording the Transpiration Flow Rate Dynamics." Biol. Plant 19:413-420.

Schulze, E. -D., J. Cermak, R. Matyssek, M. Penka, R. Zimniermann, F. Vasicek, W. Gries, and J. Kucera. 1985. "Canopy Transpiration and Water Fluxes in the Xylem of the Trunk of Larix and Picea Trees - A Comparison of Xylem Flow, Porometer and Cuvette Measurements." Oecologia 66:475-483.

Swanson, R. N. 1972. "Water Transpired by Trees as Indicated by Heat Pulse Velocity." Agric. Meteor. 10:277-281.

Swanson, R. N., and D. W. A. Whitfield. 1981. "Numerical Analysis of the Heat Pulse Velocity Theory." LLExpt. Bot. 32:221-239. 


\section{FIGURES}

Figure A.1 Diurnal Patterns of Stem Flow for Shrub 1. Shrub 1 is in the Weighing Lysimeter at the Hanford Tower Site. Data are presented for Julian

Dates 209, 215, 222, and 230 Corresponding to July 28 and August 3 , 10 , and 18,1990

Figure A.2 Trends in Stem Flow for Shrub 1 Between Julian Dates 208 and 230, July 27 and August 18, 1990, Respectively. Shrub 1 is in the weighing lysimeter at the Hanford tower site. 


\section{DISTRIBUTION}

No. of

Copies

\section{QFFSITE}

2 DOE/Office of Scientific and Technical Information

2 Los Alamos National Laboratory P. O. Box 1663

Los Alamos, NM 87545

ATTN: T. E. Hakonson

J. W. Nylan

2 U. S. Ecology

P. O. Box 7246

9200 Shelbyville Rd

Suite 526

Louisville, KY 40207

ATTN: R. E. Sauer

D. Lane

W. Brewer

Office of High-Level Nuclear Waste Management

Washington State Department of Ecology

Olympia, WA 98504

2 Agronomy Department

Washington State University

Pullman, WA 99164

ATTN: A. J. Busacca

G. S. Campbell

E. M. Carlin

Low-Level Radioactive Waste Program

Washington Department of Ecology

Mail Stop PV-11

Olympia, WA 98504
No. of

Copies

Chem Nuclear Geotech

P.O. Box 14000

Grarıd Junction, CO 81502

ATTN: W. J. Waugh

2 U.S. Department of Energy

785 DOE Place

Idaho Falls, ID 83402

ATTN: O. D. Markham

T. E. Reynolds

EG\&G Idaho, Inc.

P. O. Box 1625

Idaho Falls, ID. 83415-3900

ATTN: K. M. Kostelnik

C. Massimino

U. S. Environmental Protection Agency

1200 Sixth Avenue

Seattle, WA 98101

Alan Rainey

Department of Health

Radiation Protection Division

Airdustrial Park

Bldg. 5, M.S. LE-13

Olympia, WA 98504

3 Low-Level Radioactive Waste Program

U.S. Geological Survey

Water Resources Division 12201 Sunrise Valley Drive Reston, VA 22092

ATTN: J. Fisher

P. Stevens

N. Trask 
No. of

Copies

L. Frank

U.S. Department of Energy

625 Marion Street, N.E.

Salem, OR 97310

D. Hillel

Department of Plant and Soil

Science

12A Stockbridge Hall

University of Massachusetts

Amherst, MA 01003

David E. Daniel

Department of Civil Engineering

University of Texas

Austin, TX 78712.

Gregory N. Richardson

Hazen and Sawyer

4011 W. Chase Blvd.

Suite 500

Raleigh, NC 27607

Lorne G. Everett

Metcalf and Eddy Consultants, Inc.

PO Box 24110

Santa Barbara, CA 93121

Charles Reith

Jacobs Engineering

Weldon Springs Site

St. Charles, MO 63301

Geoff W. Spaulding

Dames and Moore

Suite 108

4220 S. Maryland Pkwy.

Las Vegas, NV 89119

E. M. Romney

Laboratory of Biomedical and

Environmental Sciences

University of California

Los Angeles, CA 90024
No. of

UC-702

copies

N. Ingraham

Desert Research Institute

Suite 1

2505 Chandler Avenue

Las Vegas, NV 89120

Thomas Nash

Department of Botany

Arizona State University

Tempe, AZ 85287

Martyn Caldwell

Department of Range Science

Utah State University

Logan, UT 84322

R. Alan Black

Department of Botany

Washington State University

Pullman, WA 99164

1. Winograd

U.S. Geological Survey

MS 432

Reston, VA 22092

R. Treat

EBASCO

Richland, WA 99352

2 Geology Department

Washington State University

Pullman, WA 99164

ATTN: K. Keller

D. Gaylord

L. J. Fritschen

Forestry Department

University of Washington

Seattle, WA 98195

2 Washington State Department of Ecology

MS-PU-11

Olympia, WA 98504-8711

ATTN: C. Cline

R.B. Hibbard 
No. of

Copies

3 Hanford Project Office

U.S. Environmental Protection Agency

712 Swift

Richland, WA 99352

ATTN: D.A. Faulk, A7-70

P. S. Innis, A7-70

D. R. Sherwood, A7-70

\section{ONSITE}

10 DOE Richland Field Office

G. J. Braken

J. J. Broderick

R.P. Carter

R. D. Freeburg

R. E. Gerton

J. D. Goodenough

A.C. Harris

J. M. Hennig

R. D. Izatt

J. P. Sands

3 Kaiser Engineers Hanford
S.D. Consort
D.L. Fort
D.L. Watkins

36 Westinghouse Hanford Cempany

M. R. Adams

W.C Alaconis

J. D. Berger

R. J. Bliss

L. C. Brown

J. W. Cammann

R. A. Carison

J. D. Davis

C. J. Geier

R.L. Gilchrist

W. F. Heine

J. M. Henderson
No. of

UC-702 cepies

G. W. Jackson

K. N. Jordan

C. J. Kemp

D. S. Larıdeen

R. E. Lerch

H. E. McGuire

D. R. Myers

D. J. Newland

B. E. Opitz

K. L. Petersen

S. J. Phillips

R. C. Roos

M. R. Sackschewsky

J. L. Scott

J. C. Sonnichsen

D. R. Speer

J. A. Voogd

S. A. Weigman

G. W. Williamson

N. R. Wing

D. D. Wodrich

R. D. Wojtasek

J.C. Womack

D. E. Wood

\section{Pacific Northwest Laboratory}

L. L. Cadwell

M. D. Campoell

J. C. Chatters

J. L. Downs

L. E. Eberhardt

J. W. Falco

M. J. Fayer

M. G. Foley

H. D. Freeman

G. W. Gee

M. G. Graham

P. C. Hays

C. T. Kincaid

R. R. Kirkham

G. V. Last

M. W. Ligotke

S. O. Link (10)

M. L. Rockhold 
PNL-8032

UC-702

No. of

Copies

L. E. Rogers

M. Al Simmons

R. L. Skaggs

S. C. Slate

D. L. Stewart

T. L. Stewart

J. A. Stottlemyre
No. of

Copies

G. P. Streile

M. E. Thiede

J.M. Thomas

W. H. Walters

R. E. Wildung

Publishing Coordination

Technical Report Files (5) 

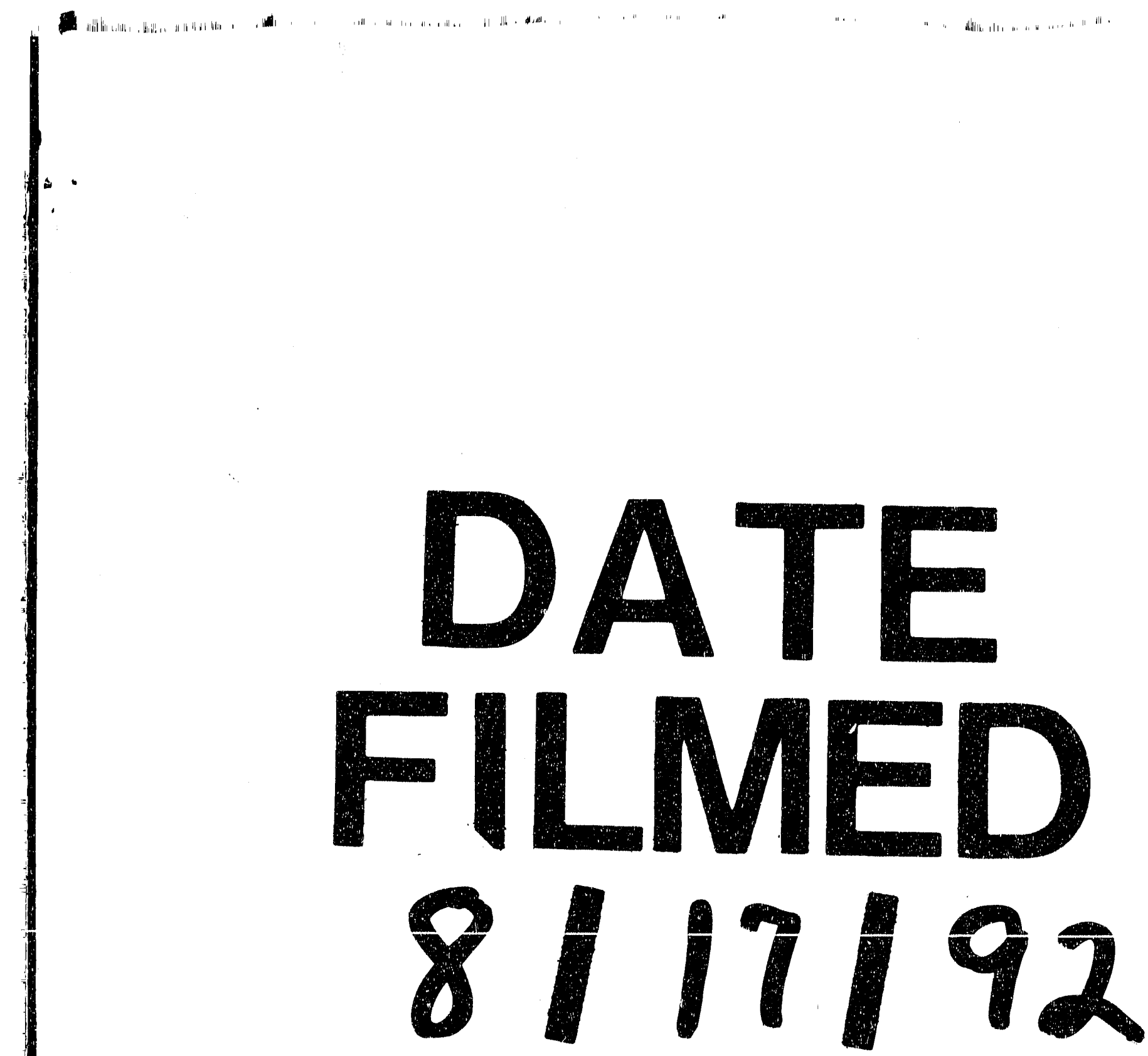
